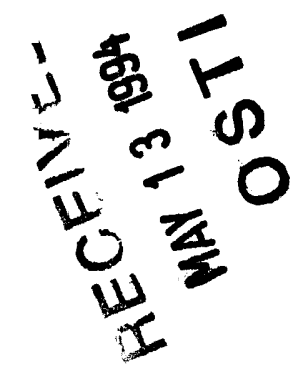

\title{
The \\ National \\ Energy \\ Modeling \\ System: \\ An Overview
}

May 1994

Energy Information Administration

Office of Integrated Analysis and Forecasting

U.S. Department of Energy

Washington, DC 20585 
This publication and other Energy Information Administration (EIA) publications may be purchased from the Superintendent of Documents, U.S. Government Printing Office.

\section{All telephone orders should be directed to:}

\author{
U.S. Government Printing Office \\ McPherson Square Bookstore \\ 1510 H Street, N.W. \\ Washington, DC 20005 \\ (202)653-2050 \\ FAX (202)376-5055
}

9 a.m. to $4: 30$ p.m., eastern time, M-F
Superintendent of Documents

U.S. Government Printing Office

Washington, DC 20402

(202)783-3238

FAX (202)512-2233

8 a.m. to 4 p.m., eastern time, M-F

\section{All mail orders should be directed to: \\ U.S. Government Printing Office \\ P.O. Box 371954 \\ Pittsburgh, PA 15250-7954}

Complimentary subscriptions and single issues are available to certain groups of subscribers, such as public and academic libraries, Federal, State, local and foreign governments, EIA survey respondents, and the media. For further information and for answers to questions on energy statistics, please contact EIA's National Energy Information Center. Address, telephone numbers, and hours are as follows:

National Energy Information Center, EI-231

Energy Information Administration

Forrestal Building, Room 1F-048

Washington, DC 20585

(202)586-8800

TTY: For people who are deaf or hard

of hearing: (202)586-1181

9 a.m. to 5 p.m., eastern time, M-F 


\title{
The National Energy Modeling System: An Overview
}

\author{
May 1994
}

Energy Information Administration Office of Integrated Analysis and Forecasting

U.S. Department of Energy

Washington, DC 20585

This report was prepared by the Energy Information Administration, the independent statistical and analytical agency within the Department of Energy. The information contained herein should not be construed as advocating or reflecting any policy position of the Department of Energy or of any other organization. 
The National Energy Modeling System: An Overview (Overview) provides a summary description of the National Energy Modeling System (NEMS). NEMS has been used to generate the forecasts of energy production, demand, imports, and prices through the year 2010 for the Annual Energy Outlook 1994 (AEO94), (DOE/EIA-0383(94)), release' 'n January 1994, and the Supplement to the Annual Energy Outlook 1994 (Suppiement), (DOE/EIA-0554(94)), released in March 1994. The AEO94 presents national forecasts of energy markets for five scenarios, including a reference case and four additional cases that assume higher and lower economic growth and higher and lower world oil prices. The Supplement provides regional projections and other underlying details of the reference case projections in the AEO94 and also presents the key quantitative assumptions underlying the projections, in response to requests for additional information on the forecasts.

The Overview presents a brief description of the methodology and scope of each of the component modules of NEMS. For further details, the reader is referred to the model documentation reports listed in Appendix B of this document.

The Overview, the AEO94 and the Supplement were prepared by the Energy Information Administration (EIA), Office of Integrated Analysis and Forecasting under the direction of Mary J. Hutzler (202/586-2222), Director of the Office of Integrated Analysis and Forecasting, Mark E. Rodekohr (202/586-1130), Director of the Energy Demand and Integration Division, and Scott Sitzer (202/586-2308), Director of the Energy Supply and Conversion Division. Detailed questions concerning the model components of NEMS may be addressed to the following analysts:

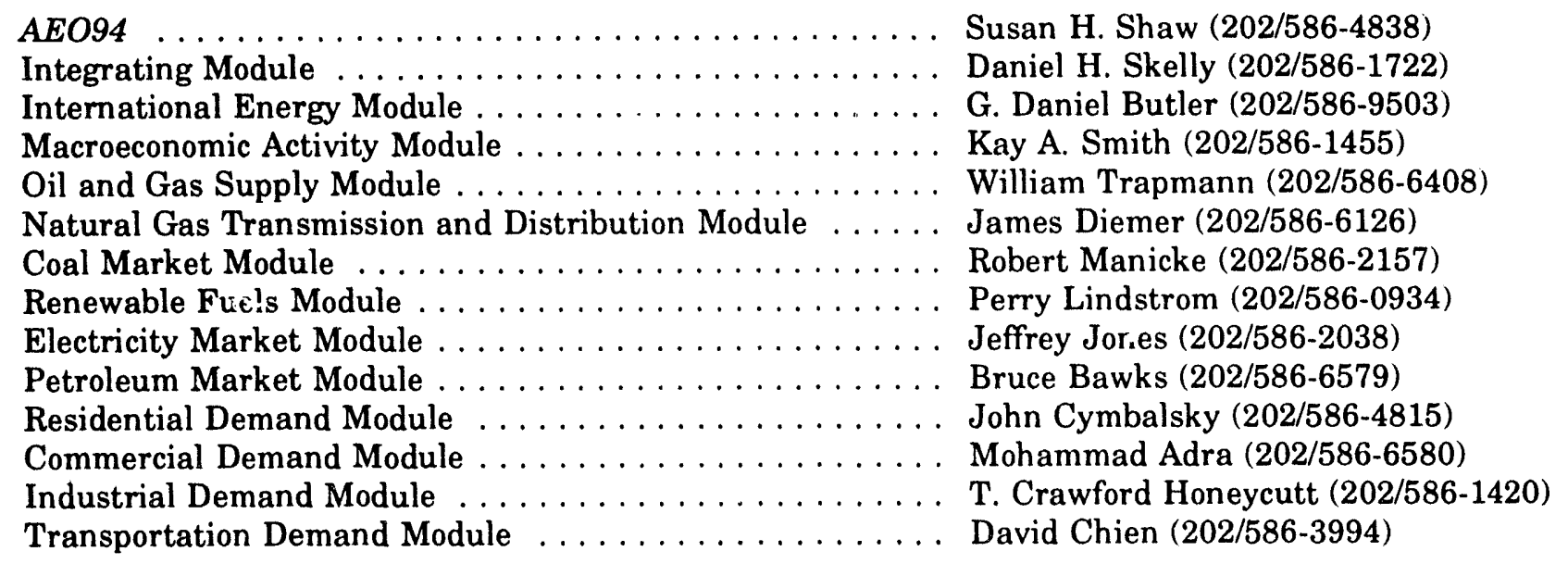

Forecast tables for the five scenarios presented in the $A E O 94$ are available via modem on EIA's Electronic Publication System (202/586-2557). The tables presented in the AEO94 and the Supplement are also available on diskette from the Office of Integrated Analysis and Forecasting. Copies of the Overview, AEO94, the Supplement, and model documentation reports for NEMS are available by contacting:

National Energy Information Center, EI-231

Energy Information Administration

Forrestal Building, Room 1F-048

Washington, DC 20585

202/586-8800

TTY: For people who are deaf

or hard of hearing: 202/586-1181

9 a.m. to 5 p.m., eastern time, M-F 


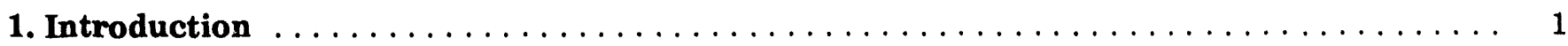

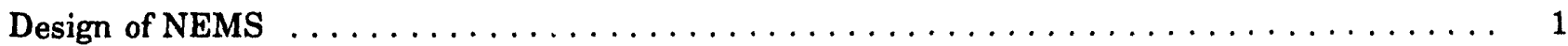

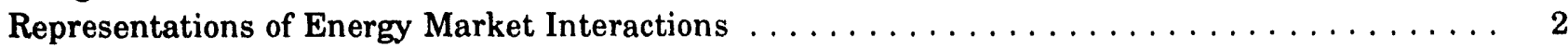

External Availability of NEMS $\ldots \ldots \ldots \ldots \ldots \ldots \ldots \ldots \ldots \ldots \ldots \ldots \ldots \ldots \ldots \ldots$

2. Overview of the Structure of NEMS $\ldots \ldots \ldots \ldots \ldots \ldots \ldots \ldots \ldots \ldots \ldots \ldots \ldots \ldots \ldots$

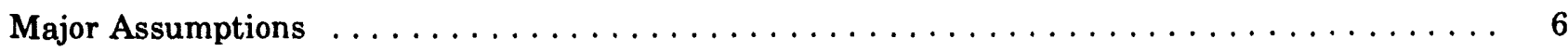

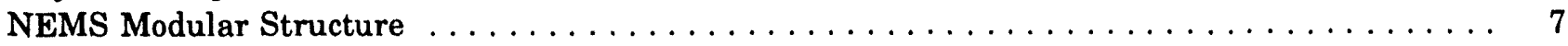

3. Integrating Module $\ldots \ldots \ldots \ldots \ldots \ldots \ldots \ldots \ldots \ldots \ldots \ldots \ldots \ldots \ldots \ldots \ldots$

Features of the Integrating Module $\ldots \ldots \ldots \ldots \ldots \ldots \ldots \ldots \ldots \ldots \ldots \ldots \ldots \ldots$

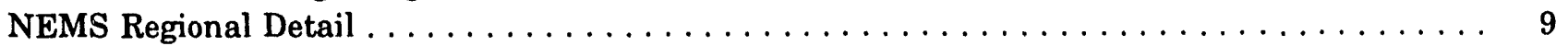

Description of the NEMS Solution Algorithm $\ldots \ldots \ldots \ldots \ldots \ldots \ldots \ldots \ldots \ldots \ldots \ldots \ldots$

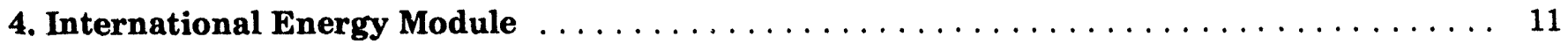

World Oil Market Submodule $\ldots \ldots \ldots \ldots \ldots \ldots \ldots \ldots \ldots \ldots \ldots \ldots \ldots \ldots \ldots$

Petroleum Products Supply Submodule $\ldots \ldots \ldots \ldots \ldots \ldots \ldots \ldots \ldots \ldots \ldots \ldots \ldots$

Oxygenates Supply Submodule $\ldots \ldots \ldots \ldots \ldots \ldots \ldots \ldots \ldots \ldots \ldots \ldots \ldots \ldots \ldots \ldots$

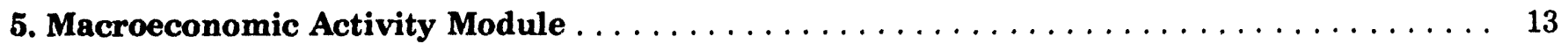

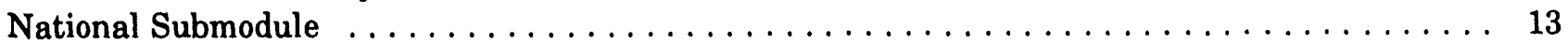

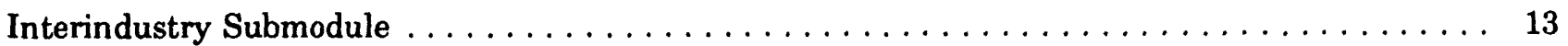

Regional Subroutine $\ldots \ldots \ldots \ldots \ldots \ldots \ldots \ldots \ldots \ldots \ldots \ldots \ldots \ldots \ldots \ldots$

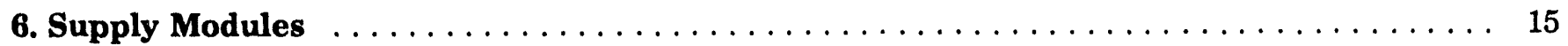

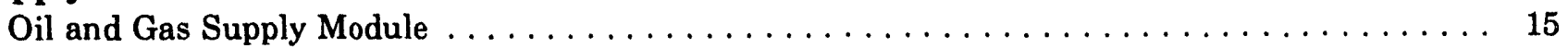

Natural Gas Transmission and Distribution Module $\ldots \ldots \ldots \ldots \ldots \ldots \ldots \ldots \ldots$

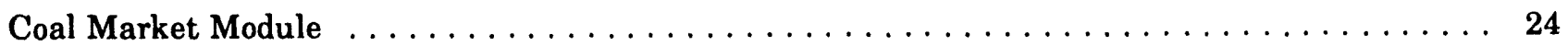

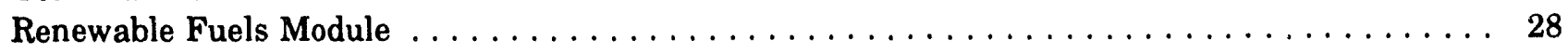

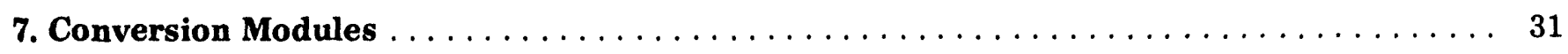

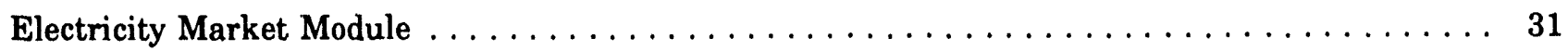

Petroleum Market Module $\ldots \ldots \ldots \ldots \ldots \ldots \ldots \ldots \ldots \ldots \ldots \ldots \ldots \ldots \ldots \ldots$

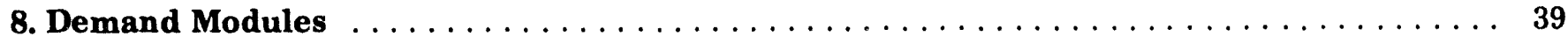

Residential Demand Module $\ldots \ldots \ldots \ldots \ldots \ldots \ldots \ldots \ldots \ldots \ldots \ldots \ldots \ldots \ldots \ldots$

Commercial Demand Module $\ldots \ldots \ldots \ldots \ldots \ldots \ldots \ldots \ldots \ldots \ldots \ldots \ldots \ldots \ldots \ldots$

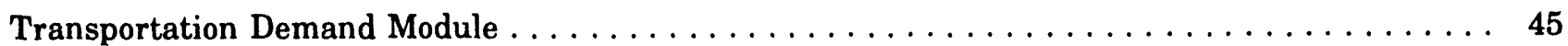

Industrial Demand Module $\ldots \ldots \ldots \ldots \ldots \ldots \ldots \ldots \ldots \ldots \ldots \ldots \ldots \ldots \ldots$

Appendices

A. EIA Predecessor Models $\ldots \ldots \ldots \ldots \ldots \ldots \ldots \ldots \ldots \ldots \ldots \ldots \ldots \ldots \ldots \ldots \ldots \ldots$

B. Bibliography $\ldots \ldots \ldots \ldots \ldots \ldots \ldots \ldots \ldots \ldots \ldots \ldots \ldots \ldots \ldots \ldots \ldots \ldots \ldots$ 


\section{Figures}

1. National Energy Modeling System $\ldots \ldots \ldots \ldots \ldots \ldots \ldots \ldots \ldots \ldots \ldots \ldots \ldots \ldots \ldots \ldots$

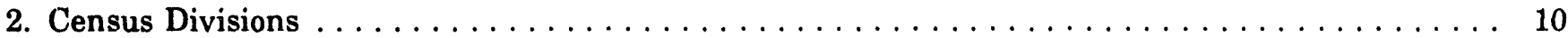

3. International Energy Module Structure $\ldots \ldots \ldots \ldots \ldots \ldots \ldots \ldots \ldots \ldots \ldots \ldots \ldots \ldots \ldots \ldots \ldots$

4. Macroeconomic Activity Module Structure $\ldots \ldots \ldots \ldots \ldots \ldots \ldots \ldots \ldots \ldots \ldots \ldots \ldots$

5. Oil and Gas Supply Module Regions $\ldots \ldots \ldots \ldots \ldots \ldots \ldots \ldots \ldots \ldots \ldots \ldots \ldots \ldots$

6. Oil and Gas Supply Module Structure $\ldots \ldots \ldots \ldots \ldots \ldots \ldots \ldots \ldots \ldots \ldots \ldots \ldots \ldots \ldots$

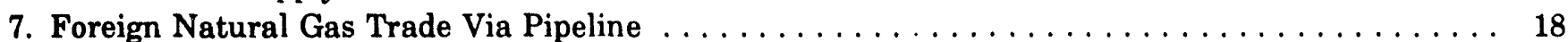

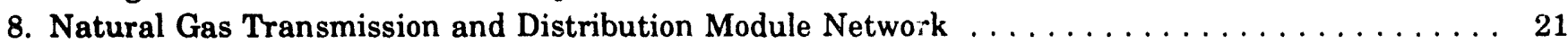

9. Natural Gas Transmission and Distribution Module Structure $\ldots \ldots \ldots \ldots \ldots \ldots \ldots \ldots \ldots . \ldots 22$

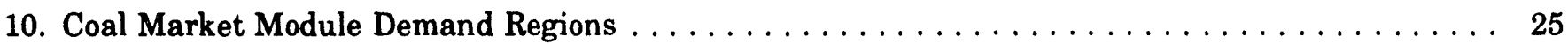

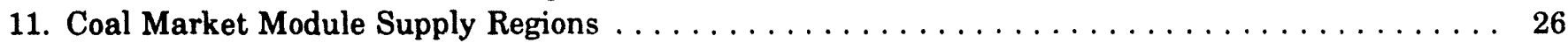

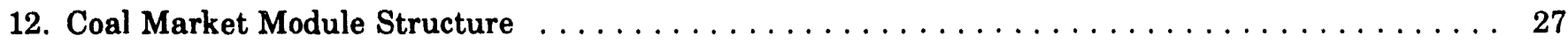

13. Renewable Fuels Module Structure $\ldots \ldots \ldots \ldots \ldots \ldots \ldots \ldots \ldots \ldots \ldots \ldots \ldots \ldots \ldots \ldots \ldots$

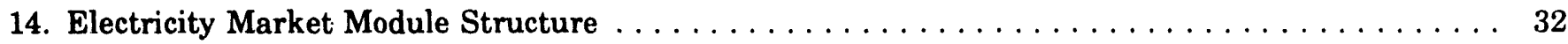

15. Electricity Market Module Supply Regions $\ldots \ldots \ldots \ldots \ldots \ldots \ldots \ldots \ldots \ldots \ldots \ldots \ldots \ldots \ldots \ldots$

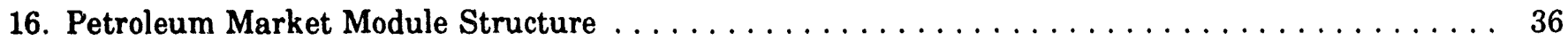

17. Petroleum Administration for Defense Districts $\ldots \ldots \ldots \ldots \ldots \ldots \ldots \ldots \ldots \ldots \ldots \ldots \ldots \ldots$

18. Residential Demand Module Structure $\ldots \ldots \ldots \ldots \ldots \ldots \ldots \ldots \ldots \ldots \ldots \ldots \ldots \ldots \ldots$

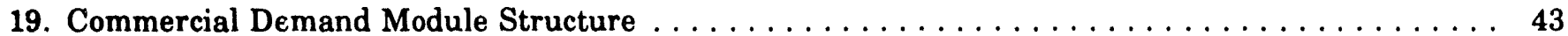

20. Transportation Demand Module Structure $\ldots \ldots \ldots \ldots \ldots \ldots \ldots \ldots \ldots \ldots \ldots \ldots \ldots \ldots$

21. Industrial Demand Module Structure $\ldots \ldots \ldots \ldots \ldots \ldots \ldots \ldots \ldots \ldots \ldots \ldots \ldots \ldots \ldots$ 
The National Energy Modeling System (NEMS) is a computer-based, energy-economy modeling system of U.S. energy markets for the midterm period of 1990 to 2010. NEMS projects the production, imports, conversion, consumption, and prices of energy, subject to assumptions on macroeconomic and financial factors, world energy markets, resource availability and costs, behavioral and technological choice criteria, cost and performance characteristics of energy technologies, and demographics.

NEMS was designed and implemented by the Energy Information Administration (EIA) of the U.S. Department of Energy (DOE) for preparing baseline forecasts of domestic energy markets and analyzing the potential impacts of proposed government policies and of alternative energy market assumptions. Baseline forecasts are published annually in the Annual Energy Outlook, with the assumptions of all existing legislation, regulations, and policies. Analyses are also prepared in response to requests for special studies by the U.S. Congress, the DOE Office of Policy, Planning, and Program Evaluation, and others. The first version of NEMS, completed in December 1993, was used to develop the forecasts presented in the Annual Energy Outlook $1994 .^{1}$

This report presents an overview of the structure and methodology of NEMS and each of its components. This chapter provides a description of the design and objectives of the system. The second chapter describes the modeling structure. The remainder of the report summarizes the methodology and scope of the component modules of NEMS. The model descriptions are intended for readers familiar with terminology from economics, operations research, and energy modeling. Additional background on the development of the system is provided in Appendix A of this report, which describes the EIA modeling systems that preceded NEMS. More detailed model documentation reports for all the NEMS modules are also available from EIA (see Appendix B, "Bibliography").

\section{Design of NEMS}

NEMS is used by EIA to project the energy, economic, environmental, and security impacts on the United States of alternative energy policies and of different assumptions about energy markets. Projections are made for each year from the present through 2010 . This time period is one in which technology, demographics, and economic conditions can be characterized sufficiently to represent energy markets with considerable detail.
The forecasts produced by NEMS are not considered to be absolute predictions of the future. They are contingent on the key assumptions made about U.S. energy systems. Contingencies include, for example, the estimated size of the economically recoverable resource base of fossil fuels; changes in world energy supply and demand; the rate at which new energy technologies are developed and the rate and extent of their penetration into commercial markets; and existing or prospective government actions or policies. NEMS provides a consistent framework for representing the complex interactions of the U.S. energy system and its response to a wide variety of alternative assumptions and policies, without attempting to determine which of many plausible energy futures is most likely to occur.

The NEMS design was formulated with three objectives:

- To provide sufficient modeling detail to support a broad range of policy analyses

- To capture the important interrelationships in U.S. energy markets in order to simulate the response of the entire energy system to changes in market. conditions

- To facilitate the development, maintenance, and use of the energy modeling system.

NEMS was built to support energy policy analysis and to serve as an important resource for the development and analysis of the impacts of alternative energy policies on key U.S. markets and economic growth. Ultimately, policy analysts and decisionmakers attempt to select those policies that promote an energy future consistent with the Nation's goals and priorities. NEMS contributes to this process by determining the likely consequences of specific government policies, or their absence, in the context of defined energy scenarios.

As a tool for policy analysis, NEMS was designed to simulate those aspects of the energy system to which policy initiatives are most likely to be directed. For example, environmental issues related to energy production and consumption have become a high priority in recent years. Accordingly, NEMS-unlike EIA's earlier modeling systems-has the capability to estimate the levels of key emissions from the production and use of energy, and to model the changes in emission levels that are likely to result from such government policies as the provisions of the Clean Air Act Amendments of 1990 . For similar reasons, NEMS contains sufficient detail in both the refining (supply)

'Energy Information Administration, Annual Energy Outlook 1994, DOE/EIA-0383(94) (Washington, DC, January 1994). 
and transportation (demand) sectors to analyze both the costs and likely market penetration of alternative or reformulated fuels.

In addition to environmental concerns, NEMS can be used to analyze the effects of existing government regulations and proposed regulatory reform related to energy production and use; the potential for the development and use of new energy production, conversion, and consumption technologies; the impacts of increased use of renewable energy sources; and the potential savings from demand-side management and increased efficiency of energy use. Other examples of energy topics that reflect the expected scope of present and future government policy-all of which can be addressed by NEMS-include the following:

- Impacts of energy tax policies on the U.S. economy and energy system

- Response of the electric utility industry to limits on $\mathrm{SO}_{2}$ emissions and the allowance trading program of the Clean Air Act Amendments of 1990

- Responses of the energy and economic systems to changes in world oil market conditions as a result of changing levels of foreign production and demand in the developing countries

- Impacts of new technologies on consumption and production patterns and emissions

- Changes in the U.S. economy and energy system that could result from emissions taxes

- Effects of specific policies, such as mandatory appliance efficiency and building shell standards, on energy consumption

- Impacts of fuel-use restrictions (for example, oxygenated and reformulated gasoline or mandated use of alternative-fueled vehicles) on emissions, energy supply and prices, and economic growth

- Changes in natural gas prices and pipeline and import capacity in response to Federal and State regulatory initiatives

- Impacts on estimates of economically recoverable resources of crude oil and natural gas resulting from improvements in exploration and production technologies.

Thus, NEMS can be an effective tool for a wide variety of detailed policy analysis issues. In the near future, a number of critical energy and economic issues are on the horizon. NEMS can be used to address such questions, including: energy security; efficiency improvements in energy production, conversion, and consumption technologies; regulatory reform in the natural gas and electricity sectors; and renewable energy. In addition, enhancements now being added to the system will provide the capability to examine important issues in the upcoming debates on policies to reduce carbon emissions in the United States.

\section{Representations of Energy Market Interactions}

NEMS is also designed to simulate the important interactions of energy markets. In the United States, energy markets are driven primarily by the fundamental economic interactions of supply and demand. Government regulations and policies can exert considerable influence, but the majority of decisions affecting fuel prices and consumption patterns, resource allocation, and energy technologies are made by private individuals or companies attempting to optimize their own economic intere.sts.

The primary objective of NEMS is to represent the market behavior of the buyers and sellers of energy products-to determine how energy is used and produced-at a level of detail that will be useful for analyzing the implications of government policy initiatives. The representation of energy markets in NEMS focuses on four important interrelationships:

- Interactions among the energy fuel supply, conversion, and consumption sectors

- Interactions between the domestic energy system and the domestic economy

- Interactions between the U.S. energy system and world energy markets

- Interactions between current production and consumption decisions and expectations about the future.

\section{Energy Supply/Conversion / Demand Interactions}

NEMS is designed as a modular system. Four end-use demand modules represent fuel consumption in the residential, commercial, transportation, and industrial sectors, subject to delivered fuel prices, macroeconomic influences, and technology characteristics. The primary fuel supply and conversion modules compute the levels of domestic production, imports, transportation costs, and fuel prices that are needed to meet domestic and export demands for energy, subject to resource base characteristics, industry infrastructure and technology, and world market conditions. The modules interact to solve for the economic supply and demand balance for each fuel. Because of the modular design, each sector can be represented with the methodology and the level of detail, including regional detail, that is appropriate for that sector. The modularity also facilitates the analysis, maintenance, and testing of 
the component modules in the multi-user environment of NEMS development.

\section{Domestic Energy System / Economy Interactions}

The general level of economic activity, represented by gross domestic product, has traditionally been used as an explanatory variable or "driver" for projections of energy consumption at the sectoral and regional levels. In turn, energy prices and other energy system activities influence economic growth and activity. NEMS captures this feedback between the domestic economy and the energy system. Thus, changes in energy prices affect the key macroeconomic variablessuch as gross domestic product, disposal personal income, industrial output, housing starts, employment, and interest rates-that drive energy consumption and capacity expansion decisions.

\section{Domestic/World Energy Market Interactions}

World oil prices play a key role in domestic energy supply and demand decisionmaking, and oil price assumptions are the typical starting point for energy system projections. The level of oil production and consumption in the U.S. energy system also has a significant influence on world oil markets and prices. In NEMS, an international energy module represents world oil production and demand, as well as the interactions between the domestic and world oil markets, and calculates the average world oil price and the supply of crude oil and petroleum products. As a result, domestic and world oil market projections are internally consistent. Imports and exports of natural gas, electricity, and coal-which are less influenced by volatile world conditions-are represented in the individual fuel supply modules.

\section{Economic Decisionmaking Over Time}

The production and consumption of energy products today are influenced by past decisions to develop energy resources and acquire energy-using capital stock. Similarly, the production and consumption of energy in a future time period will be influenced by decisions made today and in the past. Current investment decisions depend on expectations about future markets. For example, the propensity to invest now to develop alternative energy sources is greater if higher energy prices are expected in the future. A variety of assumptions about planning horizons, the formation of expectations about the future, and the role of those expectations in economic decisionmaking can be applied within the individual NEMS modules.

\section{External Availability}

In accordance with EIA requirements, NEMS is fully documented and archived. EIA also intends to make the system available for use and review by energy analysts outside EIA to the maximum extent possible. There are a number of levels at which this goal can be achieved. The ultimate objective is to package and transfer the entire system, including its data structure and user interface programs, to external users, with arrangements for periodic updates as NEMS evolves.

At present, the transportability of NEMS is limited. A user interface for personal computer versions of the individual NEMS modules is under development, and plans have been made for all the modules to be converted for use on personal computers, with an interface that will allow the user to view and manipulate key parameters and assumptions, run alternative scenarios, and view and compare model results. A prototype user interface, using the transportation demand module, is currently under external review. Collections of modules, as well as individual modules, will be made available successively, and by 1995 , NEMS should be available on a workstation platform. The migration of a fully integrated version of NEMS to a personal computer platform probably will not be completed for several years. 
NEMS is a model of domestic energy markets. The decisions to produce, convert, or consume energy products are presumed to serve the economic selfinterests of those making the decisions. Many NEMS modules explicitly represent the economic decisionmaking involved in the portion of the energy system being modeled. For example, the market penetration of a new energy technology is projected only if NEMS finds the technology to be economically viable at projected energy prices; future fuel use by electric utilities is projected to be the cost-minimizing mix of fuels; or consumer appliance acquisitions are assumed to minimize the life-cycle costs of the appliance services (such as lighting and heating). To facilitate analysis, additional detail is necessary, since there may be wide variations in product usage and cost from one region to another. Consequently, using an analysis at only the national level could give misleading results. A summary of NEMS product and regional detail is shown below.

\begin{tabular}{|c|c|c|}
\hline Energy Activity & Categories & Reglons \\
\hline \multicolumn{3}{|l|}{ Supply } \\
\hline Oil & $\begin{array}{l}\text { Conventional } \\
\text { Enhanced }\end{array}$ & $\begin{array}{l}\text { Six lower } 48 \text { onshore regions } \\
\text { Three lower } 48 \text { oftshore regions } \\
\text { Three Alaska regions }\end{array}$ \\
\hline Natural gas & $\begin{array}{l}\text { Conventional shallow } \\
\text { Conventional deep } \\
\text { Coalbed methane } \\
\text { Devonian shale } \\
\text { Tight } \\
\end{array}$ & $\begin{array}{l}\text { Six lower } 48 \text { onshore regions } \\
\text { Three lower } 48 \text { offshore regions } \\
\text { Three Alaska regions }\end{array}$ \\
\hline $\begin{array}{l}\text { Natural gas transmission } \\
\text { and distribution }\end{array}$ & $\begin{array}{l}\text { Firm vs. interruptible } \\
\text { Peak vs. offpeak }\end{array}$ & $\begin{array}{l}\text { Twelve regions } \\
\text { Nine pipeline border points } \\
\text { Five liquefied natural gas terminals }\end{array}$ \\
\hline Coal & $\begin{array}{l}\text { Four sulfur categories } \\
\text { Four thermal categories } \\
\text { Underground and surface mining types }\end{array}$ & $\begin{array}{l}\text { Sixteen supply regions } \\
\text { Twenty-three demand regions } \\
\text { Sixteen export regions } \\
\text { Twenty import regions }\end{array}$ \\
\hline Renewables & $\begin{array}{l}\text { Hydroelectric, wind-electric, } \\
\text { geothermal-electric, solar-electric, } \\
\text { municipal solid waste, ethanol, wood }\end{array}$ & $\begin{array}{l}\text { Thirteen electricity supply regions } \\
\text { Five Petroleum Administration } \\
\text { for Defense Districts } \\
\text { Nine Census divisions }\end{array}$ \\
\hline \multicolumn{3}{|l|}{ Conversion } \\
\hline Electricity & $\begin{array}{l}\text { Utilities } \\
\text { Independent and small power producers } \\
\text { Cogeneration }\end{array}$ & $\begin{array}{l}\text { Thirteen supply regions } \\
\text { Nine Census divisions for demand }\end{array}$ \\
\hline Refining & $\begin{array}{l}\text { Five crude oil categories } \\
\text { Seven product categories }\end{array}$ & $\begin{array}{l}\text { Five Petroleum Administration } \\
\text { for Defense Districts }\end{array}$ \\
\hline \multicolumn{3}{|l|}{ Demand } \\
\hline Residential & $\begin{array}{l}\text { Eight end-use services } \\
\text { Three housing types }\end{array}$ & Nine Census divisions \\
\hline Commercial & $\begin{array}{l}\text { Nine end-use services } \\
\text { Eleven building types }\end{array}$ & Nine Census divisions \\
\hline Transportation & $\begin{array}{l}\text { Six car sizes } \\
\text { Six truck sizes } \\
\text { Ten vintages }\end{array}$ & Nine Census divisions \\
\hline Industrial & $\begin{array}{l}\text { Thirty-two industries } \\
\text { Eight energy-intensive industries }\end{array}$ & $\begin{array}{l}\text { Four Census regions, } \\
\text { shared to nine Census divisions }\end{array}$ \\
\hline
\end{tabular}




\section{Major Assumptions}

Each module of NEMS embodies many assumptions necessary to characterize the future production, conversion, or consumption of energy products in the United States. Any one or more of several hundred variables can be altered to create a new scenario. Two major categories of assumptions are made for the entire system prior to a model run: assumptions about economic growth in the United States, and assumptions about foreign energy supply and demand as they influence world oil prices.

\section{Domestic Economy}

The user can select variables that describe macroeconomic conditions in the United States. Predefined cases differentiate among growth rates assumed for the domestic labor force, capital, and productivity.

\section{Foreign Energy Markets}

The user can select variables that 1 el ite to circumstances influencing world oil prices. T'ese assumptions stipulate the vigor of foreign ener $w$ demand in conjunction with the relative sufficien $y$ of foreign energy supplies, particularly as measured by the assumed production capacity of the Organization of Petroleum Exporting Countries (OPEC).

High, medium, and low estimates of the key variables describing the macroeconomy and the world oil market are provided. The user can choose among these three or specify other variables as needed to tailor a specific scenario.

\section{NEMS Modular Structure}

Overall, NEMS represents a modeling system that simulates tha behavior of energy markets and their interactions with the U.S. economy. The model achieves a supply/demand balance in the end-use demand regions (defined as the nine Census divisions) by solving for the prices of each energy type that will balance the quantities producers are willing to supply with the quantities consumers wish to consume. The system reflects market economics, industry structure, and energy policies and regulations that influence market behavior.

NEMS consists of four supply modules (oil and gas, natural gas transmission and distribution, coal, and renewable fuels); two conversion modules (electricity and petroleum refineries), four demand modules (residential, commercial, transportation, and industrial); one module to simulate energy/economy interactions (macroeconomic activity); one module to simulate world oil markets (international energy activity), and one module that provides the mechanism to achieve a general market equilibrium among all the other modules (integrating module). Figure 1 shows the high-level modularity of NEMS.

\section{Modularity}

Because energy markets are heterogeneous, a single methodology cannot adequately represent all fuel supply, energy conversion, and end-use demand sectors. The modularity of the NEMS design provides the necessary flexibility for the methodology and coverage that is most appropriate for each component of the U.S. energy system. Furthermore, modularity provides the capability to execute the modules individually, or to substitute alternative modules to represent a specific function (provided the required interfaces are present). The interactions between these modules are controlled by the integrating mechanism.

\section{Coordination of Modules and Data}

Required linkages between modules are passed through common interfaces via the integrating module. The primary flows between these modules are the delivered prices of energy and the quantities consumed, by product, region, and sector. The information flows are not limited to prices and quantities, but include other information such as economic activity, international supply curves, and characteristics of renewable fuel technologies. The delivered prices of fuel encompass all the activities necessary to produce, import, and transport fuels to the end user.

\section{Data Structure}

The NEMS Global Data Structure is nsed to implement its modular structure. The Global Data Structure is defined as the set of data communicated amorg the 13 NEMS modules or subsets thereof. The Global Data Structure includes energy market prices and consumption; macroeconomic variables; energy production, transportation, and conversion information; and centralized model control variables, parameters, and assumptions. The Global Data Structure excludes variables that are defined locally within the modules and are not communicated to other modules.

An important subset of the Global Data Structure is the energy market data structure, which consists of the energy market end-use prices and quantities of fuels needed to equilibrate the NEMS energy balance. The variables in the energy market data structure are the principal variables used directly by the integrating module in its convergence algorithm. Additional macroeconomic and international trade variables are also tested for convergence in the solution algorithm. 
Figure 1. Natlonal Energy Modellng System

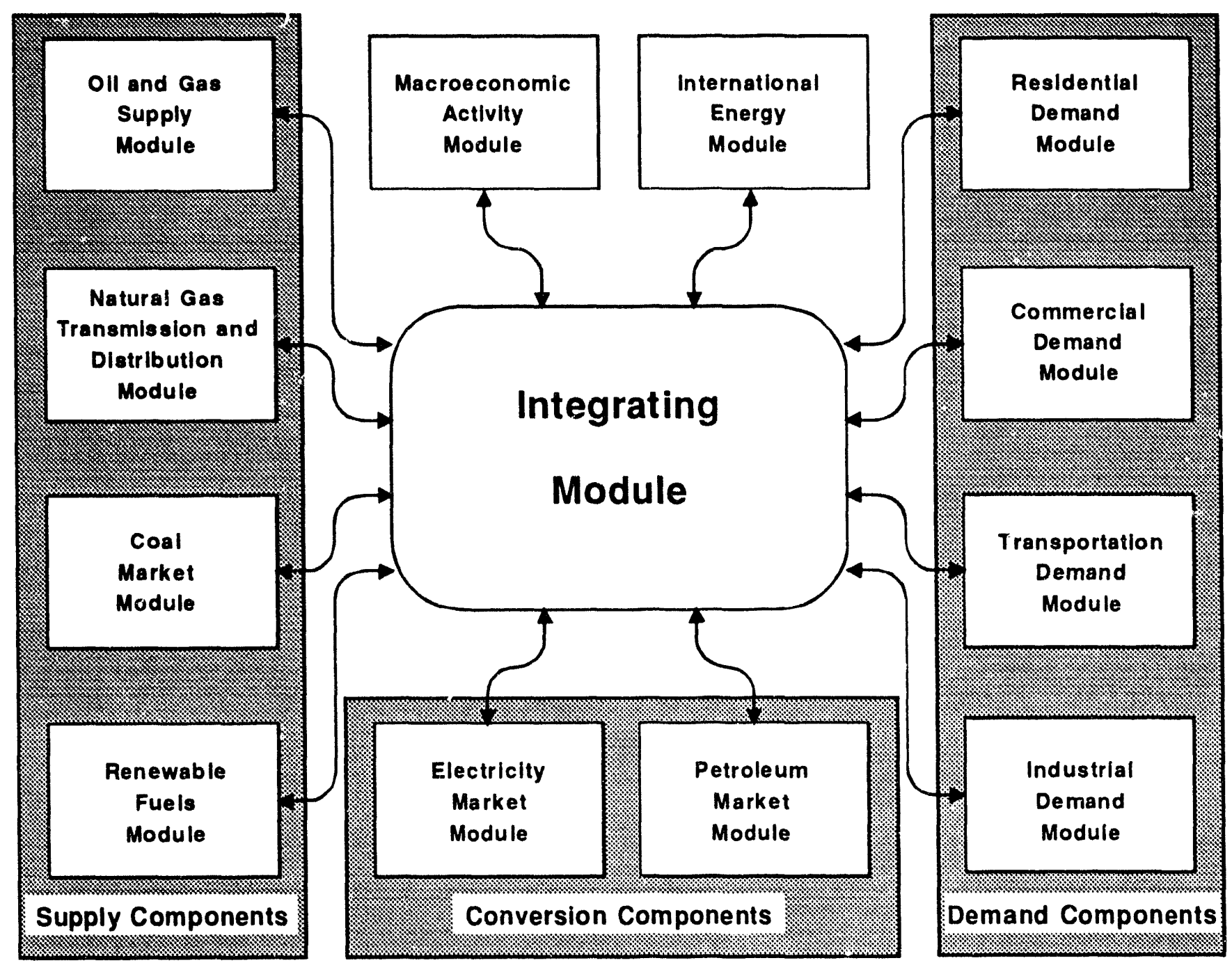


The NEMS integrating module supervises tlie entire NEMS process as it iterates to determine a general market equilibrium across all the NEMS modules. It has the following functions:

- Manages the NEMS Global Data Structure

- Executes all or any of the user-selected modules in an iterative convergence algorithm

- Checks for convergence, while reporting variables that remain out of convergence

- Implements price relaxation between iterations to accelerate convergence

- Updates expected values of the key NEMS variables.

\section{Features of the Integrating Module}

The integrating module executes the demand, conversion, and supply modules iteratively until it achieves an economic equilibrium of supply and demand in all the consuming and producing sectors. Each fuel supply, conversion, or end-use demand module is called in sequence and solved, assuming that all other variables in the energy markets are fixed. The modules are called iteratively until the end-use prices and quantities remain constant within a specified tolerance-a condition defined as convergence. Equilibration is achieved annually through the midterm period to 2010.

The integrating framework incorporates interfaces to the macroeconomic and international modules, exchanging information between them and the domestic energy modules. The solution algorithm incorporates equilibration tests and iterative calls for the NEMS macroeconomic and international modules. The convergence tests ascertain the stability of a set of key macroeconomic and international trade variables in response to interaction with the domestic energy system. The integrating framework also accounts for global system values, such as emissions, capital requirements, and foreign trade, to allow for the incorporation of feedback effects of such values on the energy system.

\section{NEMS Regional Detail}

The integrating module of NEMS functions at the level of the nine Census divisions (Figure 2). The four Census regions (shown in Figure 2 by breaks between State groups) and nine divisions are a common, mainstream level of regionality widely used by EIA and other organizations for data collection and analysis. The Census divisions are defined and numbered in the integrating module and data structure as shown in Figure 2.

\section{Description of the NEMS Solution Algorithm}

The NEMS algorithm executes the system of modules until convergence is reached. The solution procedure for one iteration involves the execution of all the component modules, as well as the updating of expectation variables (related to foresight assumptions) for use in the next iteration.

The system is executed sequentially for each year in the forecast period. During each iteration within a year, each of the analytical modules is executed in turn, with intervening convergence checks that isolate specific modules that are not converging. A separate convergence check is made for prices and quantities, consisting of a comparison of the absolute values of the percentage changes to an assumed tolerance. To avoid unnecessary iterations for changes in insignificant values, the quantity convergence check is omitted for quantities less than a user-specified minimum level. The order of execution of the modules may affect the rate of convergence but will not alter the final results.

An optional relaxation routine can be executed to dampen swings in solution values between iterations. With this option, the current iteration values are reset partway between solution values from the current and previous iterations. 
Figure 2. Census Divisions

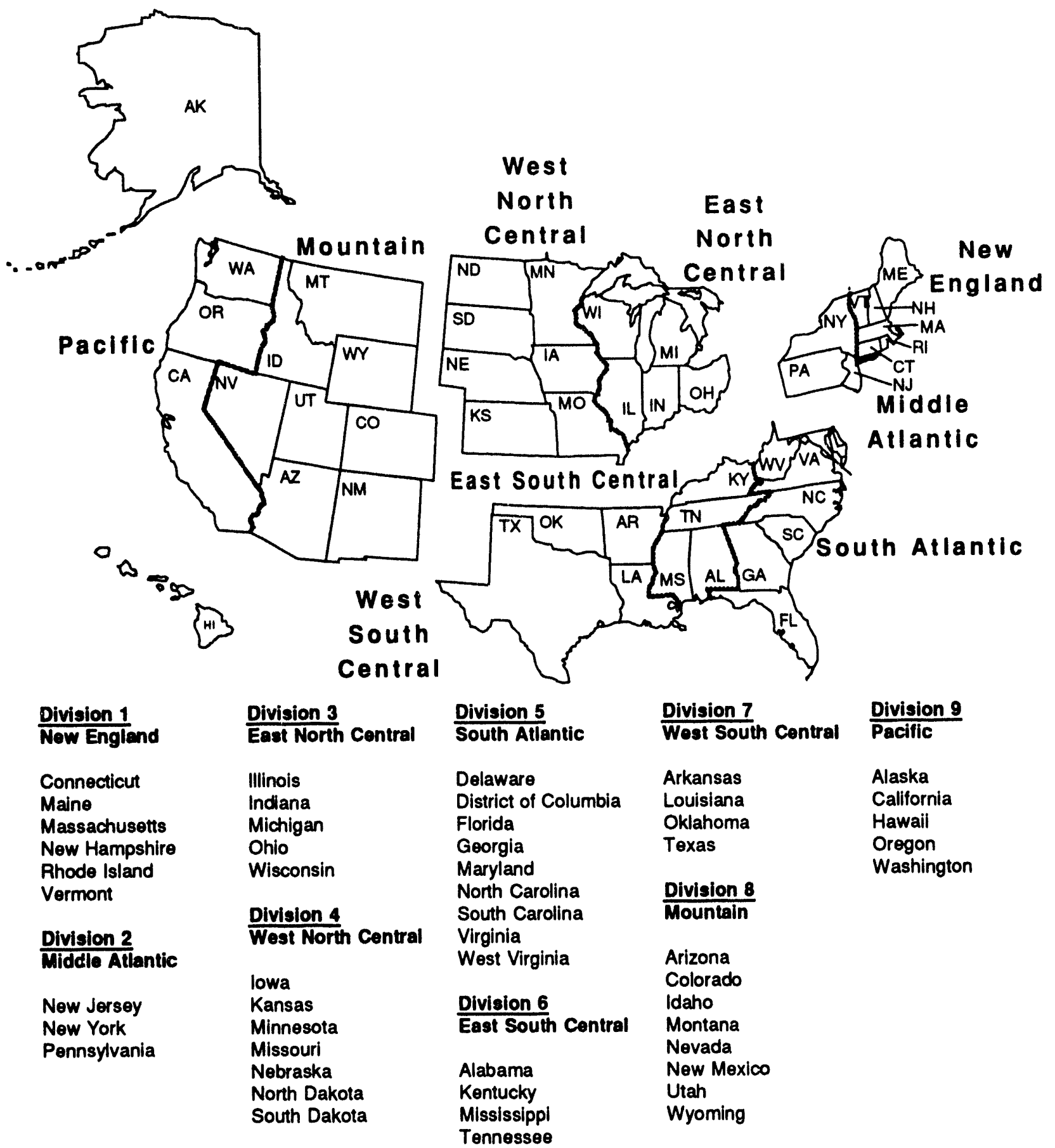

Source: Energy Information Administration, Office of Integrated Analysis and Forecasting. 
The international energy module (IEM) calculates the average price of imported crude oil and provides supply curves for five grades of crude oil for import into the United States. In addition, it performs the following functions:

- Calculates the change in world oil price in response to shifts in U.S. supply and demand

- Provides petroleum product supply curves with a representation of foreign product supply levels and associated costs for imports of petroleum products into the United States

- Calculates shifts in supply curves for petroleum product imports as a result of variations in demand for U.S. product imports, world oil price, and economic conditions

- Provides supply curves for U.S. imports of the oxygenates methyl tertiary butyl ether (MTBE) and methanol.

Three separate submodules of the IEM (Figure 3) carry out these functions. The world oil market submodule is an expanded version of the Oil Market Simulation Model that was used for world oil price forecasts before NEMS was develcped. The world oil market submodule forecasts international crude oil market conditions, including price and supply availability, and the effects of U.S. demand on the world market. The petroleum product supply submodule produces supply curves for petroleum products imported into the United States. These supply curves reflect conditions in the international market, including refinery capacity, transportation costs, and the effects of U.S. demand on world markets. Finally, the oxygenates supply submodule produces supply curves for U.S. imports of MTBE and methanol.

The petroleum products supply and oxygenates supply submodules use the world oil price generated by the world oil market submodule. Otherwise, the three submodules of the IEM are independent, providing feedback through the rest of NEMS during system iteration. A summary of important IEM inputs and outputs is given below.

\section{World Oil Market Submodule}

EIA's modeling of the near- to mid-term world oil market depends on two key assumptions: (1) oil is the marginal fuel, and (2) OPEC produces such marginal supply at prices that tend to inhibit the market penetration of new technologies. Under these assumptions, world oil prices are computed to provide a balance of supply and demand for crude oil in the international market as a function of OPEC production decisions, supply of non-OPEC oil, and international demand for oil, which depends upon worldwide economic growth. Under the assumption that oil is the marginal fuel, competition between oil and other fuels can be ignored, because switching between fuels is assumed to be too small to affect the world oil price. The second assumption means that the price of oil is not allowed to go so high as to induce the market penetration of new technology that would reduce the demand for oil sufficiently to produce substantial downward pressure on its price. U.S. import supply curves for several qualities of crude oils are generated as a function of the world oil price, production sources, transportation rates, and assumptions about the utilization and/or expansion of worldwide refining capacity. World crude oil sales are mapped into the five classes used in the petroleum market module (see page 37).

\section{Petroleum Products Supply Submodule}

The petroleum prociucts supply submodule consists of a set of supply curves for import to all five PADDs for each petroleum product to be imported in NEMS. The petroleum market module uses the supply curves to determine the quantity of products to be imported at a given price. The supply curves were developed from a separate large-scale model of international refining and transportation that is used as an auxiliary to NEMS. Supply curves for 10 products are provided: traditional gasoline (including aviation), reformulated gasoline, No. 2 heating oil, low-sulfur distillate oil, high- and low-sulfur residual oil, jet fuel (including naphtha jet), liquefied petroleum gas, petrochemical feedstocks, and other.

\begin{tabular}{|l|l|l|}
\hline \multicolumn{1}{|c|}{ Important IEM Outputs } & Important Inputs from NEMS & \multicolumn{1}{|c|}{ Important Exogenous Inputs } \\
\hline $\begin{array}{l}\text { World oil price } \\
\text { Crude oil import supply } \\
\begin{array}{l}\text { Product import supply } \\
\text { Methyl tertiary butyl ether and methanol supply } \\
\text { Other oxygenate prices }\end{array}\end{array}$ & $\begin{array}{l}\text { U.S. oil supply/demand } \\
\text { U.S. net product imports }\end{array}$ & $\begin{array}{l}\text { OPEC production path } \\
\text { Reference non-U.S. oil supply } \\
\text { and demand }\end{array}$ \\
\hline
\end{tabular}


Figure 3. International Energy Module Structure

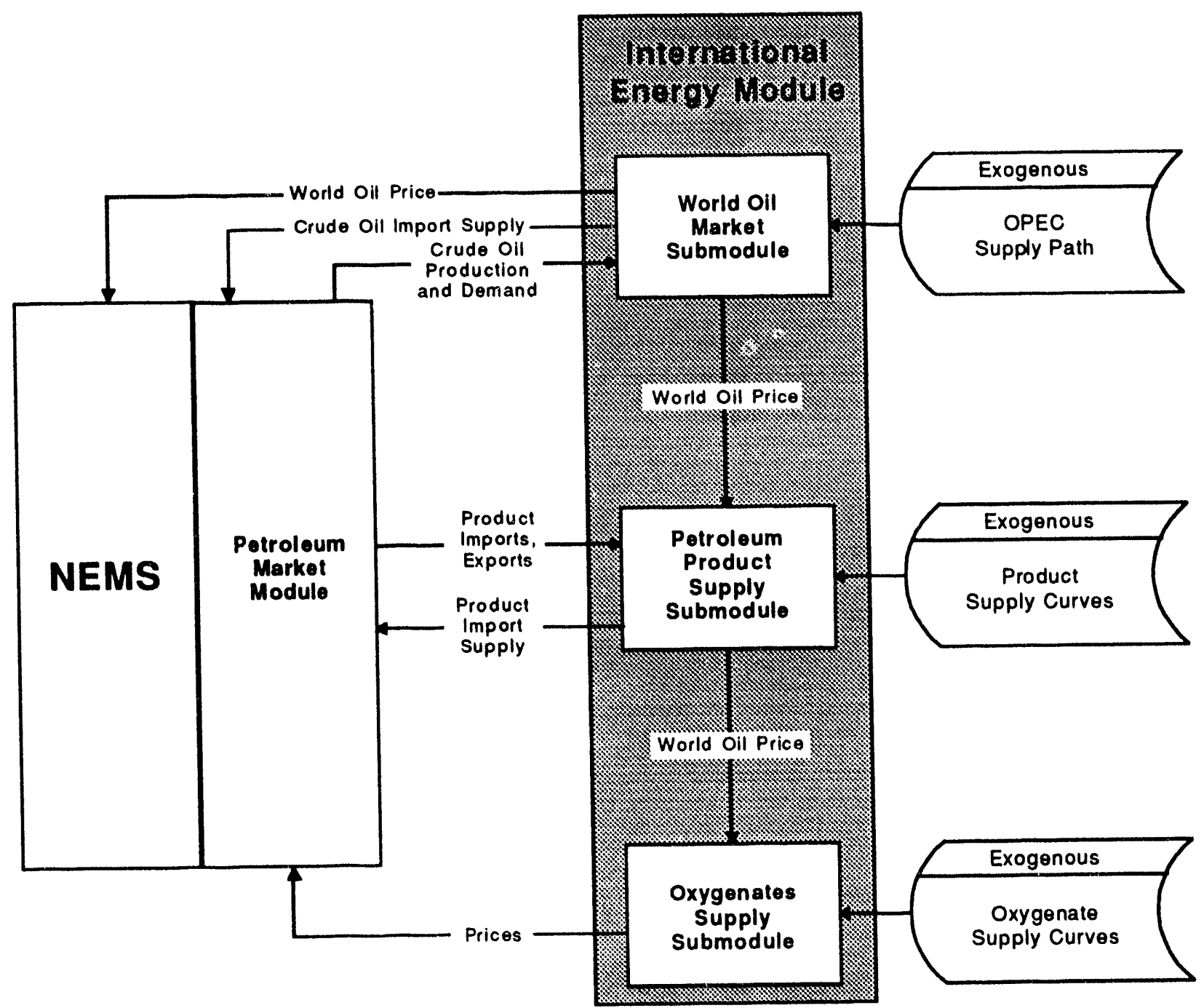

\section{Oxygenates Supply Submodule}

Supply curves for MTBE and methanol are developed from data on pricing practices for current production capacity and assumptions about pricing for new production capacity that is under construction or expected to be constructed in the future. The curves are used in the same ways as the petroleum product supply curves described above. The oxygenates supply submodule calculates prices for oxygenate imports, based on import quantities estimated by the petroleum market module. The petroleum market module then recalculates the quantity of imports and iterates with the oxygenates supply submodule until convergence is obtained.

Because of the potential expansion of the U.S. ethanol industry and the lack of commercial markets for other oxygenates, it is assumed that ethanol, ethyl tertiary butyl ether (ETBE), tertiary amyl methyl ether (TAME), and tertiary butyl alcohol (TBA) are all supplied from domestic sources. Therefore, the IEM does not provide import supply curves for these oxygenates. 
The macroeconomic activity module (MAM) provides forecasts of economic variables to the energy modules within NEMS, and forecasts the impacts on the aggregate economy of changes in energy market conditions. The MAM consists of two submodules (the national and interindustry submodules) and a subroutine (the regional subroutine), which are run in sequence. The national submodule provides forecasts of a wide range of economic variables at the national level. In particular, it provides variables that drive other parts of NEMS, including interest rates, final demands for goods and services, and disposable income. The interindustry submodule calculates the industrial output needed to satisfy the final demands from the national submodule. The levels of industrial output are used by the industrial and transportation demand modules in NEMS to calculate energy consumption in those sectors. Finally, the regional subroutine of the MAM takes national variable values from the national and interindustry submodules and transforms them into appropriate regional values. The overall interrelationships are shown in Figure 4.

The sequence of interactions in the MAM can be summarized as follows: The energy supply and demand modules of NEMS determine the reaction of energy prices to changes in events or policies. These energy price effects are passed to the national submodule, and the economy is projected to react to the altered energy price paths. The altered macroeconomic final demands are in turn passed to the interindustry submodule, which calculates their effect on interindustry activity. The altered interindustry projections are then passed back to the other NEMS modules, and the system iterates until convergence is achieved.

MAM outputs include measures of macroeconomic performance and manufacturing and nonmanufacturing sector production activities. Depending on the concept, these measures are provided nationally or at the geographic level of the nine Census divisions (see Figure 2). A summary of important MAM inputs and outputs is given below.

\section{National Submodule}

The national submodule of MAM is a response surface representation of the Data Resources, Inc. (DRI) U.S. Quarterly Model. (A response surface representation is a set of equations embodying important inputs and outputs of a larger, detailed model. The coefficients of the equations are estimated via statistical/econometric methods, based on "pseudodata" derived from repeated runs of the larger model being represented.) The response surface representation simulates the reaction to changing energy prices of the larger version of the DRI U.S. Quarterly Model. The growth potential of the economy is essentially grounded in the growth of the factors of production-labor, capital, and energy-and the aggregate productivity of these factors. The user can select three different macroeconomic growth cases before executing the MAM, and incremental changes can be made exogenously to any macroeconomic growth case. For example, the case chosen can be changed either by using different labor force or productivity assumptions or by choosing a different gross domestic product growth rate.

The national submodule responds to two sets of information: energy prices at the wholesale and retail level and exogenously specified information on labor force growth and productivity. The energy supply and demand modules of NEMS determine the reaction of energy prices to changes in events or policies. These energy price effects are passed to the national submodule, where the economic system reacts to the altered energy price paths. The altered macroeconomic variables are then passed back to the other modules of NEMS, and the system iterates until convergence is reached.

\section{Interindustry Submodule}

The interindustry submodule provides industrial output projections to the regional MAM subroutine and the energy modules. It also calculates interindustry impacts associated with energy events and policies. A response surface version of the DRI Input-Output Model for the Personal Computer constitutes the core

\begin{tabular}{|c|c|c|}
\hline Important MAM Outputs & Important Inputs from NEMS & Important Exogenous Inputs \\
\hline $\begin{array}{l}\text { Gross domestic product } \\
\text { Oher economic activity measures } \\
\text { Price indices and deflators } \\
\text { Production rates for manufacturing } \\
\text { Production rates for nonmanufacturing } \\
\text { Interest rates }\end{array}$ & $\begin{array}{l}\text { Wholesale and retail prices for electricity } \\
\text { Wholesale and retail prices and production rates } \\
\text { for oil, gas, and coal } \\
\text { Rate of refinery activity }\end{array}$ & $\begin{array}{l}\text { Labor force } \\
\text { Productivity }\end{array}$ \\
\hline
\end{tabular}


Figure 4. Macroeconomic Activity Module Structure

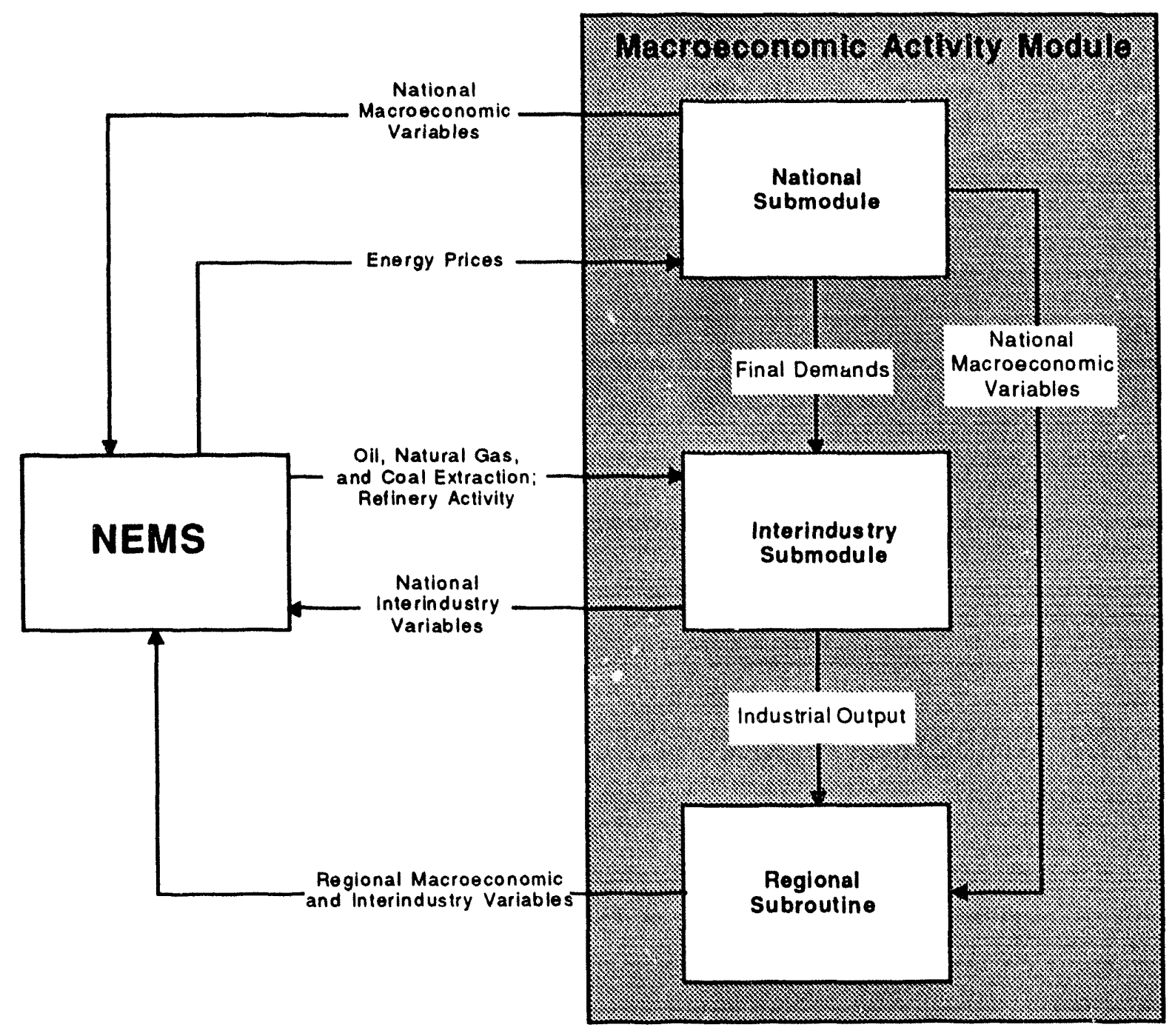

interindustry segment of this submodule, which is fully linked to other NEMS components.

The interindustry submodule calculates deviations from a given baseline interindustry projection whenever macroeconomic final demands change. Because of the top-down structure of input-output modeling, the interindustry and national submodules do not iterate directly with each other. However, through their joint effect on the projections of the energy supply and demand modules, which in turn alter the macroeconomic outlook, changes in interindustry projections affect the results of the national submodule.

\section{Regional Subroutine}

The initial implementation of the regional subroutine is a set of equations that share national economic and industrial output data to specific regions. The sharing equations are derived from the Regional Macroeconomic Model (RMM) developed by DRI. The next version of the regional subroutine will be a response surface version of the RMM, which will describe how regional shares respond to changes in regional energy prices. The regional subroutine disaggregates national economic variables such as disposable income, industrial production, and consumer prices into appropriate regional values. 


\section{Oil and Gas Supply Module}

The oil and gas supply module (OGSM) consists of a series of process submodules that project the availability of:

- Domestic crude oil production and dry natural gas wellhead production from onshore, offshore, and Alaskan reservoirs

- Imported pipeline-quality gas from Mexico and Canada

- Imported liquefied natural gas.

The OGSM regions are shown in Figure 5.

The driving assumption of the OGSM is that domestic oil and gas exploration and development is undertaken if the discounted present value of the recovered resources at least covers the present value of taxes and the cost of capital, exploration, development, and production, subject to a budget constraint. In contrast, international gas trade is determined in part by scenario-dependent, noneconomic factors. Crude oil is transported to refineries (which are simulated in the petroleum market module) for conversion and blending into refined petroleum products.

The individual submodules of the oil and gas market module are solved independently, with feedbacks achieved through NEMS solution iterations (Figure 6). Important OGSM inputs and outputs are shown below.

\section{Lower 48 Supply Submodule}

Lower 48 supplies consist of oil and gas produced by conventional recovery methods in onshore and offshore regions, and unconv ntional gas recovery in onshore regions. (Unconventional gas is defined as gas produced from nonconventional geologic formations, as opposed to conventional clastic (sandstones) and carbonate rock formations. The three nonconventional geologic formations considered are low-permeability or tight sandstones, Devonian shale, and coalbed methane.) Enhanced oil recovery from onshore regions is handled separately. The "lower 48 submodule" actually consists of three separate submodules: onshore lower 48 conventional oil and gas supply, offshore oil and gas supply, and unconventional gas recovery supply.

The lower 48 submodule accounts for drilling, reserves estimates, production capacity, capital expenditures, and emissions. The national onshore and offshore expenditures for exploratory and development drilling initially are set to base year levels. The disaggregation of drilling expenditures is executed by means of a twotier sharing procedure. The first step in the sharing process divides expenditures between regions. The second step divides expenditures by fuel and well type within the regions. The disaggregated drilling expenditures are divided by drilling costs to determine the base level of drilling in each period. The base level of drilling by category is then adjusted as a function of the current wellhead price. A wells algorithm yields the number of wells drilled in each region by well class and fuel category. The next steps use regional finding rate equations to forecast new field discoveries from new field wildcats, new pools and extensions from other exploratory drilling, and reserve revisions from development drilling. Production is determined within the market equilibration of the natural gas transmission and distribution module and the petroleum market module on the basis of fuel demands, reserves (including new reserve additions), previous productive capacity, and flow from new wells.

\section{Alaska Oil and Gas Submodule}

This submodule projects the crude oil and natural gas produced in Alaska. The Alaska oil and gas submodule is divided into three sections: new field discoveries, development projects, and producing fields. Oil and gas transportation costs to lower $\mathbf{4 8}$ facilities are used in conjunction with the relevant market price of oil or gas to calculate the estimated net price received at the wellhead, sometimes called the "netback price." A discounted cash flow method is used to determine the economic viability of each project at the netback price. Alaskan oil and gas supplies are modeled on the basis of discrete projects, in contrast to the onshore lower 48 conventional oil and gas supplies, which are modeled

\begin{tabular}{|l|l|l|}
\hline \multicolumn{1}{|c|}{ Important OGSM Outputs } & Important Inputs from NEMS & \multicolumn{1}{|c|}{ Important Exogenous Inputs } \\
\hline $\begin{array}{l}\text { Supply curve parameters } \\
\text { Oil and gas financial data } \\
\text { Pipeline gas and liquefied natural gas } \\
\text { imports and exports }\end{array}$ & Oil and gas production by fuel type & $\begin{array}{l}\text { Resource levels } \\
\text { Finding rate parameters and costs } \\
\text { Emissions from oil and gas production }\end{array}$ \\
$\begin{array}{l}\text { Reserves and reserve additions } \\
\text { Annual drilling levels }\end{array}$ & & $\begin{array}{l}\text { Production profiles } \\
\text { Tax parameters } \\
\text { Import capacity }\end{array}$ \\
\hline
\end{tabular}




\section{OIL AND GAS SUPPLY MODULE}

\section{Figure 5. Oll and Gas Supply Module Reglons}
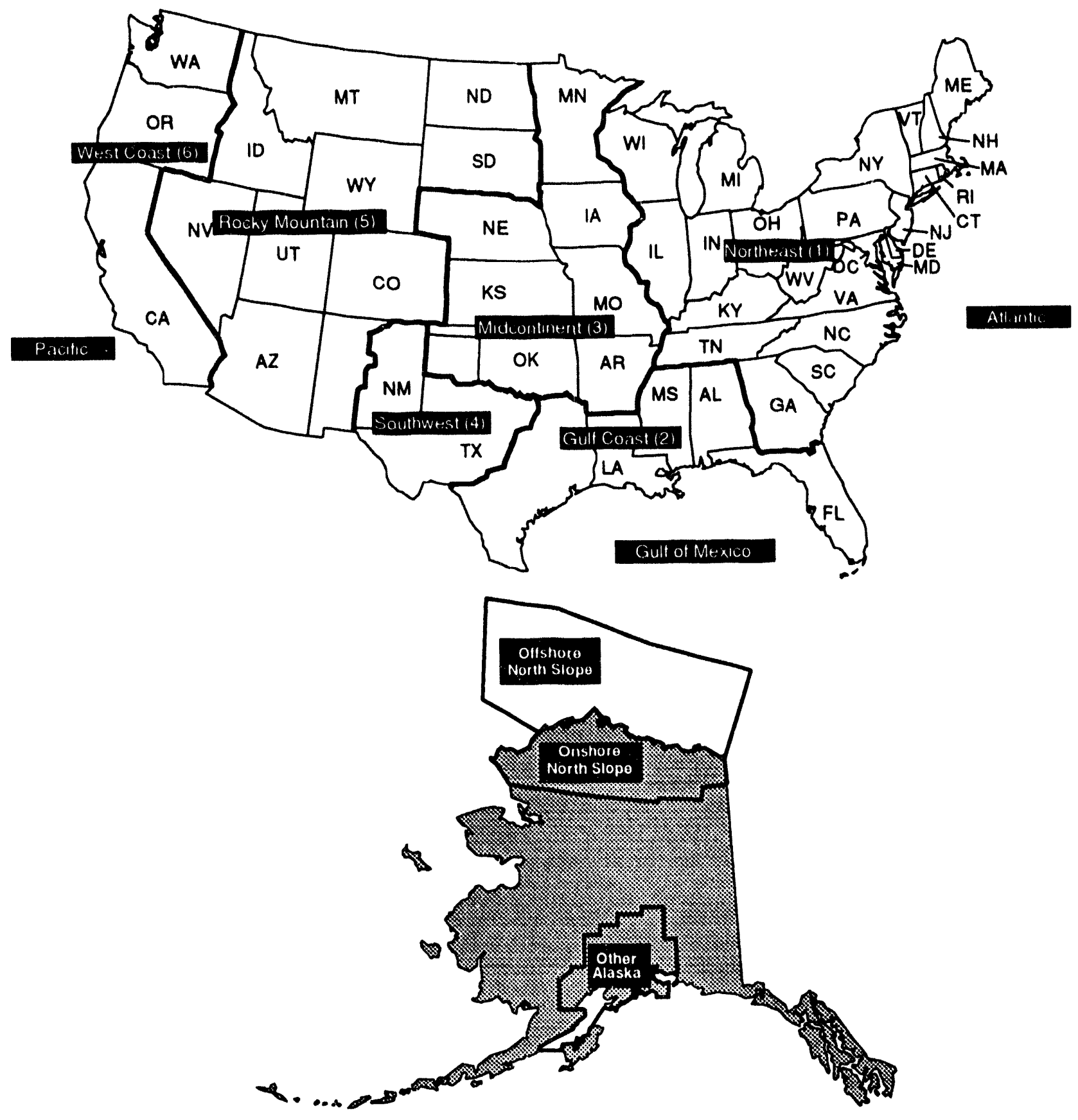

Source: Energy Information Administration, Office of Integrated Analysis and Forecasting. 
Figure 6. Oll and Gas Supply Module Structure

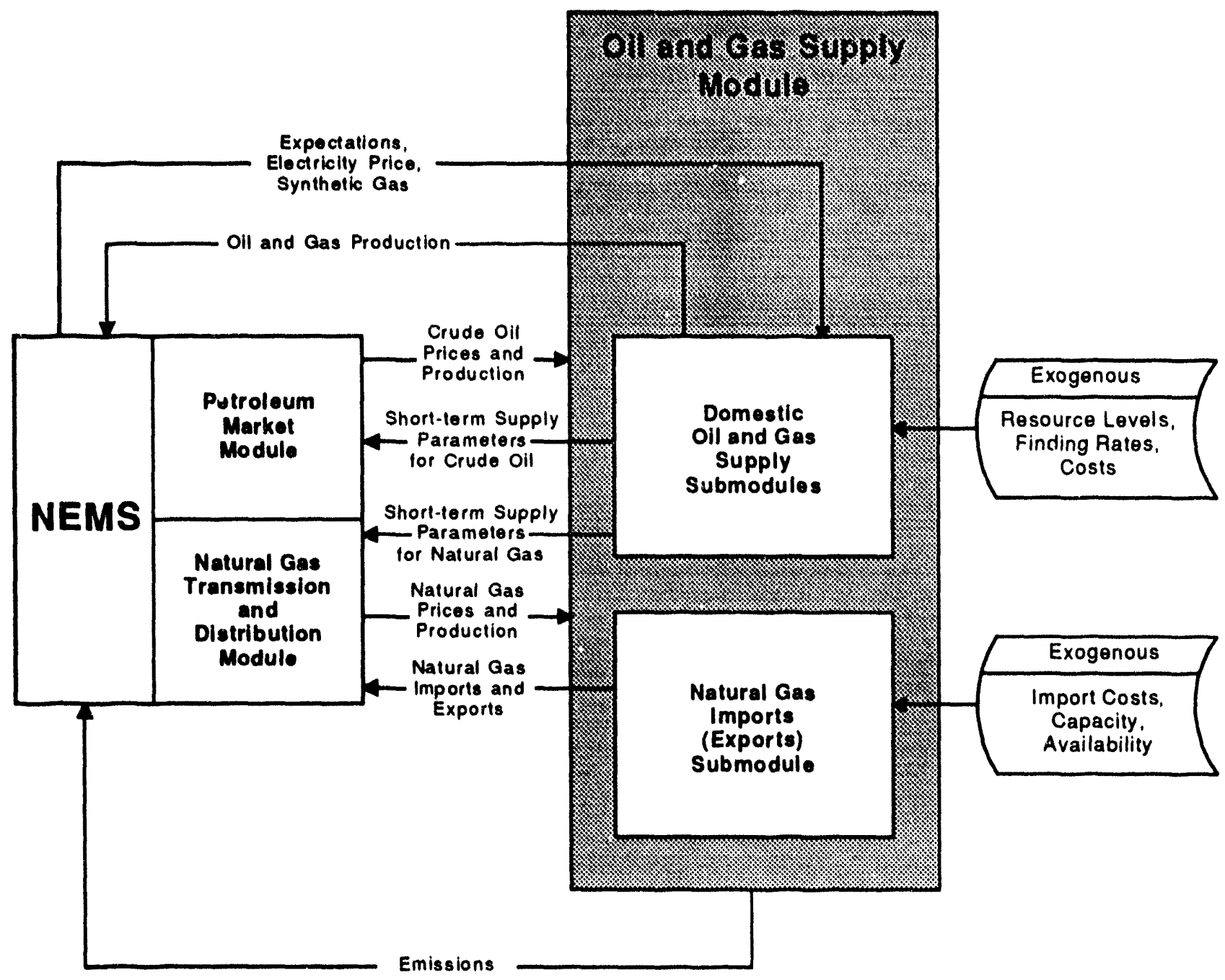

on an aggregate level. The continuation of the exploration and development of multi-year projects, as well as the discovery of a new field, is dependent on its profitability. Production is determined on the basis of assumed drilling schedules and production profiles for new fields and developmental projects, historical production patterns, and announced plans for currently producing fields.

\section{Enhanced Oil Recovery Submodule}

Enhanced oil recovery enters the NEMS as an exogenously determined projection. The OGSM requires regional production estimates from the onshore regions of the lower 48 States on a yearly basis.

\section{Foreign Natural Gas Supply Submodule}

The foreign natural gas supply submodule projects natural gas trade via pipeline with Canada and Mexico, as well as liquefied natural gas (LNG) trade. The receiving regions for foreign gas supplies correspond to those of the natural gas integrating framework as established for the natural gas transmission and distribution module. Pipeline natural gas import volumes flow from two sources: Canada and Mexico. U.S. natural gas trade with Canada is represented by six entry/exit points, and trade with Mexico is represented by three entry/exit points (Figure 7). 
Figure 7. Forelgn Natural Gas Trade Via Pipeline

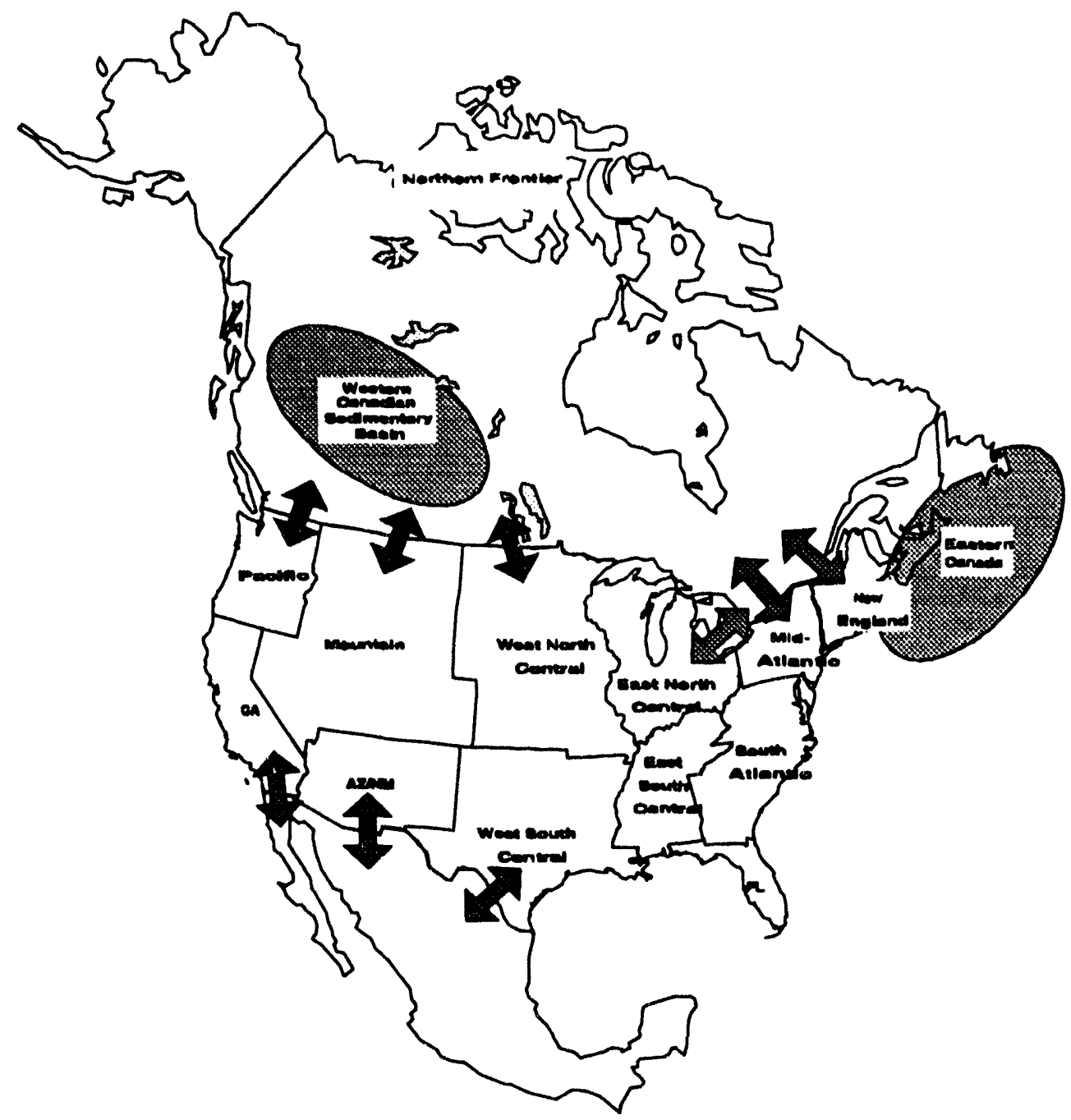

\section{Canadian Gas Submodule}

This submodule determines net Canadian natural gas supplies to the United States at six border crossing locations, over a range of gas prices. The initial step is to provide projections of Canadian drilling activity and supply. Canadian demand is then subtracted from supply to determine gas available for export. Gas supply is allocated to regional Canadian/U.S. border crossing points by an allocation algorithm that accounts for the associated pipeline capacities and the price responsiveness of supplies at the border points. The determination of the import volumes themselves occurs in the equilibration process of the natural gas supply and distribution module.

\section{Mexican Gas Submodule}

Mexican gas trade is a highly complex issue. A range of noneconomic factors influence, if not determine, flows of gas between the United States and Mexico. The uncertainty is so great that not only is the magnitude of flow for any future year in doubt, but also the direction of flow. Reasonable scenarios have been developed and defended in which Mexico may be either a net importer or exporter of hundreds of billions of cubic feet of gas by 2010 .

The vast uncertainty and the importance of noneconomic factors in future Mexican gas trade with the United States suggest that these flows should be handled on a scenario basis. Such a scenario can be 
introduced into the Mexican gas submodule as a userspecified path of future Mexican imports and exports. Otherwise, the analysis uses a prespecified default outlook for Mexican trade, drawn from the recent National Petroleum Council study on natural gas. Alternatively, the outlook can be developed from an assessment of current and expected industry and market circumstances, as indicated in industry announcements or articles and reports in relevant publications. The outlook, regardless of its source, is fixed and is not responsive to energy price changes.

\section{Liquefied Natural Gas Submodule}

This submodule projects the volume of LNG available for import into the United States at various price levels. Imported LNG costs do not compete with the wellhead price of domestically produced gas; rather, LNG costs compete with the purchase price of gas prevailing in the vicinity of the import terminal. This is a significant element in evaluating the competitiveness of LNG supplies, since LNG terminals vary greatly in their proximity to domestic producing areas. Terminals close to major consuming markets and far from competing producing areas may provide a sufficient economic advantage to make LNG a competitive gas supply source in some markets.
In addition to costs, extensive operational assumptions are required to determine LNG imports/exports. Dominant general factors affecting the outlook include: expected developments with respect to the use of existing capacity, expansion at existing sites, and construction at additional locations. The LNG submodule requires specification of a combination of factors: available gasification capacity, schedules for and lags between constructing and opening a facility, tanker availability, expected utilization rates, and worldwide liquefaction capacity. For inactive terminals, it is necessary to determine the length of time required to restart operations (normally, between 12 and 18 months). These considerations are taken into account when the economic viability of LNG supplies is determined.

\section{Emissions}

The environmental impacts of energy production and consumption are key policy issues. The OGSM includes a system of emissions accounting. This procedure employs coefficients that relate emissions to source-specific production of different fuels. 


\section{NATURAL GAS TRANSMISSION AND DISTRIBUTION MODULE}

\section{Natural Gas Transmission and Distribution Module}

The natural gas transmission and distribution module (NGTDM) is the component of NEMS that represents the midterm natural gas market. The NGTDM models the natural gas transmission and distribution network in the lower 48 States, which links suppliers (including importers) and consumers of natural gas. The module determines regional market-clearing prices for natural gas supplies (including border prices) and enduse consumption.

The NGTDM has four primary submodules: the annual flow Submodule, the capacity expansion submodule, the pipeline tariff submodule, and the distributor tariff submodule. The annual flow submodulethe central component of the NGTDM-is used to derive flows and prices of natural gas in conjunction with an annual natural gas market equilibrium. Conceptually, the annual flow submodule is a simpli-

fied representation of the natural gas transmission and distribution system, structured as a network of nodes and arcs. The network representation is in terms of 12 internal nodes and 9 border transshipment nodes (Figure 8). The other three submodules provide parameters to the annual flow submodule that define some of the characteristics of the system's nodes and arcs. Other parameters for defining the natural gas market (such as supply and demand curves) are derived from information passed from other NEMS modules. The capacity expansion submodule provides the annual flow submodule with regional underground storage capacities and maximum annual flows allowed along each of the arcs in the network. The pipeline and distributor tariff submodules provide price parameters for establishing the tariffs to be charged along each of the interregional, intraregional, and distribution arcs. Data are also passed back to these submodules from the annual flow submodule and between the submodules themselves.
The primary outputs from the NGTDM, which are used as input in other NEMS submodules, result from establishing a natural gas market equilibrium solution: end-use prices, wellhead and border crossing prices, and associated production and Canadian import levels. In addition, the module provides a forecast of lease and plant fuel consumption, pipeline fuel use, and the corresponding emissions, as well as pipeline and distributor tariffs, pipeline and storage capacity expansion, and interregional natural gas flows. Capital investments associated with the expansion of pipeline and storage capacity are also provided. The basic NGTDM structure and its relationship with other NEMS modules is shown in Figure 9. Important inputs and outputs are given below.

\section{Annual Flow Submodule}

The annual flow submodule is the main integrating component of the NGTDM. One of its major functions is to simulate the natural gas price determination process. The annual flow submodule brings together all major economic and technological factors that influence regional natural gas trade in the United States. The economic considerations include the demand for and the supply of natural gas, competition from substitute fuels and conservation options, and competition from imported natural gas.

The annual flow submodule integrates all components of the NGTDM - the annual flow submodule itself, the capacity expansion submodule, the pipeline tariff submodule, and the distributor tariff submodule). Through this integration process, the annual flow submodule derives average annual natural gas prices (wellhead, city gate, and end-use). that reflect a market equilibrium among competing gas supplies, end-use sector consumption, and transportation routes. End-use prices are derived for both firm and interruptible markets. Within NEMS, the classification of

\begin{tabular}{|c|c|c|}
\hline Important NGTDM Outputs & Important Inputs from NEMS & Important Exogenous Inputs \\
\hline $\begin{array}{l}\text { End-use natural gas prices } \\
\text { Natural gas wellhead prices } \\
\text { Natural gas border crossing prices } \\
\text { Domestic natural gas production } \\
\text { Canadian natural gas imports and production } \\
\text { Lease and plant fuel consumption } \\
\text { Pipeline fuel use } \\
\text { Pipeline and distribution tariffs } \\
\text { Interregional natural gas flows } \\
\text { Investment for facilities expansion } \\
\text { Pipeline emissions } \\
\text { Storage and pipeline capacity expansion }\end{array}$ & $\begin{array}{l}\text { End-use natural gas demands } \\
\text { Natural gas supply parameters } \\
\text { Natural gas exports } \\
\text { Canadian pipeline capacity } \\
\text { Natural gas consumption from plant } \\
\text { operations (percentage of production) } \\
\text { Crude oil production } \\
\text { Consumption parameters from dual-fired } \\
\text { plants }\end{array}$ & $\begin{array}{l}\text { Historical consumption patterns } \\
\text { Historical flow patterns } \\
\text { Rate design specifications } \\
\text { Company-level financial data } \\
\text { Pipeline and storage capacity } \\
\text { and utilization data } \\
\text { Historical end-use prices } \\
\text { State and Federal tax parameters }\end{array}$ \\
\hline
\end{tabular}


Figure 8. Natural Gas Transmisslon and Distribution Module Network

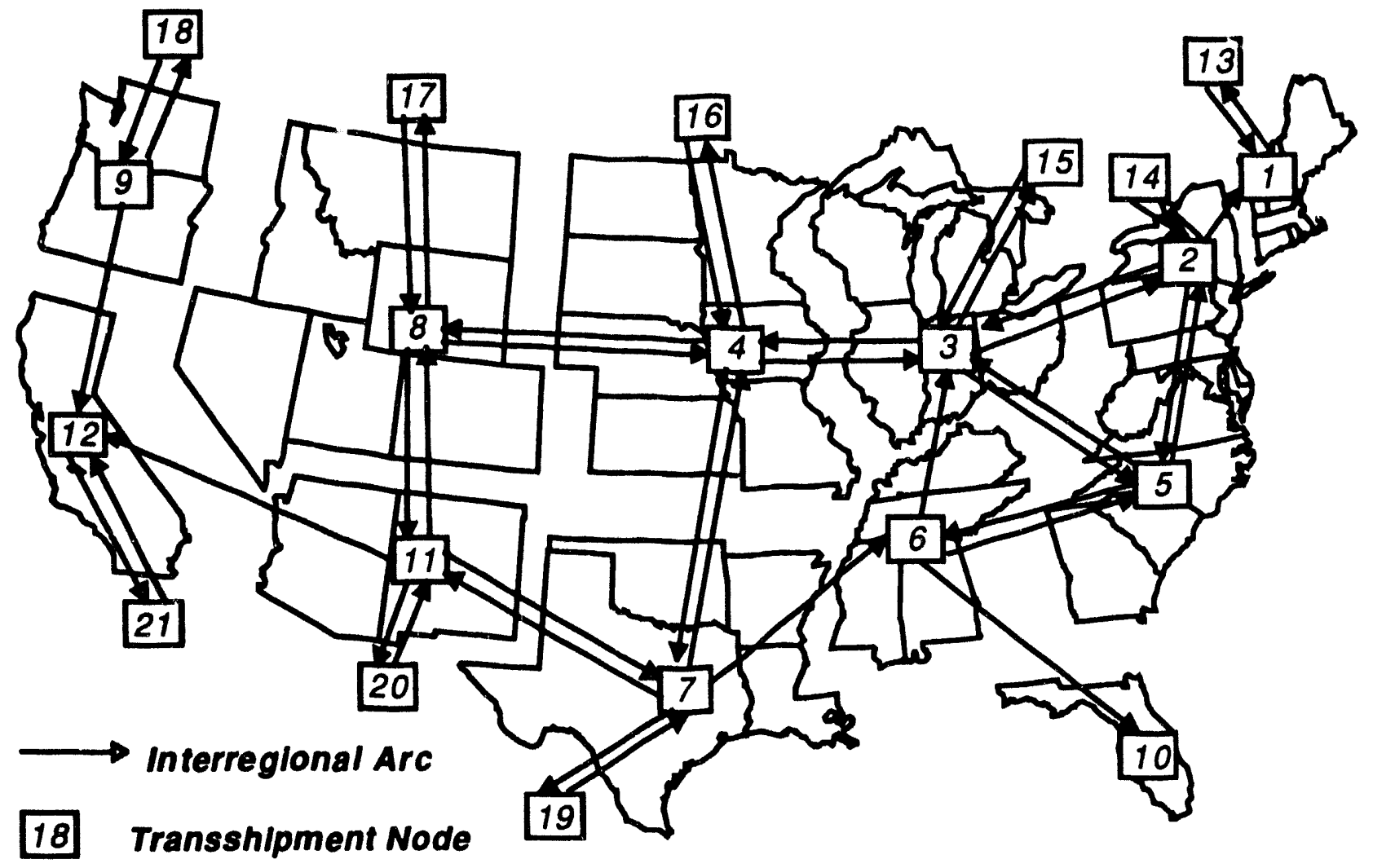

customers that will purchase firm versus interruptible service is predetermined.

\section{Capacity Expansion Submodule}

the capacity expansion submodule simulates the decisionmaking process for expanding pipeline and/or storage capacity in the U.S. gas market. In simulating gas pipeline capacity expansion, the capacity expansion submodule (1) determines the amount of pipeline and storage capacity to be added between or within regions in the NGTDM, and (2) establishes effective (or practical) maximum annual utilization rates for each of the interregional pipeline routes represented in the annual flow submodule. Maximum utilization rates (or load factors) for pipeline routes are established to capture the impact of variations in seasonal demand on the maximum amount of gas that can practically flow between regions within a year. Pipeline and storage capacity additions are used in the annual flow submodule (in combination with the maximum load factors) to set limits on annual interregional flows and to set working gas storage levels. These capacity additions are also used in the pipeline tariff submodule for the determination of future storage rates and interregional pipeline tariffs.

\section{Pipeline Tariff Submodule}

The pipeline tariff submodule computes tariffs for transportation and storage services provided by interstate pipeline companies. The tariffs are used within the annual flow submodule to derive supply and end-use prices and within the capacity expansion 


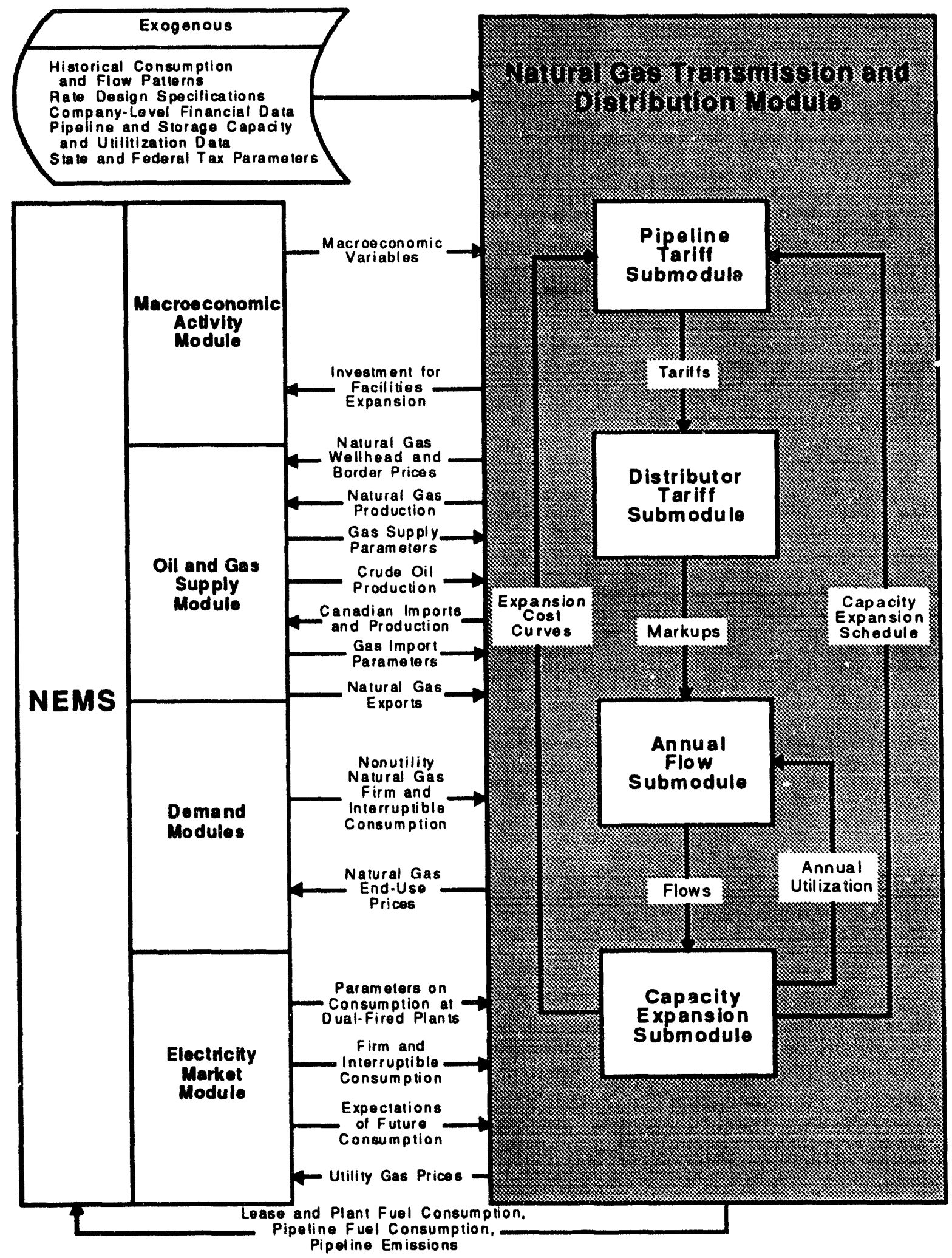




\section{NATURAL GAS TRANSMISSION AND DISTRIBUTION MODULE}

submodule to derive capacity additions. The tariffs ure computed for individual pipeline companies, then aggregated to the major gas pipeline corridors or arcs (in the United States) specified in the NGTDM network (Figure 8). An accounting system is used to track costs and compute rates under various rate design and regulatory scenarios. Tariffs are computed for both firm and interruptible transportation and storage services. Transportation tariffs are computed for the interregional arcs defined by the NGTDM network. These network tariffs represent an aggregation of the tariffs for individual pipeline companies supplying the network arc. Storage tariffs, defined at regional NGTDM network nodes, likewise represent an aggregation of individual company storage tariffs.

\section{Distributor Tariff Submodule}

The distributor tariff submodule determines the components of end-use prices that are regulated by
State and local authorities. These consist of (1) distributor markups charged by local distribution companies for the distribution of natural gas from the city gate to the end user, and (2) markups charged by intrastate pipeline companies for intrastate transportation services. Although the distribution service performed by local distribution companies and the transportation service performed by intrastate carriers are distinct activities, separate distribution and intrastate markups are not determined. Rather, the distributor tariff submodule determines a volumetric charge that covers the cost of providing distribution or transportation services from the city gate to the end user. This charge represents the difference between the price to the customer and the price to the local distribution company (or intrastate carrier) at the city gate. Where end-use service is distinguished by service type (firm or interruptible), the distributor tariff submodule provides separate firm and interruptible distribution markups. 


\section{Coal Market Module}

The coal market module (CMM) represents the mining, transportation, and pricing of coal, subject to enduse demand. Coal supplies are differentiated by physical characteristics such as heat, sulfur, and ash content. The CMM also determines U.S. coal exports as a part of the worldwide market for coal trade. Coal supply is projected on a cost-minimizing basis, constrained by existing contracts and the propensity to renew existing contracts. The expansion of existing coal mining capacity is related to the expected domestic and international demand for coal. Twenty-eight different coal types are differentiated with respect to thermal grade, sulfur content, and underground or surface mining. The domestic production and distribution of coal is forecast in terms of 16 supply regions and 23 demand regions (Figures 10 and 11).

The solutions for the components of the CMM are found simultaneously. The sequence of solution among components can be summarized as follows. Coal supply curves are produced by the coal production submodule and input to the coal distribution submodule. Feedback from the coal distribution submodule and other NEMS modules is necessary to project annual mine capacity levels. Given the coal supply curves and distribution costs, the coal distribution submodule projects delivered coal prices. The module is iterated to convergence with respect to material balance conditions. Important inputs and outputs are shown below, and the structure of the CMM is shown in Figure 12.

\section{Coal Production Submodule}

This submodule produces annual coal supply curves, relating annual production to marginal costs. The supply curves are constructed from a regression analysis of coal production, prices, and costs. A separate supply curve is provided for each mine type (surface or underground), coal type, and supply region. The supply curves are used as inputs to the other submodules.

The factors accounted for in constructing the supply curves are reserve depletion, capacity utilization, leadtime constraints on the opening of new mines, labor productivity, and real labor and fuel costs. A different set of supply curves is provided for each year in the forecast period.

\section{Coal Distribution Submodule}

This submodule determines the least-cost supplies of coal for a given set of coal demands by demand sector and region. The solution is found by comparing delivered prices (the sum of minemouth and freight charges) from alternative coal sources. The solution algorithm assumes that coal consumers minimize delivered costs. Since factors other than costs influence consumers' purchasing decisions-for example, reliability of supply, and coal characteristics, such as ash and moisture, which are not accounted for-existing coal supply contracts are factored into the solution process to constrain the solution.

Coal transportation costs are simulated using interregional coal transport costs derived by subtracting reported minemouth costs from reported delivered costs. Shipping costs are adjusted through the forecast period by mode-specific trends in factor input costs, such as labor productivity and fuel cost charges.

\section{Coal Export Submodule}

The coal export submodule determines the quantities of coal imported and exported from the United States. The quantities are determined within a world trade context, based on user-provided characteristics of foreign coal supply and demand. The submodule disaggregates coal into 16 coal export regions and 20 import regions, as shown on the following page.

\begin{tabular}{|l|l|l|}
\hline \multicolumn{1}{|c|}{ Important CMM Outputs } & \multicolumn{1}{|c|}{ Important Inputs from NEMS } & Important Exogenous Inputs \\
\hline Coal production and distribution & Coal demand by sector & Base year production \\
Minemouth coal prices & Refined product prices & Contract quantities \\
End-use coal prices & Interest rates & Labor productivity \\
Coal exports & Price deflators & Labor costs \\
Transportation rates & Projected coal-fired generating capacity & Transportation costs \\
Coal quality by source and destination & Labor cost escalators \\
& Ciesel fuel prices & Coal production capacity \\
\hline
\end{tabular}


COAL MARKET MODULE

\begin{tabular}{|ll|ll|}
\hline \multicolumn{2}{|c|}{ Coal Export Reglons } & & \multicolumn{2}{c|}{ Coal Import Regions } \\
\hline U.S. East Coast & South Africa & U.S. East Coast & Iberia \\
U.S. Guf Coast & Poland & U.S. Gulf Coast & Italy \\
U.S. Southwest and West & CIS (Europe) & U.S. Northern interior & Mediterranean and Eastern Europe \\
U.S. Northern Interior & CIS (Asia) & U.S. Noncontiguous & Mexico \\
U.S. Noncontiguous & China & Eastern Canada & South America \\
Australia & Colombia & Interior Canada & Japan \\
Canada, Western & Indonesia & Scandinavia & East Asia \\
Canada, Interior & Venezuela & United Kingdom and Ireland & Hong Kong \\
& & Germany & ASEAN (Association of South East Asia Nations) \\
& & Other Nurthwestern Europe & India and South Asia \\
\hline
\end{tabular}

Figure 10. Coal Market Module Demand Regions

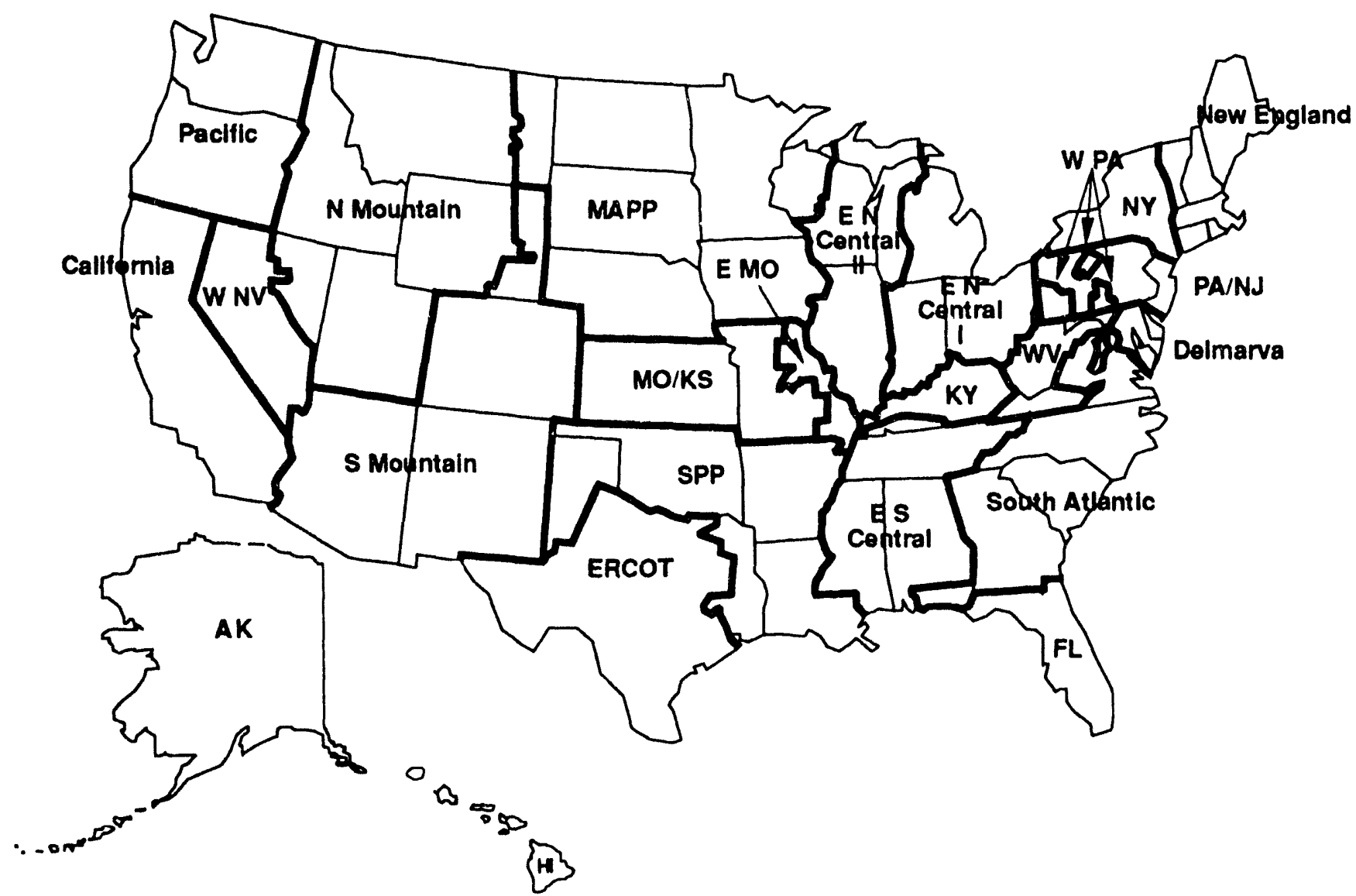

Source: Energy Information Administration, Office of Integrated Analysis and Forecasting. 
Figure 11. Coal Market Modulo Supply Reglons

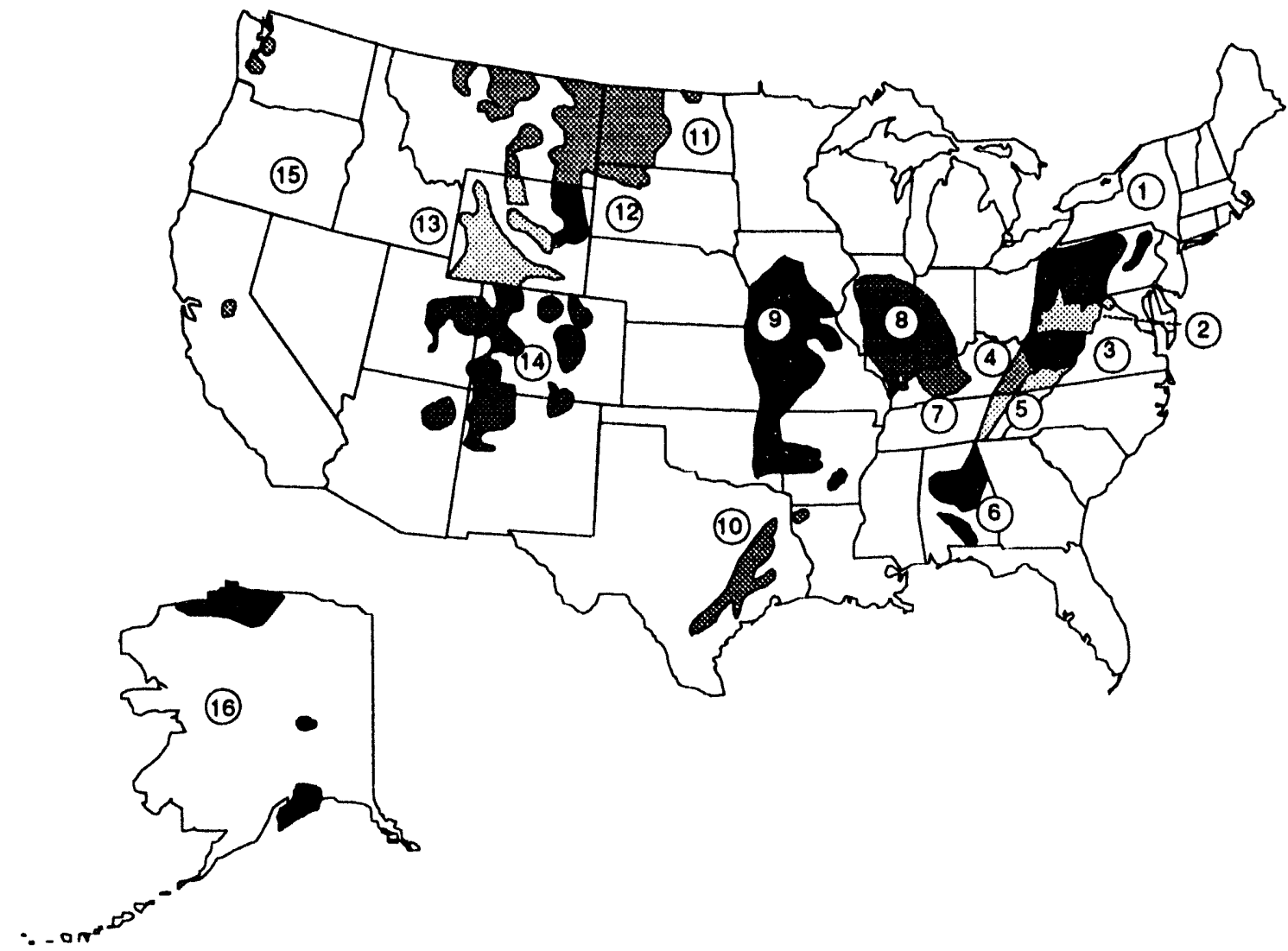

Region

Dofinition

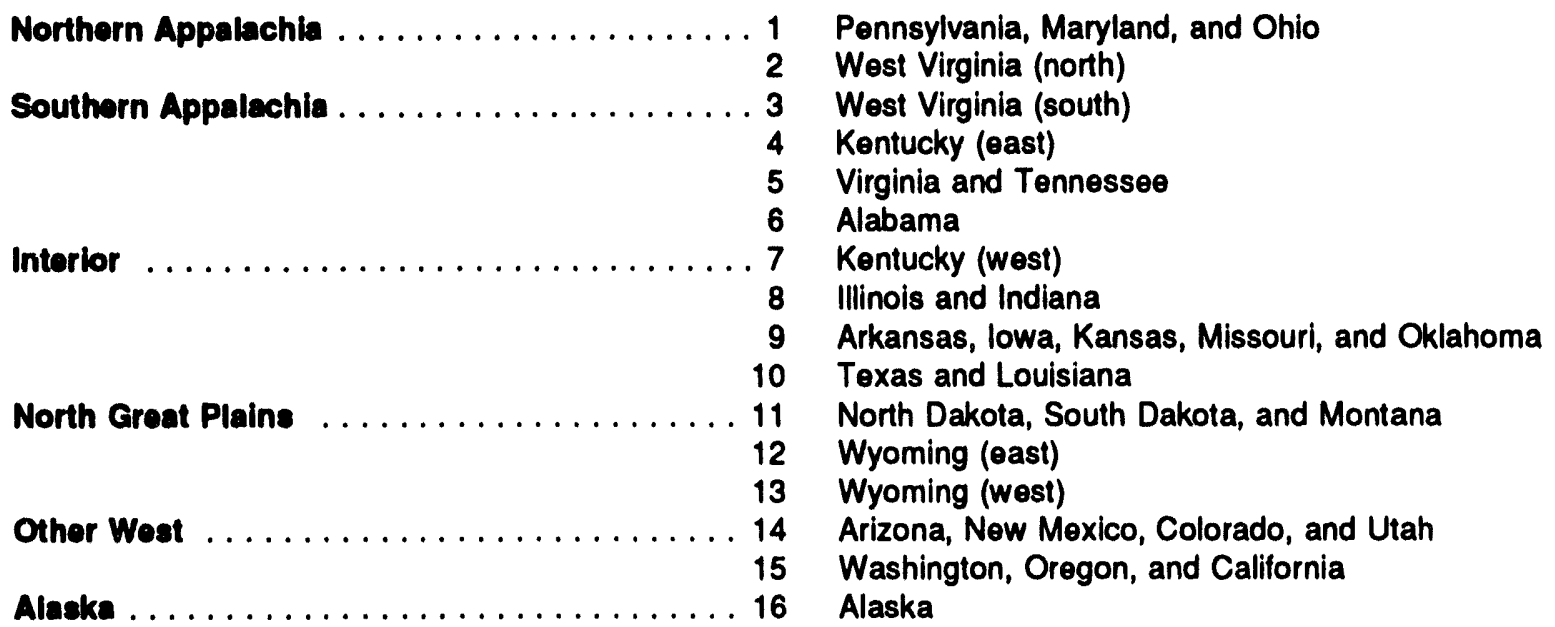

Source: Energy Information Administration, Office of Integrated Analysis and Forecasting. 


\section{Figure 12. Coal Market Module Structure}

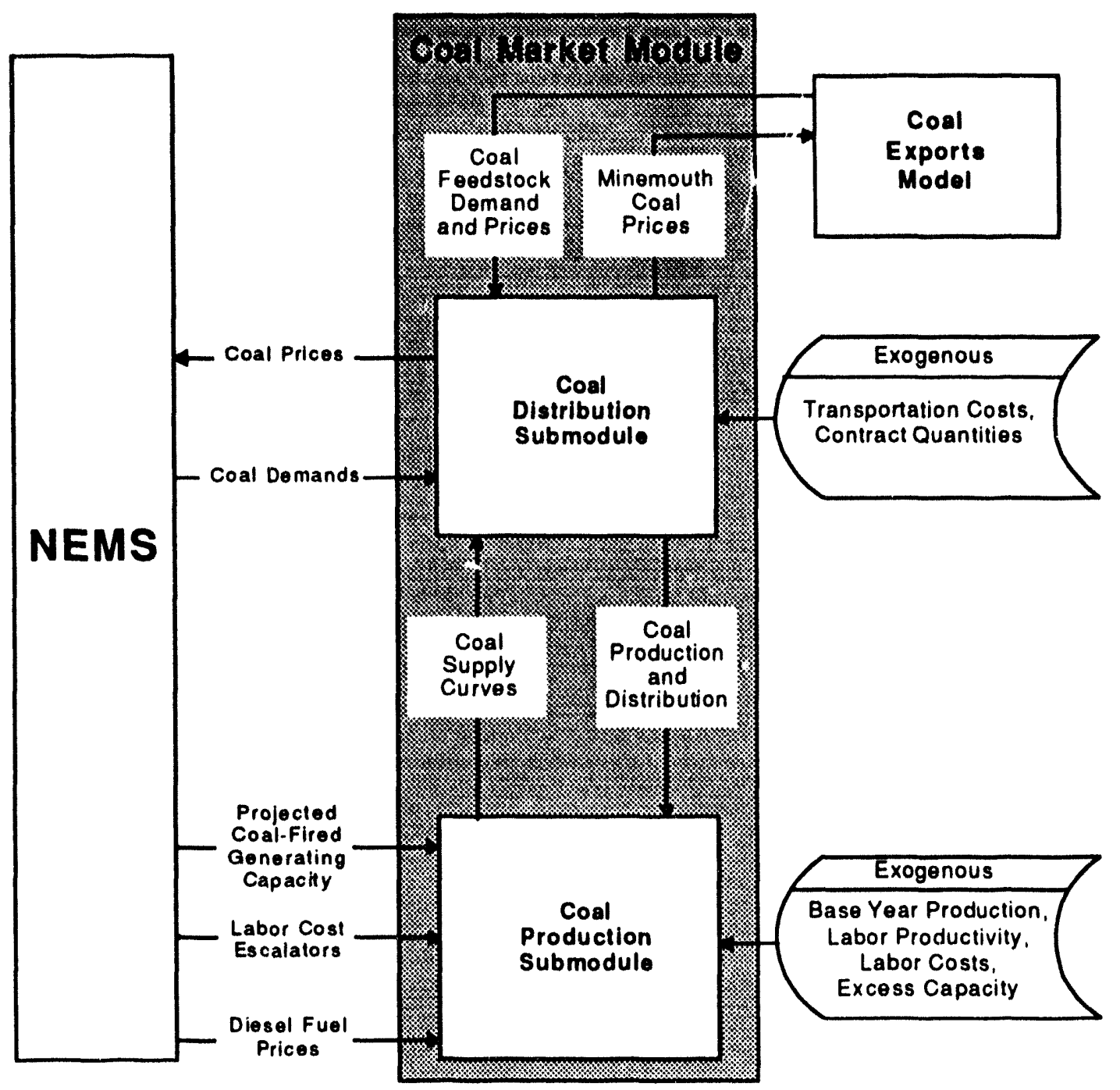

The export submodule is a small linear program that determines world coal trade distribution by minimizing overall costs for coal, subject to U.S. coal supply prices and a number of constraints. Supply costs (mining and preparation plus transportation) for each coal export region, coal type, and end use compete in two demand sectors (coking and steam). It also takes into account limits on sulfur dioxide emissions and concerns about diversity of coal sources. The sub- module is executed outside NEMS, and coal export demand is passed to the NEMS coal distribution submodule.

\section{Emissions Submodule}

Emissions reporting for coal that relates to coal consumption is provided by the end-use demand modules and the electricity market module. 


\section{RENEWABLE FUELS MODULE}

\section{Renewable Fuels Module}

The renewable fuels module (RFM) consists of several submodules that represent the various types of renewable energy (Figure 13). Since most renewables (wind, solar, and geothermal) are used to generate electricity, the interaction with the electricity market module and its various submodules is important for modeling gridconnected renewable-electric applications. On the other hand, many renewables are especially well suited for dispersed applications or generation at the point of end use. In the current version of the RFM, only grid-connected applications are modeled endogenously; date on dispersed applications are input exogenously. Biomass can also be used to produce liquid fuels such as ethyl alcohol (ethanol). Therefore, a primary NEMS interaction is with the petroleum market module, which determines refinery demand for ethanol as a gasoline blending component.

Each submodule of the RFM is solved independently of the rest. Interactions among the submodules occur indirectly throujgh each submodule's interaction with other NEMS midules. Important inputs and outputs are shown below.

\section{Hydroelectric Submodule}

The hydroelectric submodule provides currently available and planned regional hydropower capacity and capacity factors for conventional hydroelectric facilities. This plant information is supplied by aggregating the responses of utility and nonutility power producers to annual EIA power plant surveys (Forms EIA-860, "Annual Electric Generator Report," EIA-759, "Monthly Power Plant Report," and EIA-867, "Annual Nonutility Power Producer Report"). The emphasis of the submodule is on planned hydroelectric capacity additions and reductions. Unplanned capacity changes can be handled by making offline capacity adjustments based on assumptions for hydropower relicensing, water availability, land use and environmental regulations, and electricity demand growth. Since hydropower operating and maintenance costs are assumed to be the lowest of any major generating technology and hydropower produces virtually no air pollution, all available hydroelectric capacity is used first by the EMM.

\section{Wind-Electric Submodule}

The wind-electric submodule projects the availability of wind resources as well as the cost and performance of wind turbine generators. This information is passed to the EMM so that wind turbines can be built and dispatched in competition with other electricity generating technologies. The wind turbine data are expressed in the form of energy supply curves, which provide the maximum amount of turbine generating capacity that could be installed, given the available land area, wind speed, and capacity factor.

\section{Geothermal-Electric Submodule}

The geothermal-electric submodule provides the EMM with forecasts of new geothermal capacity that can be built, along with related cost and performance data. The data are expressed in the form of a supply curve, which consists of the aggregate amount of new capacity and associated costs that can be offered from each geothermal site. The principal factor determining how much can be offered is the amount of previously installed capacity relative to the total potential capacity for the site, based on the historical experience of geothermal development at existing sites.

Geothermal resource data are based on Sandia Laboratory's 1991 geothermal resource assessment. Only hydrothermal (hot water and steam) resources are considered initially. Hot dry rock resources are not included, because they require additional data preparation and technology definition. The penetration of geothermal generation is determined by the EMM.

Capital and operating costs are estimated separately, and life-cycle costs are calculated according to standardized NEMS assumptions. The costing methodology includes ways to analyze effects of Federal and State energy tax construction and production incentives (if any). Individual reservoirs and their sizes and

\begin{tabular}{|c|c|c|}
\hline Important RFM Outputs & Important Inputs from NEMS & Important Exogenous Inputs \\
\hline $\begin{array}{l}\text { Energy production capacities } \\
\text { Capital costs } \\
\text { Operating cosis (including wood supply } \\
\text { prices for the wood submodule) } \\
\text { Ethanol supply curves } \\
\text { Capacity factors for solar-thermal, } \\
\text { solar-photovoltaic, and wind }\end{array}$ & $\begin{array}{l}\text { Installed energy production capacity } \\
\text { Gross domestic product } \\
\text { Interest rates }\end{array}$ & $\begin{array}{l}\text { Site-specific geothermal resource quality data } \\
\text { Agricultural feedstock data } \\
\text { (biofuels submodule) } \\
\text { Site-specific wind resource quality data } \\
\text { Plant utilization (capacity factor) } \\
\text { Technology cost and performance parameters }\end{array}$ \\
\hline
\end{tabular}


Figure 13. Renewable Fuels Module Structure

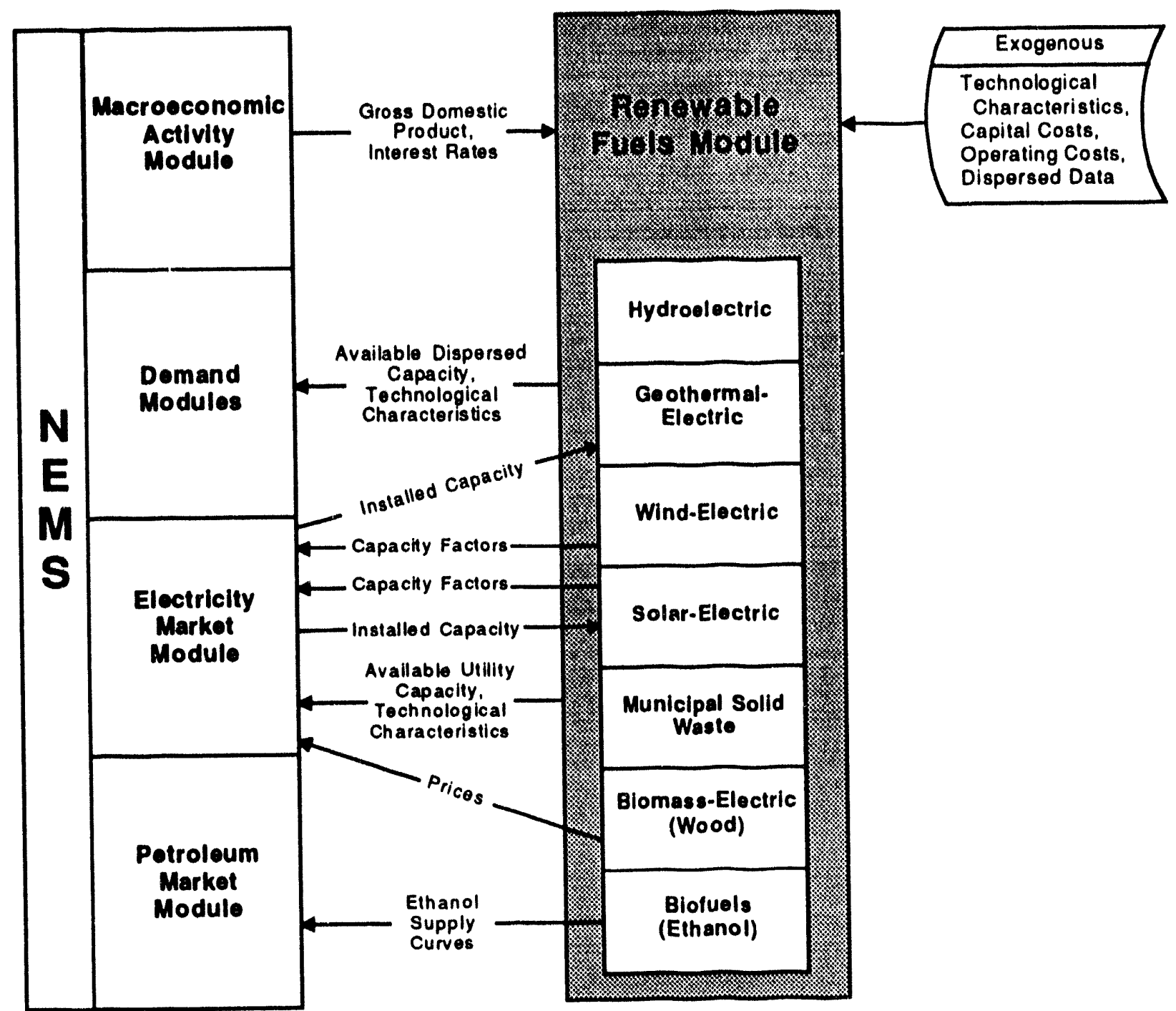

locations are mapped and matched to the NEMS electricity supply regions (see Figure 15 on page 33). The submodule also includes a procedure for estimating the cost of transmitting power from the well site to the grid.

\section{Solar-Electric Submodule}

The solar-electric submodule models both solar-photovoltaic and thermal-electric installations. Only gridconnected applications constructed by a utility or independent power producer are considered as generators. Grid-connected solar facilities can be utility or nonutility, a distinction that is internal to the EMM.
The required input information is similar for each type.

Capacity projections are developed as endogenous inputs to be competed against other generating technologies on the basis of capital costs, capacity factors, and fixed and variable operation and maintenance costs. Solar energy is a form of renewable energy that requires a more detailed characterization to represent its intermittent nature and regionality. This is dealt with by the regional load shapes used by the EMM and different time slices to represent intermittency. Little, if any, solar capacity is being built currently because of its high cost. 


\section{Biofuels (Ethanol) Submodule}

This submodule employs supply functions (cost vs. quantity) by PADD (see Figure 17 on page 36) for ethanol produced from corn. Agricultural feedstock production quantities and costs are provided exogenously from a U.S. Department of Agriculture linear programming model, the Agricultural Resources Interregional Modeling System. The supply curves take into account feedstock costs, feedstock conversion costs, and energy prices. The supply functions are used by the petroleum market module to compute regional demands for ethanol.

\section{Biomass-Electric (Wood) Submodule}

The wood submodule provides forecasted wood fuel prices and technology characterization information (capital costs, operating costs, capacity factors, etc.) for the EMM, thereby allowing wood-fired power plants to compete with other electric generating technologies. Wood fuel prices are represented by a supply curve constructed according to the accessibility of wood resources to the electricity generation sector. The supply curve employs wood resource inventory and cost data from the U.S. Forest Service, as well as wood distribution and preparation cost data. The supply schedule wood prices are combined with other variable operating costs associated with burning wood. The aggregate variable cost is then passed to the EMM.

Dispersed consumption of wood energy is modeled in the industrial, commercial, and residential demand modules.

\section{Municipal Solid Waste Submodule}

The municipal solid waste (MSW) submodule provides annual projections of energy produced from the incineration of MSW. It uses the quantity of MSW produced (derived from an econometric equation that uses gross domestic product as the principal forecast driver), the heating value of a pound of MSW, and shares of MSW combusted for energy recovery. The energy production forecasts are disaggregated by consuming sector (commercial, industrial, and utility). In addition, the submodule supplies the EMM with capital and operating cost information, which is used only for calculations of electricity prices. (MSW energy production does not compete with other electric generating technologies, because MSW is viewed as a byproduct of a community's waste disposal activities rather than a competitive alternative to other fuels.) 


\section{Electricity Market Module}

The electricity market module (EMM) represents the generation, transmission, and pricing of electricity, subject to delivered prices for coal, petroleum products, natural gas, and synthetic fuels; the cost of centralized generation from renewable fuels; macroeconomic variables for costs of capital and domestic investment; and electricity load shapes and demand. The submodules consist of capacity planning, fuel dispatching, finance and pricing, and load and demand-side management, in conjunction with the demand modules (Figure 14). In addition, nonutility supply and electricity trade are represented in the fuel dispatching and capacity planning submodules. Nonutility generation from cogenerators and other facilities whose primary business is not electricity generation are represented in the demand and fuel supply modules. All other nonutility generation is represented in the EMM. The supply of electricity is accounted for in 13 supply regions (Figure 15), allocated for consumption to the 9 Census divisions.

Electric power generation is provided by the costminimizing mix of facilities and fuels, subject to environmental constraints. Construction of generating plants with long leadtimes is selected with planning horizons up to six periods into the future; the planning horizon can change with respect to the generating technology being considered. Electricity demand is expressed by load curves, which vary by region and season and by the penetration of demand-side management programs.

The solution to the submodules of the EMM is simultaneous in that, directly or indirectly, the solution for each submodule depends on the solution to every other submodule. Important inputs and outputs are shown below. A solution sequence through the submodules can be viewed as follows:

- The load and demand-side management submodule processes electricity demand, demand-side manage- ment programs, and other avoided costs of utilities to construct load curves.

- The electricity capacity planning submodule projects the construction of new utility and nonutility plants, the penetration of demand-side management programs, the level of firm power trades, and the addition of scrubbers for environmental compliance.

- The electricity fuel dispatch submodule dispatches the available generating units, both utility and nonutility, allowing surplus capacity in select regions to be dispatched for another region's needs (economy trade).

- The electricity finance and pricing submodule calculates total revenue requirements for each utility operation and computes average electricity prices.

\section{Electricity Capacity Planning Submodule}

The electricity capacity planning (ECP) submodule determines how best to meet expected growth in electricity demand, given available resources, expected load curves, expected demands and fuel prices, environmental constraints, and costs for utility and nonutility technologies. When it is decided that building new capacity is the best alternative for meeting some future increase in demand, then the timing of the demand increase, the expected utilization of the new capacity, and the construction and operating costs of various technologies primarily determine what technology is chosen. The ownership of the facility (utility or nonutility) influences the decision, because the capital costs differ according to the ownership-and corresponding capital structureof the facility.

The expected utilization of the capacity is important in the decisionmaking process. If the capacity is expected to operate continuously (to serve base load), then a technology with relatively low operating costs (primarily fuel costs) is appropriate. Peak load, which

\begin{tabular}{|l|l|l|}
\hline \multicolumn{1}{|c|}{ Important EMM Outputs } & \multicolumn{1}{|c|}{ Important Inputs from NEMS } & Important Exogenous Inputs \\
\hline Electricity prices and price components & Electricity sales & General financial data \\
Fuel demands & Fuel costs & Tax assumptions \\
Capital requirements & Cogeneration supply & Capital costs \\
Emissions & Renewable technology characteristics & Operation and maintenance costs \\
Demand-side management options & and capacity & Operating parameters \\
& Renewable capacity factors & Emissions rates \\
& Gross domestic product & New technologies \\
& Interest rates & Existing facilities \\
& & Transmission constraints \\
\hline
\end{tabular}


Floure 14. Electrletty Market Module Siructure

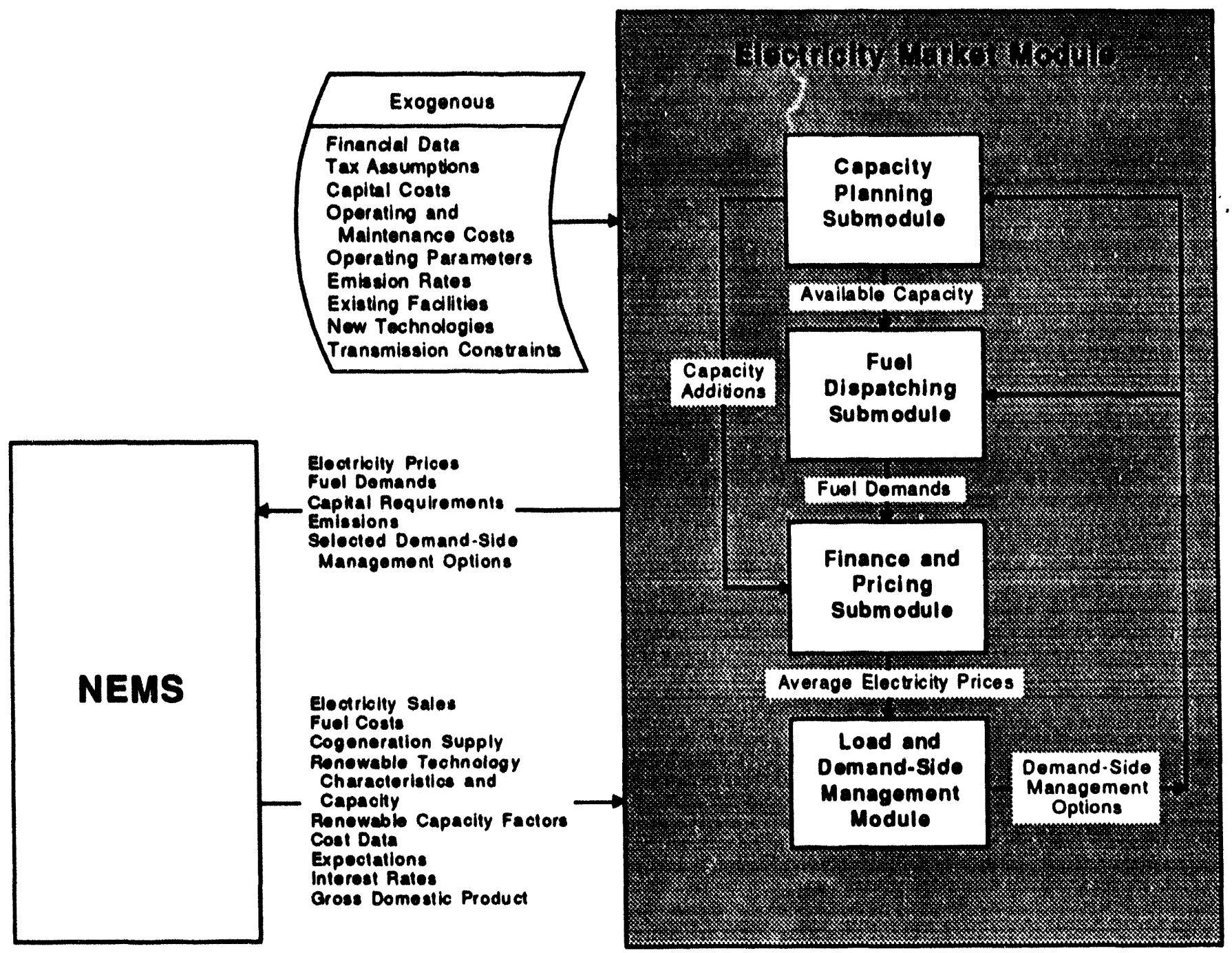

occurs infrequently (only when demand on the system is highest), is best served by a plant that is relatively inexpensive to construct. Intermediate or cycling load occupies a middle ground between base and peak load and is best served by plants that are cheaper to build than baseload plants and cheaper to operate than peak load plants.

The timing of the demand increase is important, because the construction times of technologies differ. The future years examined by the submodule depend on the technologies under consideration. As new technologies are added, the planning horizon may change. The ECP submodule looks up to six periods into the future when identifying new capacity needs. A multi-period optimization is performed, whereby capacity choices in each year are made by looking at several years in the future rather than a single year.

In the future, this submodule, after performing its levelized cost analysis, will use a market penetration algorithm to share capacity additions among existing and new technologies of similar types. The purpose of the algorithm will be to address uncertainty about the costs and performance of existing and new generating technologies. In the ECP submodule, cost and performance characteristics are represented as single point estimates; in reality, they are better represented as distributions. Also in the future, economic decisions about whether to retire, repower, or extend the life of capacity, and whether to contract for firm power imports from Canada and neighboring electricity 
Figure 15. Electriclty Market Module Supply Reglons

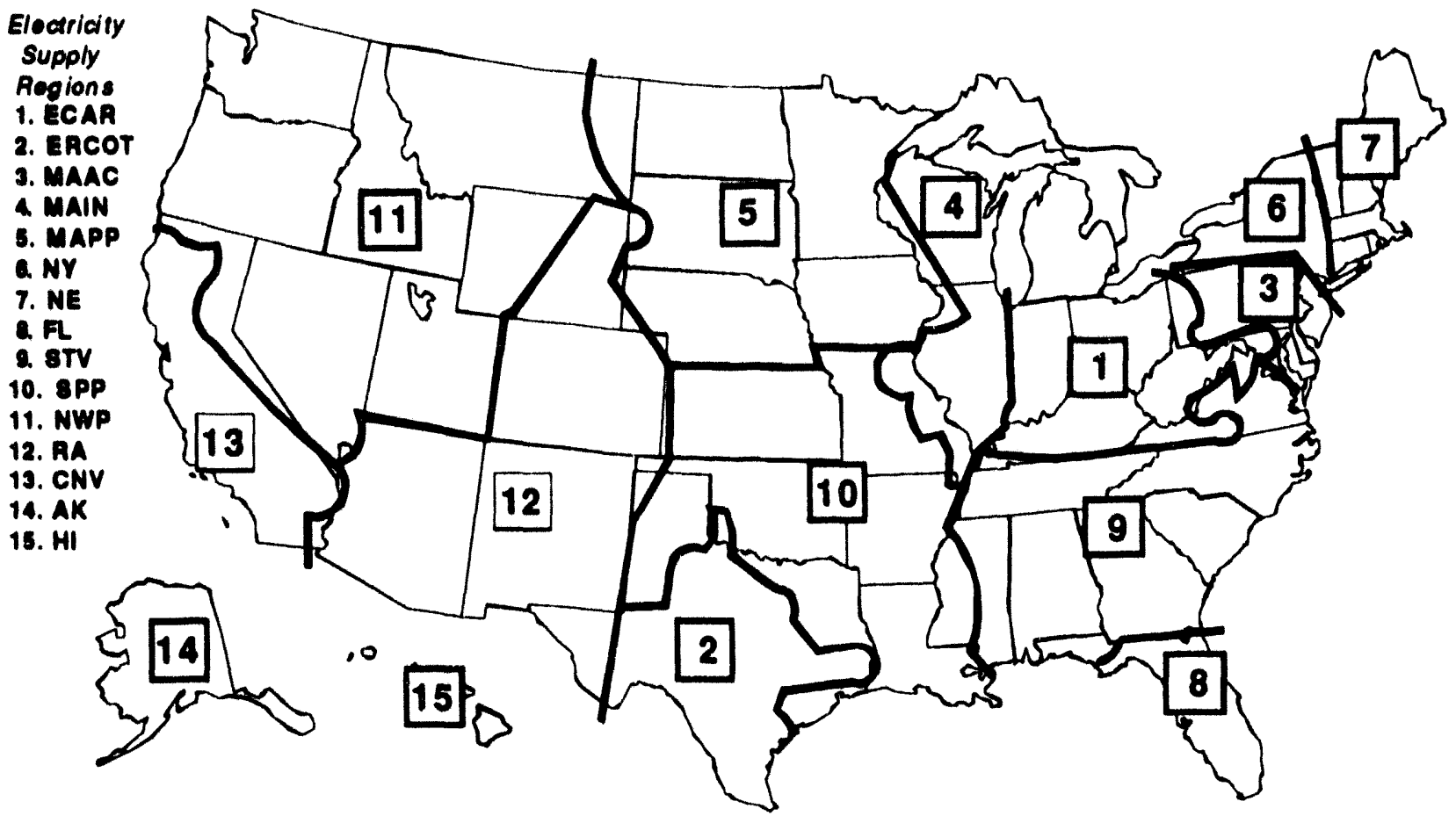

supply regions, will be represented in the ECP submodule.

After building new capacity, the submodule passes total available capacity to the electricity fuel dispatch submodule and new capacity expenses to the electricity finance and pricing submodule. The following technologies are considered:

\begin{tabular}{|c|}
\hline Fossll Firod \\
\hline 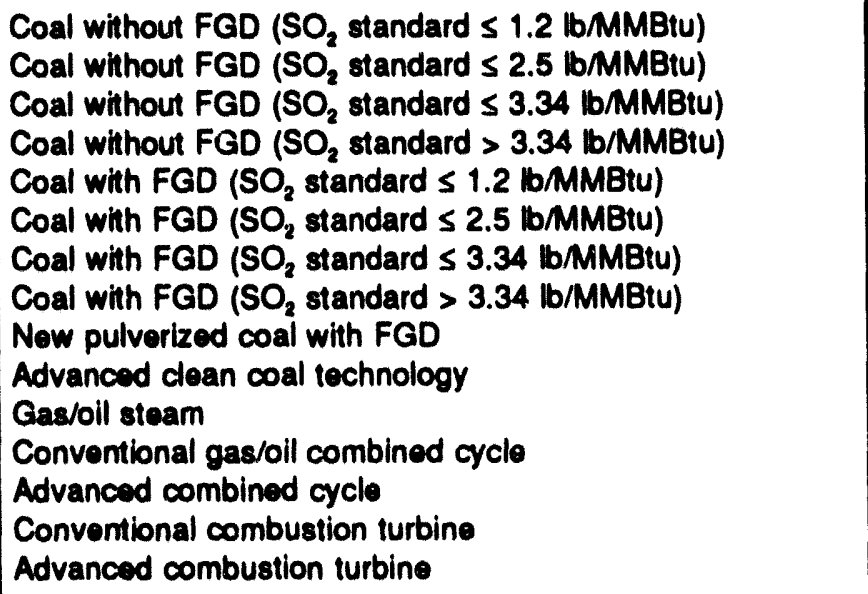 \\
\hline
\end{tabular}

\begin{tabular}{|l|}
\hline \multicolumn{1}{|c|}{ Nuclear } \\
\hline $\begin{array}{l}\text { Conventional nuclear } \\
\text { Advanced nuclear }\end{array}$ \\
\hline \multicolumn{1}{|c|}{ Renewables } \\
\hline Conventional hydropower \\
Pumped storage hydropower \\
Geothermal \\
Solar-thermal \\
Solar-photovoltaic \\
Wind \\
Wood \\
Municipal solid waste
\end{tabular}

\section{Electricity Fuel Dispatch Submodule}

Given available capacity, firm purchased-power agreements, fuel prices, and load curves, the electricity fuel dispatch (EFD) submodule solves for generation facility utilization and economy power exchanges to satisfy a demand that varies by time and region. The submodule uses merit order dispatching: that is, utility, independent power producer, and small power producer plants are dispatched until demand is met, 
in a sequence based on their operating costs, with least-cost plants being operated first. ${ }^{2}$ Limits on emissions of sulfur dioxide from generating units and the engineering characteristics of units serve as constraints. During off-peak periods, the submodule institutes load following, which is the practice of running plants near their minimum operating levels rather than shutting them down and incurring shutoff and startup costs. In addition, to account for scheduled and unscheduled maintenance, the capacity of each plant is derated (lowered) to the expected availability level. Finally, the operation of utility and nonutility plants for each region is simulated over six seasons to reflect the seasonal variation in electricity demand.

Interregional economy trade is also represented in the EFD submodule by redetermining the dispatch decision and allowing surplus energy in one region to displace energy in an importing region, resulting in a cost savings. International economy trade is determined exogenously and incorporated into the subinodule by decrementing demand by the estimated level of international trade. After dispatching, fuel use is reported back to the fuel supply modules, operating expenses and revenues from trade are reported to the electricity finance and pricing submodule, and emissions are reported to the integrating module.

\section{Electricity Finance and Pricing Submodule}

The costs of building capacity, instituting demand-side management programs, buying power, and generating electricity are tallied in the electricity finance and pricing (EFP) submodule, which simulates the cost-ofservice method often used by State regulators to determine the price of electricity. Using historical costs for existing plants (derived from various sources such as FERC Form 1, "Annual Report of Major Electric Utilities, Licensees and Others," and Form EIA-412, "Annual Report of Public Electric Utilities"), cost estimates for new plants, fuel prices from the NEMS fuel supply modules, unit operating levels, DSM program costs, plant decommissioning costs, plant phase-in costs, and purchased power costs, the EFP submodule calculates total revenue requirements for each area of utility operation-generation, transmission, and distribution. Revenue requirements shared over sales by customer class yield the price of electricity for each class. Electricity prices are returned to the demand modules. In addition, the submodule generates detailed financial statements.

\section{Load and Demand.Side Management Submodule}

The load and demand-side management (LDSM) submodule generates curves representing the demand for electricity and develops data on the impacts of specific demand-side management programs. The demand for electricity varies over the course of a day because it is a flexible energy source that can be used to power many different technologies, each requiring a different level of capacity for different lengths of time. For operational and planning analysis, it is useful to construct an annual load duration curve, which represents the aggregated hourly demands. Because demand varies by region and over the course of a year, the LDSM submodule generates load curves for each region and season.

The LDSM submodule evaluates utility-sponsored demand-side management programs, which attempt to alter the load curves by reducing or shifting demand. The submodule determines which programs are competitive and then passes the decermination to the ECP submodule for competition against supply options. (The demand modules of NEMS also model some price-induced conservation programs by accounting for the penetration of more efficient end-use technologies in each sector.) If the ECP submodule selects demandside management programs to meet the demand for electricity, the programs that penetrate are passed back to the demand modules so that their impacts are reflected in the future demands for electricity.

\section{Emissions}

The EMM tracks emission levels for sulfur dioxide $\left(\mathrm{SO}_{2}\right)$, nitrogen oxides $\left(\mathrm{NO}_{\mathrm{x}}\right)$, carbon dioxide $\left(\mathrm{CO}_{2}\right)$, carbon $(\mathrm{C})$, carbon monoxide (CO), and volatile organic compounds (VOCs). Facility development, retrofitting, and dispatch are constrained to comply with the pollution constraints of the Clean Air Act Amendments of 1990 (CAAA90) and other pollution constraints. An innovative feature of this legislation is a system of trading emissions allowances. The trading system allows a utility with a relatively low cost of compliance to sell its excess compliance (i.e., the degree to which its emissions per unit of power generated are below maximum allowable levels) to utilities with a relatively high cost of compliance. The trading of emissions allowances does not change the national aggregate emissions level set by CAAA90, but it does tend to minimize the overall cost of compliance.

\footnotetext{
${ }^{2}$ Hydroelectric plants and other intermittent, renewable-based tech nologies are exceptions to merit order dispatch. Because energy from hydroelectric plants is limited by water flow and their operating costs are small relative to other plant types, they are assigned a portion of the load duration curve exactly matching the energy available, with the remaining plants dispatched (by merit order) to the surrounding area of the curve.
} 


\section{Petroleum Market Module}

The petroleum market module (PMM) is a linear programming representation of refining, established with regional detail. The PMM represents the pricing of petroleum products, crude oil and product import activity (in conjunction with the international energy module), and domestic refinery operations, subject to the demand for petroleum products, the prices for raw material inputs and imported petroleum products, the costs of investment, and the domestic production of crude oil and natural gas liquids. The PMM structure is shown in Figure 16.

Models of refining, even at the regional level, can embody considerable detail. Such detail is necessary to determine the impacts upon refinery operations and the marginal costs of refined products of changes in, for example, the slate of products demanded, crude oil or feedstock quality and prices, refinery processing unit capacity or technology, and the specification of the composition of petroleum products (such as reformulated gasoline to comply with the Clean Air Act Amendments of 1990). The incorporation of detail in the NEMS representation of refining conflicts with the system's requirements for speed and economy of core memory. Tradeoffs among level of detail, size, and speed of execution occur in the design of every NEMS module. In the case of the PMM, the maximum detail for refinery representation consistent with integration with the rest of NEMS was not judged to be sufficient for some types of policy analysis. As a result, a separate, standalone, detailed refinery model was developed. This standalone detailed refinery model contains sufficient detail to assess such issues as the product specification problems associated with pollution control requirements.

Operating from the same database as the detailed refinery model, the PMM aggregates input data to a somewhat coarser level of detail, analyzing only five domestic and five imported types of crude oil (that is, fewer products and processes are modeled in the PMM than in the detailed refinery model). Refining operations are represented by linear programming formulations for each of five Petroleum Administration for Defense Districts (PADDs) (Figure 17). The level of detail varies by PADD. The most detailed representation is for PADD III (Texas and nearby States), where more than 30 distinct refinery processes are modeled. The PMM is best represented as an optimized choice of refinery operations and product distribution, rather than flows of information among distinct components.

The PMM chooses a mix of refinery operations that minimizes the costs of meeting demand. Crude oil and petroleum product import quantities are chosen as part of the process of minimizing costs. Important PMM inputs and outputs are shown below.

An important innovation in the NEMS involves the relationship between the domestic and international markets. Whereas earlier models postulated entirely exogenous prices for oil on the international market (the world oil price), NEMS includes an international energy module that solves for supply curves for imported crude oils and products based on, among other factors, U.S. participation in international trade.

\section{Regions}

The PMM models U.S. crude oil refining capabilities based on the five PADDs (Figure 17). These regions were established during World War II and are still used by EIA for data collection and analysis. The use of PADD data permits the PMM to take full advantage of EIA's historical database and allows analysis and forecasting within the same framework used by the petroleum industry.

\begin{tabular}{|l|l|l|}
\hline \multicolumn{1}{|c|}{ Important PMM Outputs } & \multicolumn{1}{|c|}{ Important Inputs from NEMS } & \multicolumn{1}{|c|}{ Important Exogenous Inputs } \\
\hline Petroleum product prices & Petroleum product demand by sector & Processing unit operating parameters \\
Crude oil imports and exports & Domestic crude oil supply functions & Processing unit capacities \\
Crude oil production & World oil price & Product specifications \\
Petroleum product imports and exports & International crude oil supply curves & Operating costs \\
Refinery fuel use & International product supply curves & Capital costs \\
Emissions & International oxygenates supply curves & Transmission and distribution costs \\
Cogeneration & Ethanol supply curves & Federal and State taxes \\
Natural gas plant liquids production & Natural gas prices & \\
Processing gain & Electricity prices & \\
Capacity additions & Natural gas production & \\
Capital expenditures & Interest rates & \\
Revenues & Deflators & \\
\hline
\end{tabular}


Figure 16. Petroleum Market Module Structure

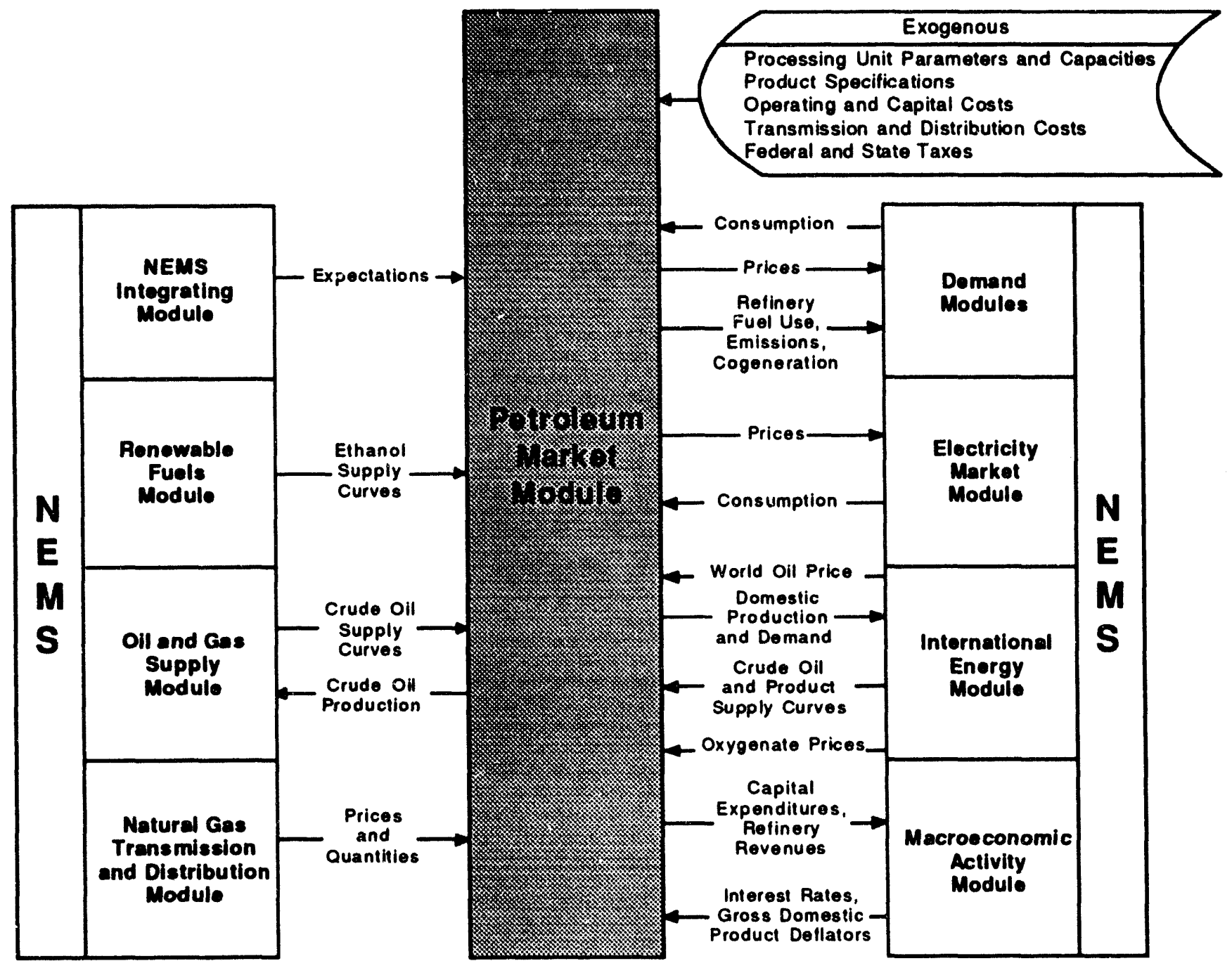

Figure 17. Petroleum Administration for Defense Districts

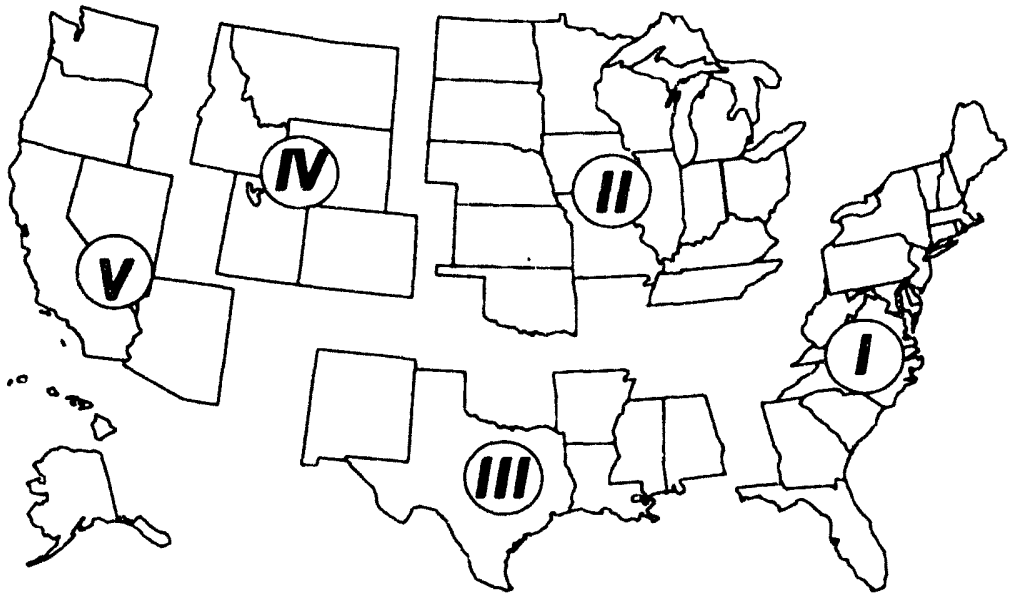




\section{Product Categories}

Product categories, specifications, and recipe blends modeled in PMM include:

Motor gasoline: unleaded, reformulated $(2.0 \%)$, oxygenated $(2.7 \%)$, California oxygenated $(2.0 \%)$, California reformulated.

Jot thels: kerosene-based.

Distlilates: kerosene, heating oil, highway diesel.

Rosidual fuals: low-sulfur, high-sulfur.

Liquofied potroleum gas: propane, LPG mixes.

Potrochemical feodstocks: potrochemical naphtha, petrochemical gas cil.

Others: asphatt and road oil, process gas, petroleum coke.

\section{Fuel Ust}

PMM determines refinery fuel use by PADD for purchased electricity, natural gas, distillate fuel, residual fuel, liquefied petroleum gas, and other petroleum. The fuels (natural gas, petroleum, and other) consumed within the refinery to generate electricity from cogeneration facilities are also measured.

\section{Crude Oil Categories}

Both domestic and imported crude oil are aggregated into five categories, as defined by the following ranges of gravity and sulfur:

\begin{tabular}{|l|c|c|}
\hline \multicolumn{1}{|c|}{ Category } & Sulfur & Gravity \\
\hline Low-sulfur light & $0-0.5 \%$ & $>24$ \\
Medium-sulfur heavy & $0.35-1.1 \%$ & $>24$ \\
High-sulfur light & $>1.1 \%$ & $>32$ \\
High-sulfur heawy & $>1.1 \%$ & $24-33$ \\
High-sulfur very heavy & $>0.7 \%$ & $<23$ \\
\hline
\end{tabular}

This aggregation of crude oil types allows the PMM to account for changes in crude oil composition over time. A "composite" crude with the appropriate yields and qualities is developed for each category by averaging characteristics of specific crude oil streams that fall into each category. While the domestic and foreign categories are the same, the composites for each type may differ, because different crude oil streams make up the composites.

\section{Natural Gas Plants}

The outputs of natural gas processing plants-ethane, propane, butane, isobutane, and natural gasoline-are modeled in the PMM. These products move directly into the market to meet demand or are inputs to the refinery.

\section{Refinery Processes}

Not every refinery processing unit is represented in PMM. The refinery processes represented were chosen because they have the most significant impact on production. The following distinct processes are represented:

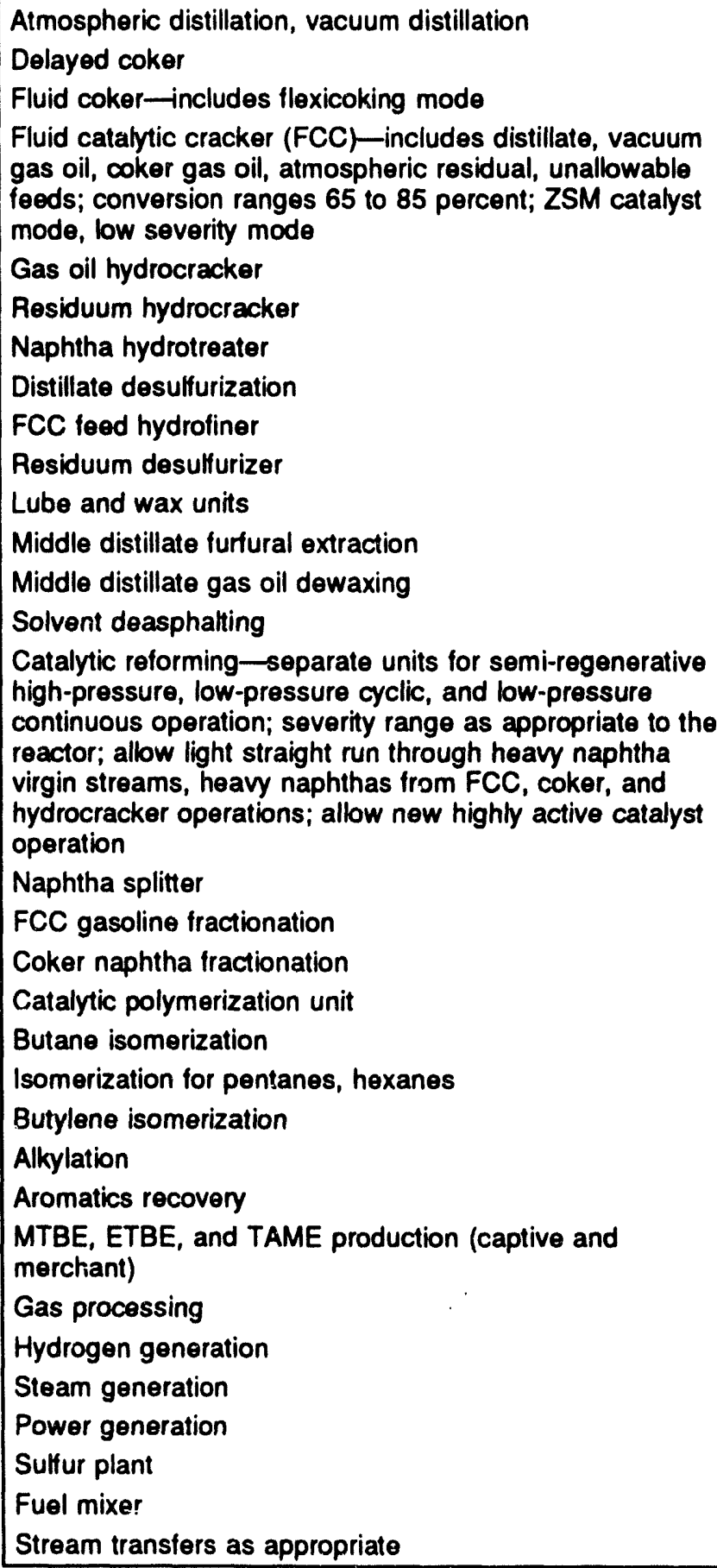




\section{End-Use Markups}

The linear programming portion of the model provides unit prices of product sold in the refinery regions (refinery gate) and in the demand regions (wholesale). End-use markups are added to produce a retail price for each of the Census divisions. The markups are based on an average of historical markups, defined as the difference between the end-use prices by sector and the corresponding wholesale price for that product. The average is calculated using data from the past 3 to 8 years. Because of the lack of any discernible trend in the historical end-use markups, the markups remain fixed over the forecast period.

\section{Gasoline Types}

The Clean Air Act Amendments of 1990 will result in the production of a number of new blends of gasoline.
In November 1992, a wintertime requirement for oxygenated gasoline, containing a minimum of 2.7 percent oxygen by weight, went into effect in the 39 worst carbon monoxide emitting areas. Starting in January 1995, gasoline sold year-round in the nine most severe ozone nonattainment areas must be "reformulated" according to U.S. Environmental Protection Agency specifications. A third type of gasoline, a higher oxygen reformulated blend, will be sold in areas where the oxygenated and reformulated requirements overlap. In addition, California gasoline standards, which are more severe than the Federal reformulated standards, will become effective for that State in March 1996. Gasoline production is modeled within NEMS to account for these requirements. Between the PMM and the detailed refinery model, additional product specifications can be accounted for as policy analysis scenarios. 


\section{Residential Demand Module}

The residential demand module (RDM) forecasts fuel consumption in the residential sector for the nine Census divisions, three housing types, and numerous end-use, fuel-specific equipment types. Energy consumption is forecast for seven categories of fuel.

The structure of the RDM and its interactions with the NEMS system are shown in Figure 18. Important inputs and outputs are shown below. NEMS provides forecasts of residential energy prices and housing starts, which are used by the RDM to develop forecasts of energy consumption for each of the seven fuels, as well as the emissions of a variety of pollutants generated by residential energy use.

The RDM develops fuel consumption forecasts by first adjusting the previous year's housing stocks, adding new construction (housing starts) and subtracting retirements from the stock. Equipment choices are then simulated for new construction as well as for the replacement of equipment that has reached the end of its useful service life. In addition to modeling the stocks of energy-consuming equipment, the RDM also models the integrity of housing shells. Shell efficiencies for existing housing improve in response to increases in real energy prices, and shells for new construction improve from year to year, based on current trends.

Next, the module's forecast of the characteristics of the residential housing and equipment stocks is used to forecast the intensity of use for the various types of equipment and the resulting energy consumption and emissions. Energy consumption for each end use is based on energy intensity estimates developed from EIA's 1990 Residential Energy Consumption Survey (RECS). These base energy intensities are modified for changes in equipment and shell efficiencies, prices, and weather. Once the modifications are made, total energy use is computed across end uses and housing types and then summed by fuel for each Census division. Emissions are calculated directly, using factors developed from engineering studies. The detail carried in the RDM incorporates the effects on fuel consumption of regional demographic trends, housing trends, the replacement of appliances with more efficient units (from both standards and technological change), fuel switching, and housing shell retrofits.

\section{Housing Stock Submodule}

The base housing stock is derived from the 1990 RECS for three dwelling types: single-family, multifamily, and mobile homes. Each element of the base stock is retired on the basis of a constant rate of decay, which varies by dwelling type. The surviving stocks are supplemented by housing starts, which are provided through the NEMS macroeconomic activity module. Any housing added after the base year is tracked and retired as a separate vintage.

\section{Appliance Stock Submodule}

The base appliance stock is based on the 1990 RECS. Additions to the base stock are tracked separately for existing stocks of residential housing and for new construction. As houses decay from the existing stock, the associated appliances are removed from the appliance stock as well. A retirement function is used to retire equipment in housing that survives from one year to the next. As appliances are removed from the stock, they are replaced by new appliances with higher efficiencies. Appliances added through new construction are handled similarly. Appliance stocks are maintained by fuel, end use, and technology as follows:

Space heating equipment: electric furnace, electric heat pump, gas furnace, gas other, kerosene furnace, liquefied petroleum gas, distillate furnace, distillate other, wood, geothermal heat pumps, gas heat pumps.

Space cooling equipment: electric room air conditioner, central air conditioner, electric heat pump, geothermal heat pump, gas heat pump.

Water heaters: solar, natural gas, electric, oil, liquefied petroleum gas.

Refrigerators: 18 cubic foot top-mounted freezer, 25 cubic foot side-by-side with through-the-door features.

Freezers: chest - manual defrost, upright - manual defrost.

Lighting: incandescent, compact fluorescent, mercury vapor.

Other appliances: gas, electric, liquefied petroleum gas, distillate.

Secondary heating: distillate, natural gas, liquefied petroleum gas, kerosene, electricity, coal, wood.

\begin{tabular}{|l|l|l|}
\hline \multicolumn{1}{|c|}{ Important RDM Outputs } & Important Inputs from NEMS & \multicolumn{1}{|c|}{ Important Exogenous Inputs } \\
\hline $\begin{array}{l}\text { Energy product demand } \\
\text { Emissions } \\
\text { Changes in housing and appliance stocks }\end{array}$ & $\begin{array}{l}\text { Energy product prices } \\
\text { Housing starts }\end{array}$ & $\begin{array}{l}\text { Current housing stocks, retirement rates } \\
\text { Current appliance stocks/ife expectancy } \\
\text { New appliance types, efficiencies, costs } \\
\text { Housing shell retrofit indices } \\
\text { Unit energy consumptions }\end{array}$ \\
\hline
\end{tabular}




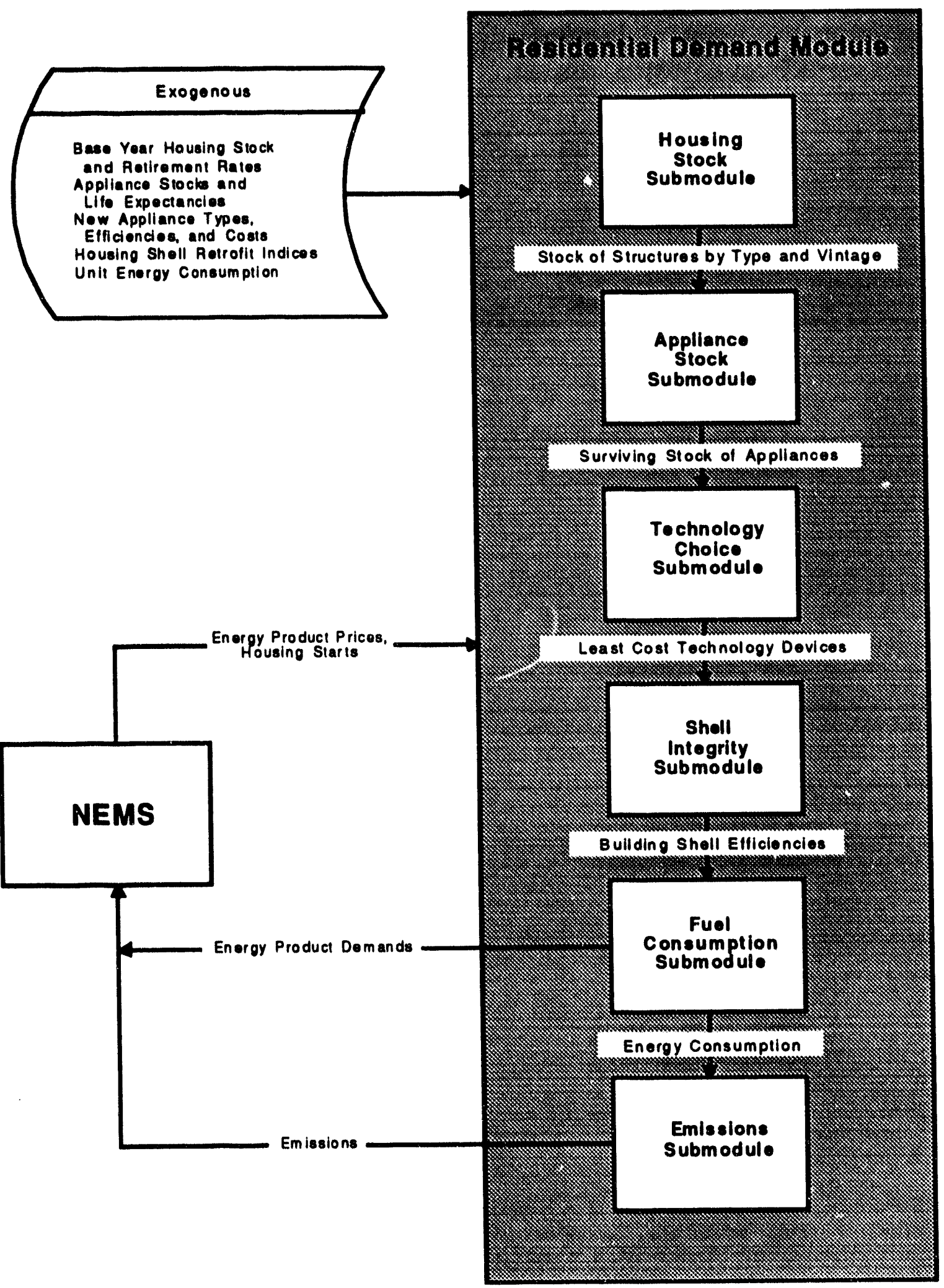




\section{RESIDENTIAL DEMAND MODULE}

\section{Technology Choice Submodule}

Fuel-specific equipment choices are made on the basis of a comparison of relative capital and operating costs. Equipment type and fuel combinations are projected on the basis of technology shares for the most recent year available, using Census Bureau survey data for new residential construction. Each equipment choice involves selecting from several efficiency levels that represent the range of efficiencies projected to be available to consumers at the time the choice is being made. At the low end of the efficiency range, base year efficiencies are adjusted to meet the minimum required standards. Choices are made on the basis of both initial capital cost and first year operating cost.

\section{Shell Integrity Submodule}

Shell integrity is also tracked separately for the two housing vintages. Existing shells are assumed to respond to increases in real energy prices by becoming more efficient. New shell efficiencies are projected to increase, based on recent trends in shell efficiency. All shell efficiencies are subject to a maximum shell efficiency based on studies of currently available residential construction methods.

\section{Fuel Consumption Submodule}

The fuel consumption submodule modifies base year energy consumption intensities in each forecast year. Energy consumption for each end use is based on energy intensity estimates developed from the 1990 RECS. The base energy intensities are modified for four effects: (1) increases in efficiency, based on a comparison of the projected appliance stock serving this end use relative to the base year stock, (2) changes in shell integrity for space heating and cooling end uses, (3) changes in real fuel prices, and (4) changes in weather relative to the base year. Once these modifications are made, total energy use is computed across end uses and housing types and then summed by fuel for each Census division.

\section{Emissions Submodule}

The emissions submodule internally calculates emissions. Emission rate factors permit calculating emissions of carbon $(\mathrm{C})$, sulfur dioxide $\left(\mathrm{SO}_{2}\right)$, and nitrogen oxides $\left(\mathrm{NO}_{\mathrm{x}}\right)$, based on the amount of fuel consumed in the residential sector. Emissions allocable to electricity generation are calculated in the electricity market module. 


\section{Commercial Demand Module}

The commercial demand module (CDM) forecasts the consumption of commercial sector fuels and electricity by building types and nonbuilding uses of energy and by category of end use, subject to delivered prices of energy, the availability of renewable sources of energy, and macroeconomic variables representing gross domestic product, employment, interest rates, and floorspace construction. The CDM structure is shown in Figure 19. Important CDM inputs and outputs are shown below.

The commercial sector encompasses business establishments that are not engaged in industrial or transportation activities. Commercial sector energy is consumed mainly in buildings. (A small amount of commercial energy consumption-from uses such as street lights-is not attributable to buildings.) Energy consumed in commercial buildings is the sum of energy required to provide specific energy services usin/, selected technologies. The model structure carries out a sequence of four basic steps, as shown in Figure 19. The first step is to forecast commercial sector floorspace. The second step is to forecast the energy services (space heating, lighting, etc.) required by that building space. The third step is to select specific technologies (gas furnaces, fluorescent lights, etc.) to meet the demand for energy services. The last step is to determine how much energy will be consumed by the equipment chosen to meet the demand for energy services. Building and equipment choices made in previous time periods determine the floorspace and equipment in place in future time periods.

The technologies and equipments selected to satisfy commercial service demand are chosen on the basis of a mixture of economic rationale (minimizing life cycle costs) and observed behavior (for example, replacing equipment that is returned with equipment using the same technology). The demand for energy is derived from the demand for end-use services. For example, the demand for energy for lighting is derived from the demand for lighting measured in lumens.
Floorspace Submodule

The pattern of energy consumption in the commercial sector depends on the number and type of buildings that make up the sector, regional differences in climate and building construction practices, and the energy-consuming equipment in the buildings. The first step is to forecast building construction and retirements by type of building and location. In this module, both demographic and economic variables are used to estimate growth in floorspace for the following 11 building types:

- Assembly

- Education

- Food sales

- Food services

- Health care

- Lodging

- Office-large

- Office-small

- Mercantile and service

- Warehouse

- Other

\section{Energy Service Demand Submodule}

Given the building inventory, the demand for energyconsuming services is forecast within the buildings. Consumers do not demand energy per se, but the services that energy provides. (Lighting is a good example of this concept. It is measured in unitslumens-that reflect consumers' perception of the level of service received.) The module specifically tracks the following nine services:

- Heating

- Cooling

- Ventilation

- Water heating

- Lighting

- Cooking

- Office equipment

- Refrigeration

- Other.

\begin{tabular}{|l|l|l|}
\hline \multicolumn{1}{|c|}{ Important CDM Outputs } & Important Inputs from NEMS & \multicolumn{1}{|c|}{ Important Exogenous Inputs } \\
\hline $\begin{array}{l}\text { Energy product demand } \\
\text { Emissions } \\
\text { Changes in floorspace and appliance stocks }\end{array}$ & $\begin{array}{l}\text { Energy product prices } \\
\text { Interest rates } \\
\text { Floorspace additions }\end{array}$ & $\begin{array}{l}\text { Existing commercial floorspace } \\
\text { Floorspace survival rates } \\
\text { Appliance stocks } \\
\text { New appliance types, efficiencies, costs } \\
\text { Service demand intensities }\end{array}$ \\
\hline
\end{tabular}


Flgure 19. Commerclal Demand Module Sinucture

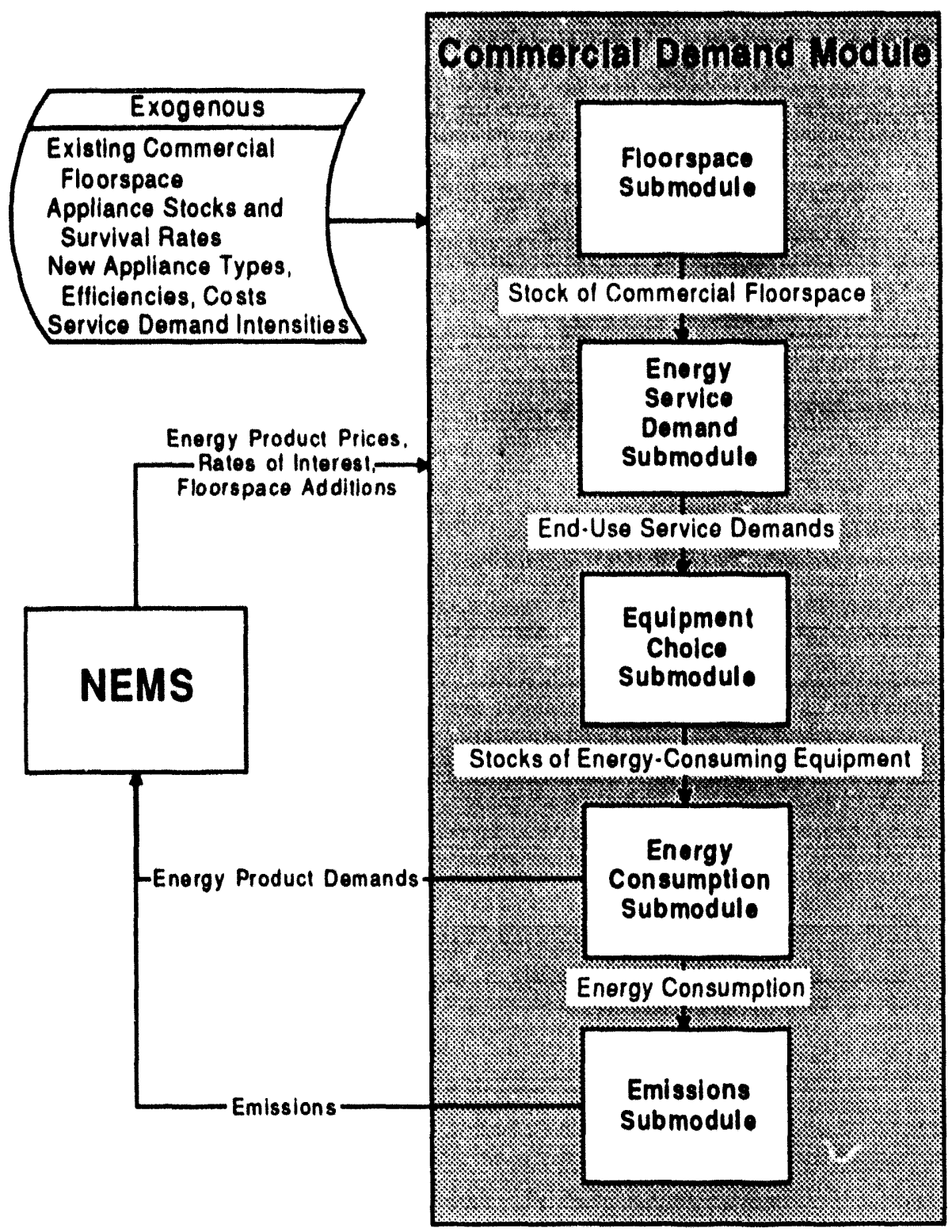

Different building types require services at different levels. A hospital must have more light than a warehouse. An office building in the Northeast requires more heating than one in the South. Total service demand for any service depends on the number, size, type, and location of buildings.

In each forecast year, some equipment wears out in existing floorspace, leaving a gap between the energy services demanded and the equipment available to meet the demand. The efficiency of the equipment chosen to replace worn-out equipment is reflected in the average efficiency of the equipment stock. Similar- ly, the efficiency of equipment chosen to meet services in new floorspace is reflected in the average efficiency of the equipment stock.

Consumers may increase or decrease their level of use of a service in response to a change in energy prices. Accordingly, service demand forecasts are adjusted using short-term (constant) price elasticities of demand as appropriate in response to real short-term changes in energy prices. However, if the price of energy is constant from one year to the next, there is no effect on service demand. 


\section{Equipment Choice Submodule}

Given the level of energy service demanded, the types of equipment and technologies that consumers purchase to satisfy the demand are projected. Consumers buy energy-using equipment to meet three types of service demand:

- Service demand in newly constructed juildings (buildings constructed in the current year)

- Service demand formerly met by retiring equipment (equipment that is at the end of its useful life and must be replaced)

- Service demand formerly met by equipment at the end of its economic life (equipment with a remaining useful life that is nevertheless retired on economic grounds).

The module is designed to allow the use of several possible assumptions about consumer behavior. The choices of consumer behavior assumptions are:

- Buy the equipment with the minimum life-cycle cost

- Buy equipment that uses the same fuel as existing and retiring equipment, but minimizes costs under that constraint

- Buy (or keep) the same technology as the existing and retiring equipment.

These behavior rules are designed to represent empirically the range of economic factors that influence the consumer's decision. Consumers who minimize lifecycle cost are the most sensitive to energy price changes. The price sensitivity of the model depends on the share of consumers using each behavior rule.

The module is designed to choose among a discrete set of technologies that are exogenously characterized by commercial availability, capital costs, operating and maintenance costs, efficiencies, and lifetime. The menu of equipment depends on technological innovation, market development, and policy intervention. The design can accommodate a changing menu of teclinology choices, recognizing that changes in energy prices and consumer demand may significantly change the set of relevant technologies the model user wants to consider. At present, more than 1,000 technological choices are included for six of the nine service demand categories, broken out by region and vintage, as follows:

Heating: electric air heat pump, electric baseboard, electric boiler, electric groundwater source heat pump, gas boiler, gas furnace, gas heat pump, oil boiler, oil furnace,

Cooling: electric centrifugal chiller, electric reciprocaling chiller, electric helical chiller, electric water heat pump, electric air heat pump, electric groundwater source heat pump, window unit electric, gas air heat pump, gas central chiller, gas engine rooftop, gas reciprocal chiller, gas two-stage absorption chiller.

Water Hoating: electric heat pump, electric resistance, gas, oil, high-efticiency electric heat pump, high-efficiency electric resistance, high-efticiency tankless electric, high-efficiency tankless gas, high-efficiency tankless oil, tankless electric, tankless gas, lankless oil.

Ventilation: constant air volume desiccant, constant air volume refrigeration, high-efticiency desiccant, high-etficiency variable air volume, variable air volume.

Cooking: electric convection oven, electric deck oven, electric iryer, electric griddle - standard, electric other, electric range - standard, gas deck oven, gas tryer standard, gas griddle - standard, gas infrared fryer, gas infrared griddle, gas other, gas range - standard, gas range - power burn, high-efficiency electric fryer.

Lighting: compact fluorescent, fluorescent, fluorescent high efficiency, incandescent, incandescent high efficiency, mercury vapor, metal halide, sodium high pressure.

\section{Energy Consumption Submodule}

Given the choice of equipment to satisfy service demands, the total amount of energy consumed is projected. To calculate energy consumption, the equipment share for each fuel and its corresponding efficiency is applied to service demand.

\section{Emissions Submodule}

Emissions are accounted for by multiplying an emissions factor for each emission times the amount of fuel use. The standardized emissions rates used are based on U.S. Environmental Protection Agency sources. 


\section{Transportation Demand Module}

The Transportation Demand Module (TRAN) forncasts the consumption of transportation sector fuels by transportation mode, including the use of renewables and alternative fuels, subject to delivered prices of energy fuels and macroeconomic variables, including disposable personal income, gross domestic product, level of imports and exports, industrial output, new car and light truck sales, and population. The structure of the module is shown in Figure 20. Important inputs and outputs are shown below.

Alternative-fuel shares are projected on the basis of a multinomial logit vehicle attribute model, subject to State and Federal government mandates. NEMS projections of future fuel prices influence the fuel efficiency, vehicle-miles traveled, and alternative-fuel vehicle market penetration for the current fleet of vehicles. Fleet vehicle characteristics and alternative fuel penetration can be set by the user to conduct an analysis of specific policy requirements.

\section{Fuel Economy Submodule}

This submodule projects new light-duty vehicle fuel efficiency by vehicle size class as a function of energy prices and income-related variables. In general, higher fuel prices lead to higher fuel efficiency estimates within each size class, a shift to a more fuel-efficient size class mix, and an increase in the rate at which alternative-fuel vehicles enter the marketplace. For purposes of policy analysis, the user can specify both fuel efficiency by size class and size class shares exogenously.

\section{Regional Sales Submodule}

This submodule is a simple accounting mechanism that uses exogenous estimates of new car and light truck sales and the results of the fuel economy submodule to produce estimates of regional sales and characteristics of light-duty vehicles, which are subsequently passed to the alternative-fuel vehicle and the light-duty vehicle stock submodules.

\section{Alternative.Fuel Vehicle Submodule}

This submodule projects the sales shares of alternative-fuel technologies as a function of time, technology attributes, costs, and fuel prices. Both conventional and new technology vehicles are considered. The alternative-fuel vehicle submodule receives regional new car and light truck sales by size class from the regional sales submodule.

The forecast of vehicle sales by technology requires a three-stage nested decision process. The first stage consists of endogenously calculating the sales shares between conventional and total alternative-fuel vehicles on a regional level, based on the following regional factors: fuel operating costs per mile (fuel price divided by fuel efficiency), vehicle price, range, emission levels, fuel availability, commercial availabil. ity, and regulatory constraints.

Once the level of total alternative-fuel vehicles per region has been calculated, the second stage estimates shares among the alternative-fuel vehicle technologies within each region, based on the same regional factors and methodology used in the prior step to calculate the shares of conventional and total alternative-fuel vehicle sales. Both the share between conventional and alternative-fuel sales and the share among the alternative-fuel vehicle technologies have a bimodal structure for either exogenously specifying the shares based on offline analysis or endogenously forecasting the shares. The third stage subdivides electric vehicle sales into individual electric vehicle technologies.

\begin{tabular}{|c|c|c|}
\hline Important TRAN Outputs & Important Inputs trom NEMS & Important Exogenous Inputs \\
\hline $\begin{array}{l}\text { Energy product demand by mode } \\
\text { Emissions } \\
\text { Sales, stocks and characteristics of } \\
\text { vehicle types by size class } \\
\text { Vehicle-miles traveled } \\
\text { Fuel efficiencies by tochnology type } \\
\text { Alternative-fuel vehicle sales by } \\
\text { technology type } \\
\text { Light-duty commercial fleet vehicle } \\
\text { charactoristics }\end{array}$ & $\begin{array}{l}\text { Energy product prices } \\
\text { Gross domestic product } \\
\text { Disposable personal income } \\
\text { Industrial output } \\
\text { New car and light truck sales } \\
\text { Level of imports and exports }\end{array}$ & $\begin{array}{l}\text { Current and projected demographics } \\
\text { Existing vehicle stocks by vintage and } \\
\text { fuel economy } \\
\text { Vehicle survival rates } \\
\text { New vehicle technologies and efficiencies, } \\
\text { relative to conventional vehicles } \\
\text { Vehicle prices, fuel availability, and } \\
\text { commercial availability } \\
\text { Vehicle salety and emissions regulations } \\
\text { Vehicle miles-per-gallon degradation rates }\end{array}$ \\
\hline
\end{tabular}


Figure 20. Tranaportation Demand Module Structure

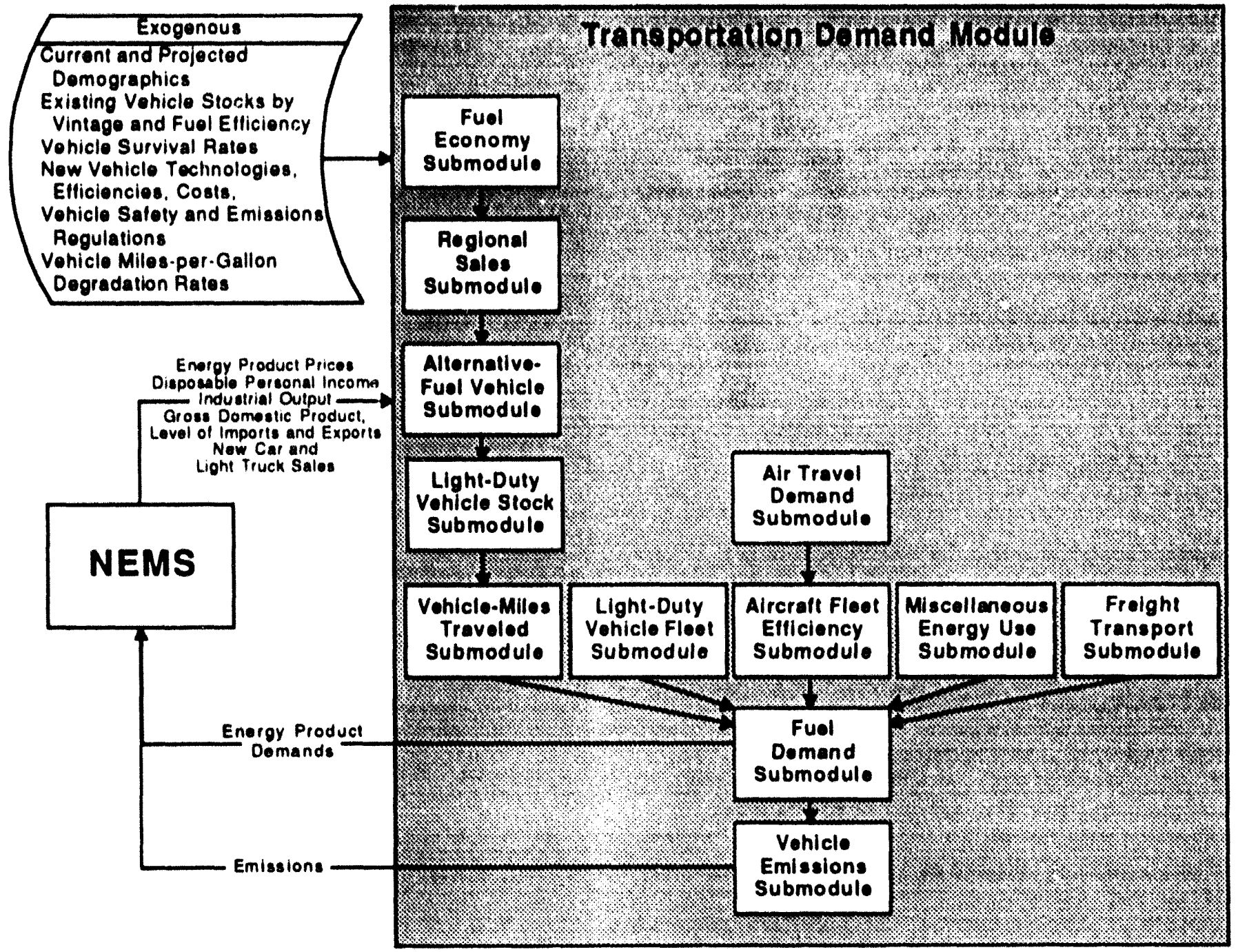

TRAN includes the following alternative-fuel technologies:

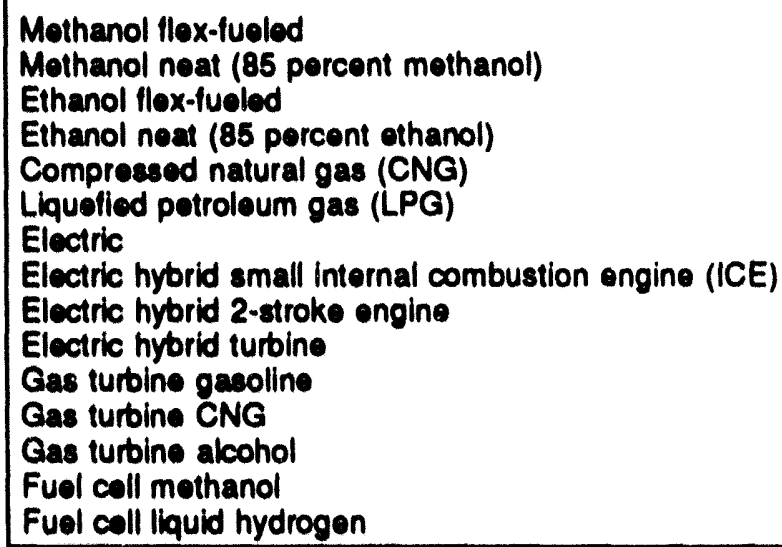

\section{Light-Duty Vehicle Stock Subnodule}

This submodule specifies the inventory of light-duty vehicles from year to year. The survival rates and new vehicle sales of different vintages and classes can be set to reflect alternative policy scenarios that target specific vintages or size classes. The fleet of vehicles and their fuel efficiency characteristics are important to the translation of transportation services demand into fuel demand.

The level of detail maintains 10 vintage classifications and 6 passenger car and 6 light truck size classes corresponding to U.S. Environmental Protection Agency interior volume classifications, as follows: 
Core:

Mini-compact - lose than 85 cuble foot

Subcompact - botwoen 85 and 99 cublc toot

Compact - between 100 and 109 cuble teot

Mid-size - between 110 and 119 cubic foot

Large - 120 or more cubic feet, including all station wagons (small, mid-size, and large)

Two-seater - designed to seat two adults

Trucke:

Passenger vans

Cargo vans

Small pickups - trucks with grose vehicle weight rating (GWWA) under 4,500 pounds

Large pickups - trucks with GWWA 4,500 to 8,500 pounds

Small utillty

Large villity

\section{Vehicle-Miles Traveled Submodule}

This submodule projects travel demand for automobiles and light trucks. The estimates are based on the fuel cost of driving, per capita disposable personal income, an index that reflects the aging of the population, and an adjustment for female-to-male driving ratios.

\section{Light.Duty Vehicle Fleet Submodule}

This submodule generates estimates of the stock of cars and trucks used in business, government, and utility fleets. It also estimates travel demand, fuel efficiency, and energy consumption for the fleet vehicles prior to their transition to the private sector at predetermined vintages.

\section{Air Travel Demand Submodule}

This submodule estimates the demand for both passenger and freight air travel. Historical data on passenger travel are disaggregated between business and personal travel, while freight travel is disaggregated by dedicated freight aircraft and air freight carried in the lower hull ("belly") of commercial passenger aircraft. In each of the four market seg- ments, the demand for air travel is estimated through regression analysis as a function of the cost of air travel (including fuel costs) and economic growth.

\section{Aircraft Fleet Efficiency Submodule}

This submodule projects commercial aircraft stocks to provide estimates of average aircraft luel efficiency (seat-miles per gallon) by size class as a function of jet fuel prices (which affect technology choices) and economic growth levels (which affect the age distribution of aircraft).

\section{Freight Transport Submodule}

This submodule translates NEMS estimates of indus. trial production into ton-miles traveled requirements for truck, rail, and ship travel, and further into fuel consumption by mode of freight travel. NEMS industrial production forecasts indicate value added by industry. Energy efficiency estimates of freight travel are structured to evaluate the potential of both technology trends and efficiency improvements related to energy prices.

\section{Miscellaneous Energy Use Submodule}

This submodule projects the use of energy in military operations, mass transit vehicles, recreational boats, and automotive lubricants, based on endogenous variables within NEMS (e.g., vehicle fuel efficiencies) and exogenous variables (e.g., the military budget).

\section{Vehicle Emissions Submodule}

This submodule estimates the aggregate transportation sector emissions levels associated with the projections of vehicle fleet characteristics and transportation demand. Emissions estimates are made for sulfur dioxide $\left(\mathrm{SO}_{2}\right)$, nitrogen oxides $\left(\mathrm{NO}_{\mathrm{x}}\right)$, carbon $(\mathrm{C})$, and volatile organic compounds (VOCs). The emissions estimates are sensitive to fuel prices and efficiencies, vehicle travel, alternative fuels, new technology vehicles, and alternative ways of meeting transportation demand. 


\section{Industrial Demand Module}

The industrial demand module (IDM) forecasts the consumption of fuels and electricity for heat and power and for feedstocks and raw materials at a process or end-use level for the energy-intensive industries, including the direct use of renewable energy, subject to delivered prices of energy and macroeconomic variables representing the value of output for each industry. The module includes industrial cogeneration of electricity that is either used in the industrial sector or sold to electric utilities. The IDM structure is shown in Figure 21. Important inputs and outputs are given below.

Industrial energy demand is projected as a combination of "bottom up" characterizations of the energyusing technology and "top down" econometric estimates of behavior. The influence of energy prices on industrial energy consumption is modeled in terms of the efficiency of use of existing capital, the efficiency of new capital acquisitions, and the mix of fuels utilized, given existing capital stocks. Energy conservation from technological change is represented over time by trend-based technology possibility curves. Energy product demands are found independently for each sector.

The IDM incorporates three major industry categories: energy-intensive manufacturing industries, nonenergy-intensive manufacturing industries, and nonmanufacturing industries. The level and type of modeling and the attention to detail can be different for each. Manufacturing disaggregation is at the 2 . digit Standard Industrial Classification (SIC) level, with some further disaggregation of more energyintensive or large energy-consuming industries. These more detailed industries include food, paper, chemicals, petroleum refining, stone/clay/glass, and primary metals.

Each industry is modeled (where appropriate) as three separate but interrelated components: buildings (BLD), boilers/steam/cogeneration (BSC), and process/ assembly (PA) activities. Buildings are estimated to account for 3 percent of energy consumption in manu- facturing industries (in nonmanufacturing industries, building energy consumption is assumed to be negligible). Consequently, the IDM uses a simple modeling approach for the BLD component. Energy consumption in industrial buildings is assumed to grow at the same rate as employment in that industry. The BSC component consumes energy to meet the steam demands from the other two components and to provide internally generated electricity to the BLD and PA components. The boiler component consumes fossil fuels to produce steam, which is passed to the PA component. Parameter estimates for the cogeneration component are based on regression from a panel of pooled timeseries and cross-sectional data.

The PA component accounts for the largest share of direct energy consumption for heat and power, 54 percent. For the seven most energy-intensive industries, process flows are modeled using engineering concepts. The production process is decomposed into the major steps, and the energy relationships among the steps are specified. The energy intensities of the process steps vary over time, both for existing technology and for technologies expected to be adopted in the future. In the IDM, this variation is based on engineering judgment and is reflected in the parameters of "technology possibility curves," which show the (declining) energy intensity of existing and new capital relative to the 1988 stock.

The model uses a vintaged capital stock accounting framework that models energy use in new additions to the stock and in the existing stock. Currently, the capital stock is grouped into three vintages: old, middle, and new. The old vintage consists of capital in production prior to 1990 , which is assumed to retire at a fixed rate each year. Middle-vintage capital is that added after 1990, excluding the year of the forecast. New production capacity is built in the forecast years when the capacity of the sxisting stock of capital in the IDM cannot produce the output forecasted by the NEMS regional subcomponent of the macroeconomic activity module. Capital additions during the forecast horizon are retired in subsequent years at the same rate as the pre-1991 capital stock.

\begin{tabular}{|l|l|l|}
\hline \multicolumn{1}{|c|}{ Important IDM Outputs } & \multicolumn{1}{|c|}{ Important Inputs from NEMS } & \multicolumn{1}{c|}{ Important Exogenous Inputs } \\
\hline $\begin{array}{l}\text { Energy product demand } \\
\text { Electricity sales to grid } \\
\text { Cogeneration output and tuel consumption } \\
\text { Emissions }\end{array}$ & $\begin{array}{l}\text { Energy product prices } \\
\text { Sectoral trends in economic activity } \\
\text { Refinery fuel consumption } \\
\text { Refinery cogeneration }\end{array}$ & $\begin{array}{l}\text { Production stages } \\
\text { in energy-intensive industries } \\
\text { Technology possibility curves } \\
\text { Unit energy consumption } \\
\text { Stock retirement rates }\end{array}$ \\
\hline
\end{tabular}


Figure 21. Inchustrial Demand Module Structure

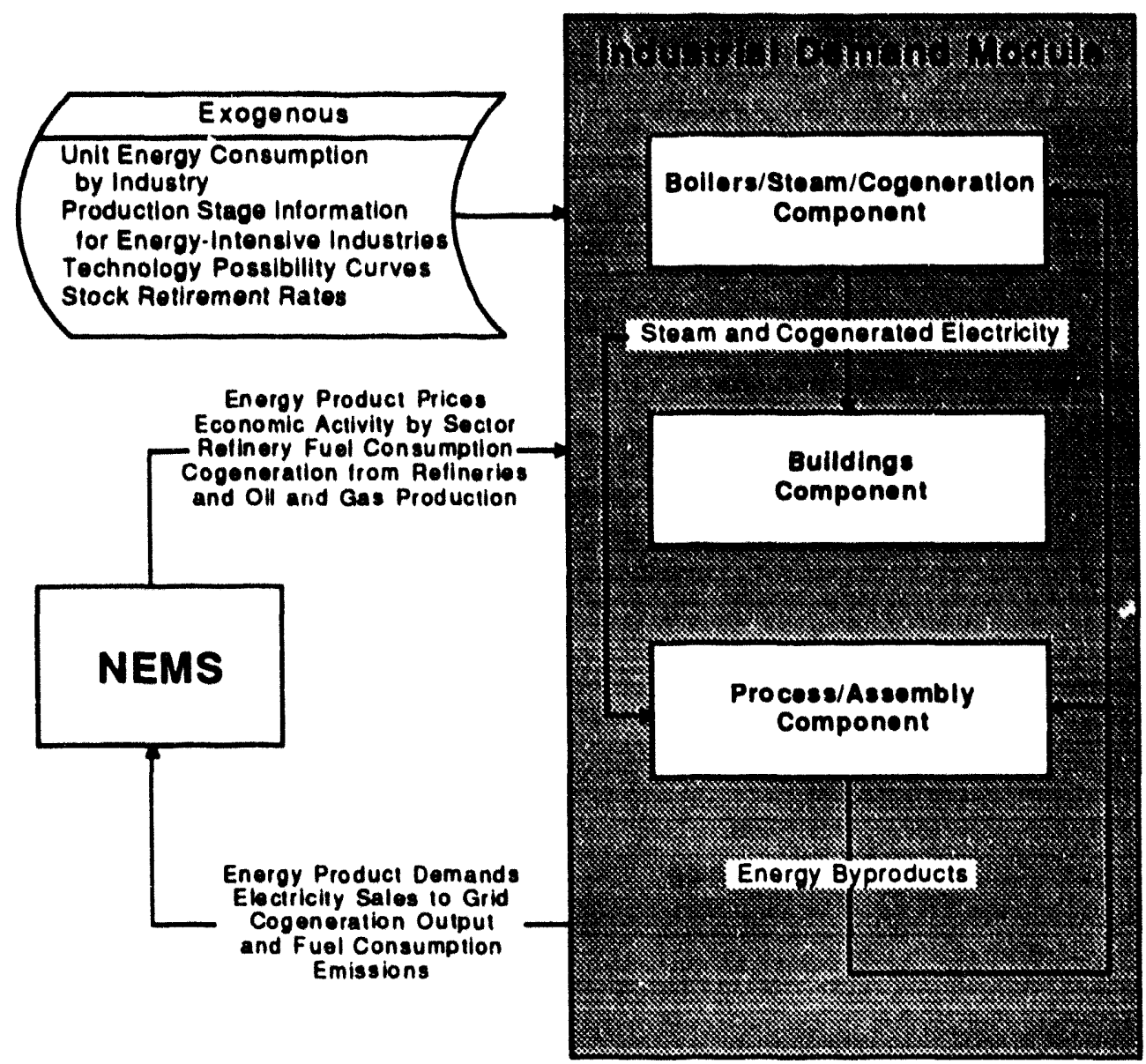

The energy-intensive and/or large energy-consuming industries are modeled with a structure that explicitly describes the major process flows or "stages of production" in the industry (some industries have major consuming uses). The concepts of aggregate production functions and cost functions are used implicitly in modoling factor shares, primarily energy, at each process level. The initial algorithms do this implicitly, but a structure is provided 80 that the algorithms can be enhanced, with relative factor shares being related to relative factor prices.

Tochnolocy penetration at the level of major processes in each industry is based on a technology penetration curve relationship. A second relationship provides additional enercy conservation resulting from changes in abeolute and relative energy prices. Elasticities, constraints, and/or technical possibilities vary according to the vintage. Major process choices (where applicable) are determined by industry production, specific process flows, and exogenous assumptions.
The model structure accommodates several industrial sector activities, including: fuel switching, cogeneration, renewables consumption, recycling, byproduct consumption, waste products, capacity utilization, airborne emissions, and others. Each industry model operates at the level of the four Census regions. The implementation of the model has been phased, beginning with the basic accounting structure and with relatively simple behavioral relationships. Features and enhancements are being added over time or as needed or appropriate for specific analyses.

\section{Emissions Submodule}

In the IDM, emissions are mudeled for total carbon, carbon monoxide, carbon dioxide, methane, volatile organic compounds, sulfur oxides, and nitrogen oxides. The emissions factors used to compute the levels are consistent with those used throughout the NEMS system. The factors are assumed to be constant throughout the forecast horizon. 


\section{Introduction}

NEMS represents a rethinking and enhancement of past modeling efforts, with particular sensitivity to current policy-related issues, such as those of interest during the development of the National Energy Strategy and, more recently, President Clinton's new economic program encompassing energy taxes and incentives. NEMS is intended to build upon, improve, and expand the scope of its predecessor models. Thus, it is instructive to briefly review earlier EIA modeling efforts which led to the design of NEMS, focusing on how NEMS improves on these earlier initiatives.

The enterprise of constructing and using a comprehensive, computer-based model of the U.S. energy system was initiated in the Federal Energy Administration in 1974. The motivation for developing such a model at that time was the issue of energy supply sufficiency prompted by the Arab oil embargo in the Fall of 1973. The energy policy analysis debate has continued since that time. In conjunction with policy analysis needs, a comprehensive energy modeling system has continuously evolved in the EIA. NEMS is the result of an exhaustive reconsideration of the characteristics such a system should necessarily have. The current design of NEMS is the outgrowth of lessons learned in the policy analysis process over almost two decades and the emergence of new policy issues over the same period (for example, a heightened concern about the environment).

\section{Project Independence Evaluation System}

The Project Independence Evaluation System (PIES), later named the Midterm Energy Forecasting System (MEFS), was initially developed in 1974 by the Federal Energy Administration, the predecessor organization to EIA. The core model of PIES/MEFS was a single linear program of fuel supply, transportation, conversion, and fixed demand activities, that optimized by solving for the least-cost solution for supply and transportation of fuel to meet end- use demand.

PIES/MEFS solved for a supply/demand equilibrium in one future time period by iterating between the linear program and an econometric (behavioral) representation of demand models. The linear program optimized the supply/conversion problem, then the marginal, or shadow, prices for each fuel delivered to the end-users were taken from the linear program. The reduced-form demand models were evaluated at these $r .$. nal prices. The revised demands for fuels were entered into the linear program which was then re-solved. This process of iterating between the linear program and demand models continued until changes in energy supplies and end-use demands at the marginal prices passed a convergence tolerance. Over the years, special features were added to PIES/MEFS to reflect regulatory policies or to ensure that certain eud-use prices from the linear program were average or regulated prices, rather than strict marginal prices.

The structure of the system required the entire linear program to be executed together without any means of decomposing the model. This frustrated testing and debugging efforts since PIES/MEFS required several hours to execute, and the simplest changes could only be tested through an entire run of the model. The satellite models and preprocessor programs produced data for the linear program but did not produce results that could be readily used for analysis or testing of individual sectors. Yet another difficulty with PIES/MEFS was the optimization methodology, which was not suitable for all portions of all the supply sectors. Special features were incorporated into the system in order to appropriately represent some of the regulatory or institutional features of various sectors; however, these became increasingly burdensome to adapt and modify as needed.

NEMS avoids these deficiencies by avoiding the use of linear programming in its integrating mechanism and by increasing the modularity of its structure to provide for the individual selection of modeling methodologies tailored directly to the nature of the specific energy markets to be simulated. Individual modules can be run on a standalone basis (with only the Integrating Module) or as a component of the overall NEMS system, thereby facilitating decomposition of the analysis of the projections.

\section{Long-Term Energy Analysis Package}

From 1979 to 1981, EIA used the Long-Term Energy Analysis Package (LEAP) for long-term forecasting. LEAP used the Generalized Equilibrium Modeling System (GEMS) as its core modeling methodology. LEAP solved for a supply/demand equilibrium, with prices and quantities of the various types of energy being computed by modules that represented production, raw material transportation, conversion, final product transportation, and end-use energy consumption. As a representation of the overall system, the order of solution was directional, prices flowing from supply to end-use demand and quantities flowing in reverse. Thus, it solved for an equilibrium by iteratively computing the energy flowing through the system network. 


\section{EIA PREDECESSOR MODELS}

Each module of LEAP/GEMS solved for all forecast years at a time, coming to an equilibrium for all years simultaneously. This approach was also used for portions of the EIA PC-AEO spreadsheet model, applied for EIA's Annual Energy Outlook from 1987 to 1990. The advantage of this approach is that modules requiring assumptions on future market conditions can use the results of the other modules directly. The result is an intertemporal consistency between market conditions assumed for planning and those realized in a given run's final solution. This approach is referred to as a "perfect foresight" approach, that is, the decisionmaker knows with perfect foresight the supply, demands, and energy prices of the future when contemplating current year investment decisions.

One feature of the GEMS system is a library of generic models, from which one can choose in building a representation of the energy system. These generic models include a simple and a complex conversion process, an allocation process, a primary resource process, an end-use demand process, and a transportation process. In building a model using GEMS, a user draws the network by selecting a generic model for each node, defining all the input and output links to other nodes, and specifying all necessary data. It is the data specification and the flows that distinguish, for example, a node representing the industrial sector demand for electricity for machine drive from a node for residential natural gas space heating demand. New generic models can be added to the library as needed to represent fundamentally different processes.

The LEAP/GEMS methodology is more limited than that employed in NEMS because of the greater discipline that the network structure and its solution process impose on the design of the supporting generic models. The integrating mechanism of NEMS allows a wider choice of modeling methodologies in the supporting modules, thereby rendering the system more adaptive for the modeling of a wide range of energy policies and regulations, as well as for representing changes in industry structure.

\section{Intermediate Future Forecasting System}

The most recent EIA midterm integrated modeling system was the Intermediate Future Forecasting System (IFFS), which was used prior to NEMS to forecast annually through 2010. NEMS resembles IFFS more closely than any of the predecessor models. IFFS also partitioned the energy system into modules representing fuel supply, conversion, and end-use demand sectors. It also solved for a supply/demand equilibrium by successively and repeatedly invoking these modules. Like NEMS, this equilibration was performed only one forecast year at a time, stepping forward to the next forecast year when the equilibrium for one year was complete.

The fuel supply modules encompassed all the activities necessary to produce, import, and transport the fuel to the end user, allowing the computation of domestic production and the regional end-use prices necessary to meet end-use demand. Each of the end-use demand modules computed the fuel requirements for the sector by region, based on the regional end-use prices of all competing fuels, as well as other factors. The electricity module, as a conversion module, consumed fuel based on relative prices and then generated and priced electricity. The refinery module might also be viewed as a conversion module, except that it used only a single primary input, crude oil, whose price was invariant, and its fuel use was represented in the industrial demand module with no direct linkage to refinery activity.

The modular nature of IFFS readily allowed each sector of the energy market to be represented with the methodology deemed most suitable to that sector, allowing for a more natural representation of each market. IFFS contained a mix of simulation, process, econometric, and optimization methods within the various sectors. It also allowed each module to vary the depth and breadth of its coverage of the sector.

Problems and deficiencies of IFFS included: too little process structure in the demand sectors, which limited the modeling of conservation technologies; too little process structure in the refinery module, which limited the scope of refinery policy issues that could be addressed; and little treatment of new technologies and renewable forms of energy.

The approach used for NEMS improves on IFFS in a number of ways. First, the system incorporates an international component to directly account for the interaction between the domestic energy market and the world oil market. This feature allows the energy system to project world oil prices indogenously. The integrating algorithm incorporates the necessary linkages and convergence tests to equilibrate the domestic and international oil markets.

Structural detail was added to NEMS in a number of areas, allowing for more accurate representation of current policy analysis issues and emerging market characteristics. Areas with expanded detail include the refining sector, all end-use demand sectors, renewable fuels, demand-side management programs, a natural gas pipeline representation, and natural gas tariffs. NEMS also incorporates emissions accounting and some limited environmental policy analysis features, 
including direct representation of the Clean Air Act Amendments of 1990 compliance options.

Another area of improvement over IFFS is the expanded ability to vary foresight assumptions with NEMS.

This additional flexibility is achieved through use of an improved centralized database design that provides greater storage and control over price and demand variables relating to the future. The integrating module allows the selection of several alternative assumptions related to future prices and demands for capacity planning. 
The National Energy Modeling System is documented in a series of model documentation reports, available by contacting the National Enercy Information Center (202/586-8800).

Energy Information Administration, National Energy Modeling System Integrating Module Documentation Report, DOE/ELA-M057 (Washington, DC, December 1993).

Energy Information Administration, Model Documentation Report: Macroeconomic Activity Module (MAM) of the National Energy Modeling System, DOE/EIAM065 (Washington, DC, February 1994).

Energy Information Administration, Documentation of the DRI Model of the U.S. Economy, DOE/EIA-M061 (Washington, DC, December 1993).

Energy Information Administration, NEMS International Energy Module, Model Documentation Report, DOE/EIA-M071 (Washington, DC, April 1994)

Energy Information Administration, EIA Model Documentation: World Oil Refining Logistics Demand Model, "World" Reference Manual, DOE/EIA-M058 (Washington, DC, March 1994).

Energy Information Administration, Model Documentation Report: Residential Sector Demand Module of the National Energy Modeling System, DOE/EIA-M067 (Washington, DC, March 1994).

Energy Information Administration, Model Documentation Report: Commercial Sector Demand Module of the National Energy Modeling System, DOE/EIA-M066 (Washington, DC, March 1994).

Energy Information Administration, Model Documentation Report: Industrial Sector Demand Module of the National Energy Modeling System, DOE/EIA-M064 (Washington, DC, January 1994).

Energy Information Administration, Model Documentation Report: Transportation Sector Model of the National Energy Modeling System, DOE/EIA-M070 (Washington, DC, March 1994).
Energy Information Administration, Model Documentation Report: Electricity Market Module, Load and Demand-Side Management Submodule. Volume 1. Model Description, DOE/EIA-M068-A/1 (Washington, DC, March 1994).

Energy Information Administration, Model Documentation Report: Electricity Market Module, Load and Demand-Side Management Submodule. Volume 2. Model Code Listing, DOE/EIA-M068-A/2 (Washington, DC, March 1994).

Energy Information Administration, Model Documentation Report: Electricity Market Module, Electricity Capacity Planning Submodule, DOE/EIA-M068-B (Washington, DC, March 1994).

Energy Information Administration, Model Documentation Report: Electricity Market Module, Electricity Finance and Pricing Submodule, DOE/EIA-M068-C (Washington, DC, March 1994).

Energy Information Administration, Model Documentation Report: Electricity Market Module, Electricity Fuel Dispatch Submodule, DOE/EIA-M068-D (Washington, DC, March 1994).

Energy Information Administration, Documentation of the Oil and Gas Supply Module (OGSM), DOE/EIAM063 (Washington, DC, March 1994).

Energy Information Administration, Model Documentation: Natural Gas Transmission and Distribution Model of the National Energy Modeling System, DOE/EIA-M062 (Washington, DC, February 1994).

Energy Information Administration, EIA Model Documentation: Petroleum Model of the National Energy Modeling System, DOE/EIA-M059 (Washington, DC, February 1994).

Energy Information Administration, Model Documentation: Coal Market Module of the National Energy Modeling System, DOE/EIA-M060 (Washington, DC, March 1994).

Energy Information Administration, Model Documentation Report: Model Documentation Renewable Fuels Module of the National Energy Modeling System, DOE/EIA-M069 (Washington, DC, April 1994). 

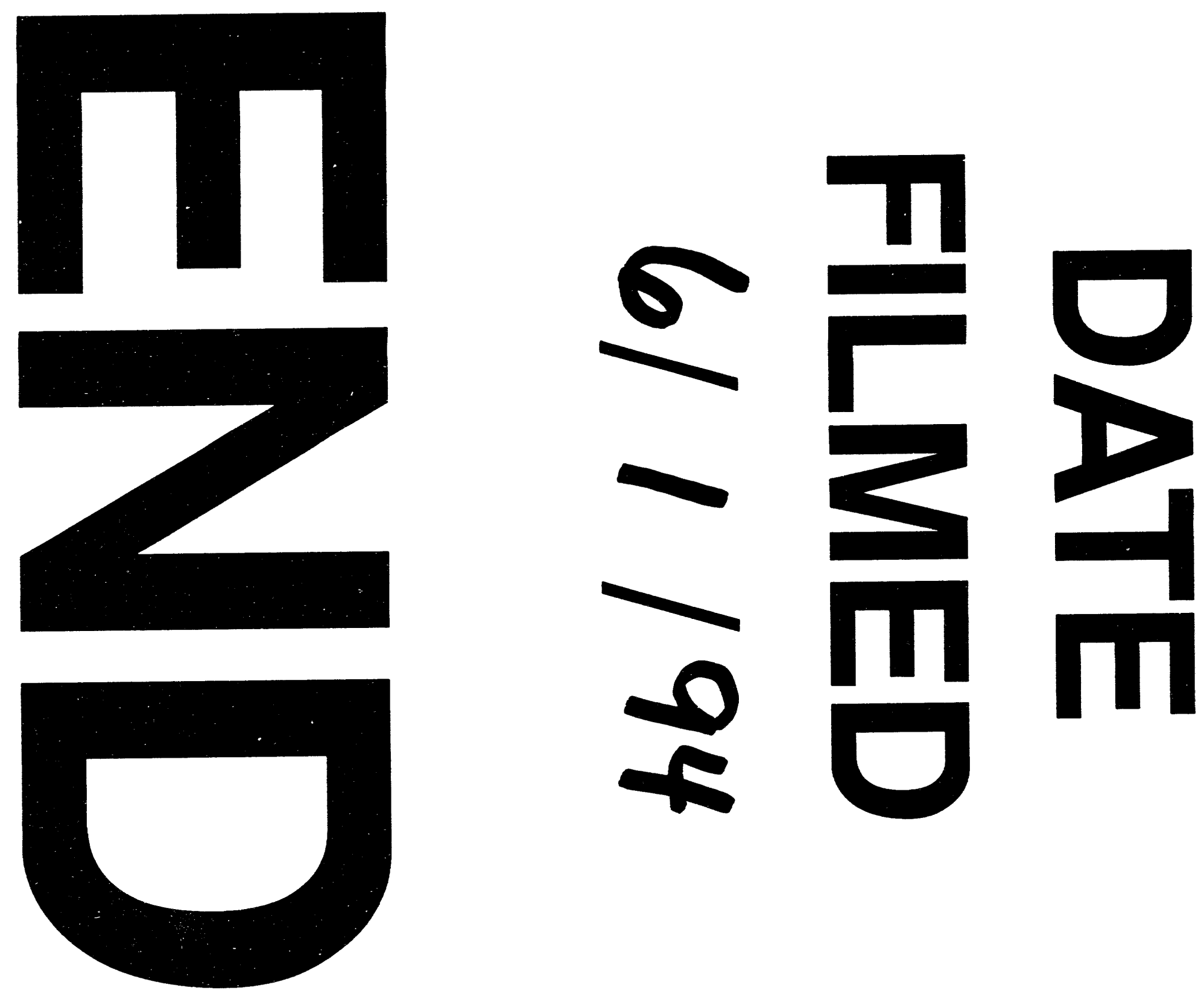
$$
\text { ב- }
$$ 